University of Louisville ThinkIR: The University of Louisville's Institutional Repository

Electronic Theses and Dissertations

$8-2019$

\title{
Emotion regulation is associated with peer victimization among children with attention- deficit/hyperactivity disorder.
}

Nicholas D. Fogleman

University of Louisville

Follow this and additional works at: https://ir.library.louisville.edu/etd

Part of the Clinical Psychology Commons

\section{Recommended Citation}

Fogleman, Nicholas D., "Emotion regulation is associated with peer victimization among children with attention-deficit/hyperactivity disorder." (2019). Electronic Theses and Dissertations. Paper 3288.

https://doi.org/10.18297/etd/3288

This Doctoral Dissertation is brought to you for free and open access by ThinkIR: The University of Louisville's Institutional Repository. It has been accepted for inclusion in Electronic Theses and Dissertations by an authorized administrator of ThinkIR: The University of Louisville's Institutional Repository. This title appears here courtesy of the author, who has retained all other copyrights. For more information, please contact thinkir@louisville.edu. 
EMOTION REGULATION IS ASSOCIATED WITH PEER VICTIMIZATION AMONG CHILDREN WITH ATTENTION-DEFICIT/HYPERACTIVITY DISORDER

\author{
By \\ Nicholas D. Fogleman \\ B.S., Loyola University Chicago, 2009 \\ M.S., University of Louisville, 2016

\begin{abstract}
A Dissertation
Submitted to the Faculty of the

College of Arts and Sciences of the University of Louisville

in Partial Fulfillment of the Requirements

for the Degree of
\end{abstract} \\ Doctor of Philosophy \\ in Clinical Psychology \\ Department of Psychological and Brain Sciences \\ University of Louisville \\ Louisville, Kentucky
}

August 2019 



\section{EMOTION REGULATION IS ASSOCIATED WITH PEER VICTIMIZATION AMONG CHILDREN WITH ATTENTION-DEFICIT/HYPERACTIVITY DISORDER \\ By \\ Nicholas D. Fogleman \\ B.S., Loyola University Chicago, 2009 \\ M.S., University of Louisville, 2016 \\ A Dissertation Approved on}

June 28, 2019

by the following Dissertation Committee:

Dissertation Director

Paul J. Rosen, Ph.D.

Brendan E. Depue, Ph.D.

Cheri A. Levinson, Ph.D.

Jeffrey C. Valentine, Ph.D.

Janet Woodruff-Borden, Ph.D. 


\section{DEDICATION}

To my two favorite people: my wife, Katie, and our daughter, Lila. 


\section{ACKNOWLEDGEMENTS}

I am grateful to my family and colleagues for their support throughout graduate school and the writing of this dissertation. I would first like to thank my wife and best friend, Katie, who has made countless sacrifices, and has helped me navigate the complex challenges of graduate school. I would also like to thank my parents, brother, and extended family members for their endless love and support, and for inspiring me to serve others and encouraging me to follow my dreams. There are also several professional mentors that I would like to acknowledge. First, I would like to thank my dissertation advisor, Dr. Paul J. Rosen, who has pushed me to become a better scientist, and whose expertise in emotion regulation and peer victimization has been critical to helping me build my program of research. In particular, his initial theoretical conceptualization of the relation between emotion regulation and peer victimization helped lay the groundwork for much of my work in graduate school, and culminates with this dissertation project. I would also like to thank Drs. Brendan E. Depue and Janet Woodruff-Borden for their advice, guidance, and mentorship throughout graduate school; they have been instrumental in my development as both a researcher and clinician. Additionally, I would like to thank Drs. Cheri A. Levinson and Jeffrey C. Valentine for taking time to serve on my dissertation committee, and for providing thoughtful feedback and improving the quality of my dissertation project. Lastly, I would like to say thank you to Dr. Stephen P. Becker for his dedication to my training and his guidance on my 
dissertation project, and William Gardner for helping me make this dissertation project possible. I would also like to thank my research mentors over the years (Drs. José A. Apud, Venkata S. Mattay, Anthony L. Burrow, Gruschen Veldtman, and Stephen I. Rennard) for opening doors for me and providing me with endless learning opportunities and experiences. 


\begin{abstract}
EMOTION REGULATION IS ASSOCIATED WITH PEER VICTIMIZATION AMONG CHILDREN WITH ATTENTION-DEFICIT/HYPERACTIVITY DISORDER

Nicholas D. Fogleman

June 28, 2019

Background: Children with Attention-Deficit/Hyperactivity Disorder (ADHD) experience higher rates of peer victimization relative to unaffected peers; however, debate remains as to whether core symptoms of ADHD - inattention, hyperactivity and impulsivity—are responsible for increased rates of peer victimization among children with ADHD. Given emotion regulation deficits co-occur among children with ADHD, and are often associated with increased peer victimization experiences, the current study examined the role of emotion regulation in peer victimization among children with
\end{abstract} ADHD.

Methods: Forty-nine children (ages 10-15 years) diagnosed with ADHD and their parents completed measures of emotion regulation and peer victimization. Children also completed a laboratory-based peer stressor task.

Results: Results supported the association of poorer emotion regulation to both childreport and parent-report of peer victimization above and beyond the effect of ADHD symptoms. Results also suggested that ADHD symptoms moderated the impact of parent- 
report of emotion regulation on child-report of peer victimization, such that poorer parent-report of emotion regulation was more strongly associated with child-report of peer victimization in the presence of a greater severity of ADHD symptoms. Results did not support an association between a child's emotional response to a discrete peer stressor (i.e., Cyberball) with child-report or parent-report of peer victimization. When examining the relation between the regulation of specific negative emotions and peer victimization, results indicated that poorer regulation anger and sadness were associated with increased peer victimization experiences among children with ADHD.

Discussion: Emotion regulation deficits, above and beyond core ADHD symptoms, were associated with increased peer victimization experiences among children with ADHD, and findings were observed both within and across raters. Furthermore, the regulation of anger and sadness appear particularly important for peer victimization experiences among children with ADHD, such that children who demonstrate more difficulties regulating their anger or sadness experienced a greater frequency of peer victimization experiences. Implications, limitations, and recommendations for future research are discussed. 


\section{TABLE OF CONTENTS}

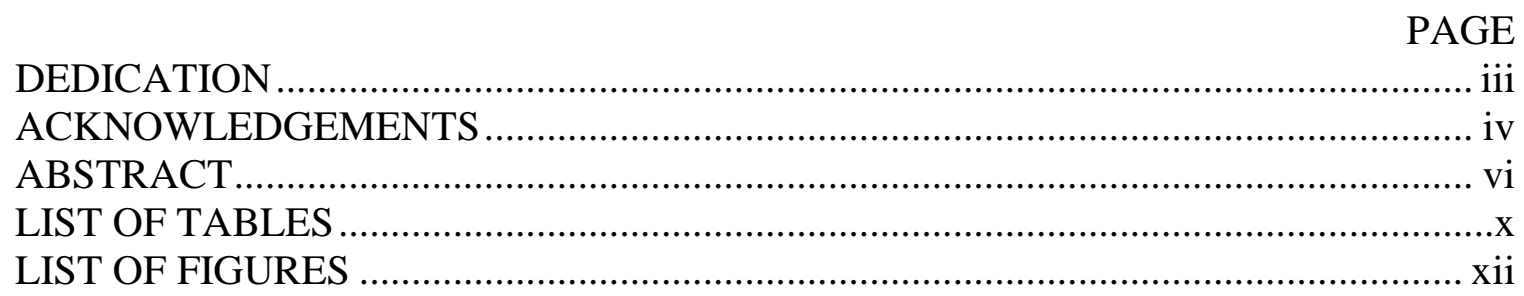

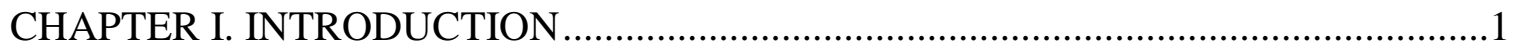

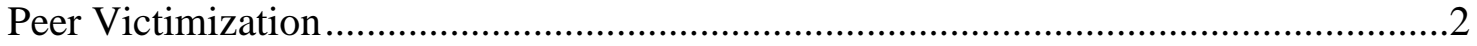

Relation Between Peer Victimization and Emotion Regulation ................................14

Relation Between Emotion Regulation and ADHD ...............................................28

Relation Between ADHD and Peer Victimization .....................................................33

Relation Between ADHD, Emotion Regulation, and Peer Victimization......................36

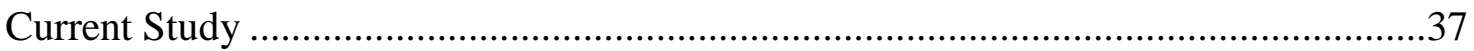

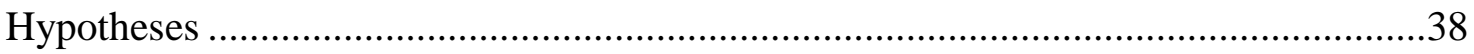

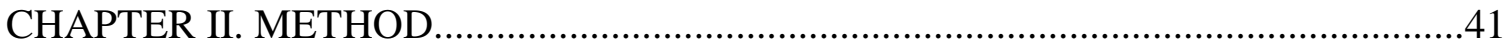

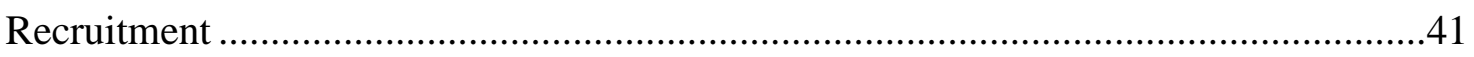

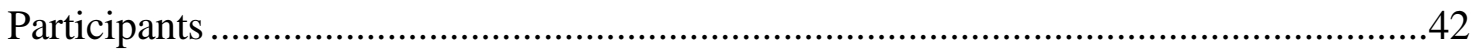

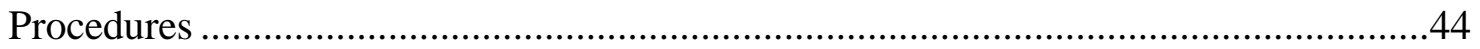

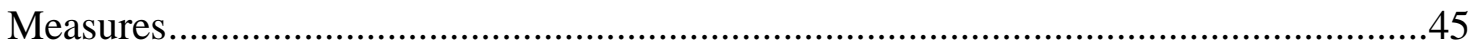

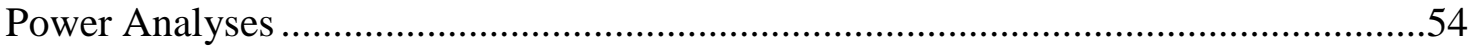

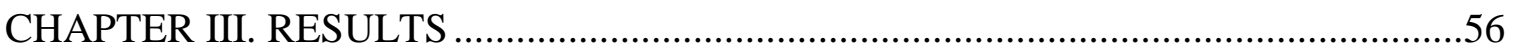




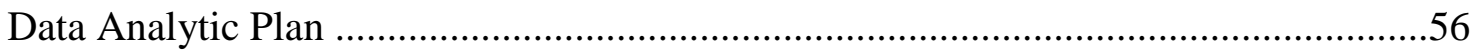

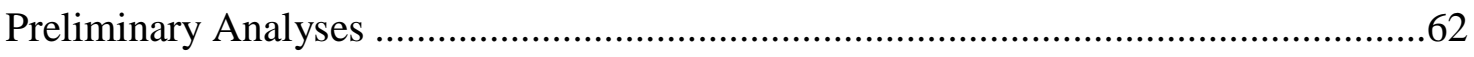

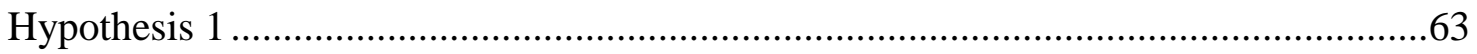

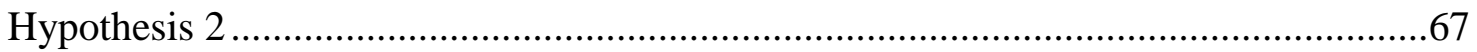

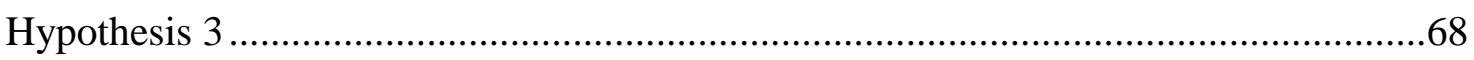

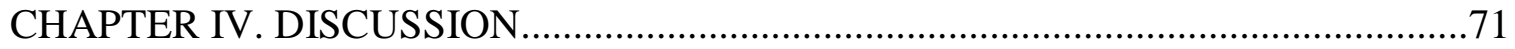

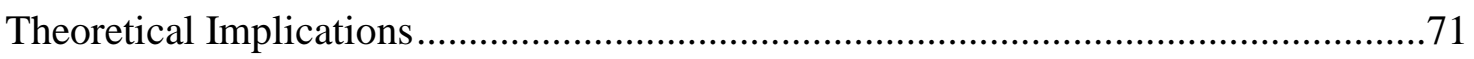

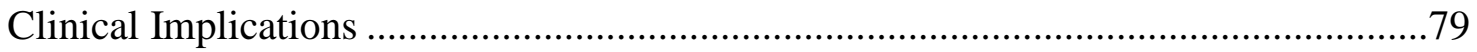

Limitations and Future Research.................................................................. 83

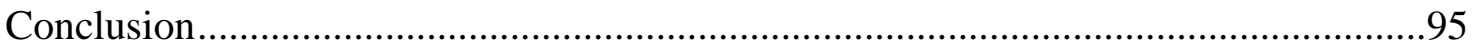

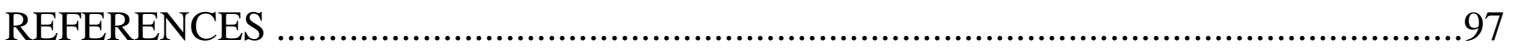

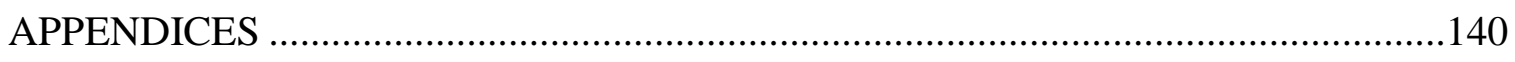

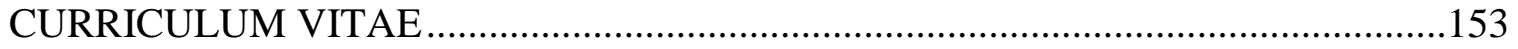




\section{LIST OF TABLES}

TABLE

PAGE

1. Sample characteristics.

2. Bivariate correlations for ADHD symptoms, child-report of emotion regulation, parent-report of emotion regulation, and child-report of peer victimization and parentreport of peer victimization.

3. Hierarchical linear regression: Relation of child-report of emotion regulation and parent-report of emotion regulation to the estimation of child-report of peer victimization

4. Hierarchical linear regression: Relation of child-report of emotion regulation and parent-report of emotion regulation to the estimation of parent-report of peer victimization

5. Bivariate correlations for child-report changes in positive affect and child-report changes in negative affect to a discrete peer stressor, and child-report of peer victimization and parent-report of peer victimization

6. Bivariate correlations for child-report of anger regulation, parent-report of anger regulation, parent-report of sadness regulation, parent-report of worry regulation, and child-report of peer victimization and parent-report of peer victimization 147

7. Hierarchical linear regression: Relation of child-report of anger regulation to childreport of peer victimization 
8. Hierarchical linear regression: Relation of child-report of anger regulation to parent-

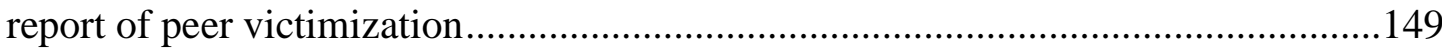

9. Hierarchical linear regression: Relation of parent-report of sadness regulation to

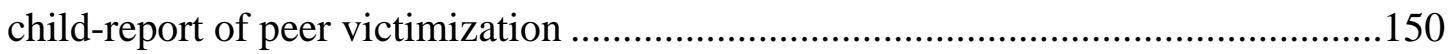

10. Hierarchical linear regression: Relation of parent-report of sadness regulation to

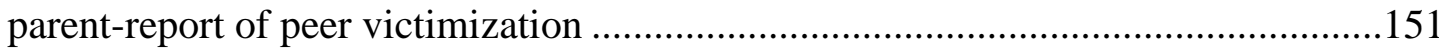




\section{LIST OF FIGURES}

$\begin{array}{lll}\text { FIGURE PAGE } & \text { PAR }\end{array}$

1. Relation of parent-report of emotion regulation and child-report of peer victimization

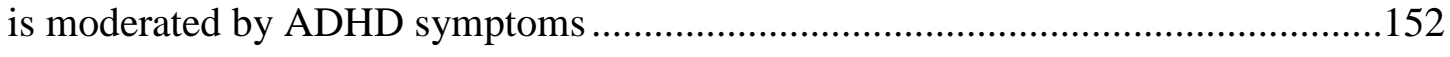




\section{CHAPTER I}

\section{INTRODUCTION}

Children with Attention-Deficit Hyperactivity Disorder (ADHD) are more likely to experience peer victimization relative to their unaffected peers (Wiener \& Mak, 2009); however, there remains considerable debate as to whether core symptoms of ADHDinattention, hyperactivity and impulsivity — are responsible for increased rates of peer victimization among children with ADHD (Chou, Liu, Yang, Yen, \& Hu, 2014; Wiener \& Mak, 2009). Given that core ADHD symptoms may not be directly attributable to increased rates of peer victimization among children with ADHD, the current study aims to examine the influence of emotion regulation on peer victimization experiences among children with ADHD. Previous literature suggests emotion regulation deficits co-occur in children with ADHD (see Shaw, Stringaris, Nigg, \& Leibenluft, 2014 for review) and are often associated with a greater frequency of peer victimization experiences (Fogleman, Walerius, Rosen, \& Leaberry, 2016; Hanish et al., 2004; Rosen, Milich, \& Harris, 2012). Therefore, the current study proposes that children with ADHD are at an increased risk for peer victimization not because they demonstrate core ADHD symptoms of impulsivity, inattention, and hyperactivity, but rather because they fail to effectively regulate their emotions in social settings. Accordingly, the current study examines the relation between ADHD symptoms, emotion regulation, and peer victimization among children diagnosed with ADHD. 


\section{Peer Victimization}

Peer victimization, initially described by Olweus (1978), is an environmentallydriven variable (Brendgen et al., 2008) that affects children across all regions of the world (Craig et al., 2009; Due et al., 2005), regardless of ethnic background (Putallaz et al., 2007; Seals \& Young, 2003) and socioeconomic status (see Card \& Hodges, 2008 for review). Described as a broad spectrum of social interactions whereby one individual experiences physical, emotional, social, or psychological harm by one or more peers (Rosen, Milich, \& Harris, 2009), peer victimization affects many children over the course of their lifespan (Haynie et al., 2001; Kochenderfer-Ladd \& Ladd, 2001) with lifetime rates exceeding 76 percent (Hoover, Oliver, \& Hazler, 1992). While many children will experience an episode of peer victimization, for approximately 10 percent of children (Hunter, Boyle, \& Warden, 2007) peer victimization becomes chronic and increasingly stable over time (Scholte, Engels, Overbeek, De Kemp, \& Haselager, 2007). Children who experience peer victimization may be targeted by a single child or small group of children (Olweus \& Solberg, 1998), with substantial rates of peer victimization occurring outside of school contexts (Turner, Finkelhor, Hamby, Shattuck, \& Ormrod, 2011). Affecting children as young as three years of age (Bonica, Arnold, Fisher, Zeljo, \& Yershova, 2003; Ostrov, Woods, Jansen, Casas \& Crick, 2004), and throughout preschool years (Crick, Casas, \& Ku, 1999), peer victimization becomes most frequent during the transition from elementary to middle school (see Troop-Gordon, 2017 for review), and often declines as children progress into adulthood (Bradshaw, Waasdorp, O’Brennan, 2013). 
Early research suggested males were more likely to experience peer victimization than females (e.g., Callaghan \& Joseph, 1995), but more recent literature indicates that females are likely to experience similar (Kochenderfer-Ladd \& Skinner, 2002), and perhaps even more peer victimization than males (Craig et al., 2009). A key development leading to these revised empirical findings is the distinction between overt and relational forms of victimization (Crick \& Grotpeter, 1995; Crick \& Grotpeter, 1996). Overt victimization is characterized as direct and confrontational, and the victim is physically harmed, threatened, or verbally attacked (Crick \& Grotpeter, 1996). In contrast, relational victimization is characterized as behavior aimed at damaging friendships and peer relations (Crick \& Grotpeter, 1995). Previous research suggests that males are more likely to experience overt victimization, and females are more likely to experience relational victimization (Betts, Houston, \& Steer, 2015; Crick, Casas, \& Nelson, 2002; Crick \& Nelson, 2002; see Espelage, Mebane, \& Swearer, 2004 for review; Tapper \& Boulton, 2004).

Children who experience peer victimization are often categorized as either aggressive or passive victims (see Olweus, 1994 for review). Aggressive victims are described as high-conflict victims; they respond to peer victimization through aggression (see Schwartz, Proctor, \& Chien, 2001 for review). Although aggressive victims may attempt to respond to peer victimization, their responses are often emotionally-driven, and they are rarely successful at reducing the frequency of their victimization in part because they tend to lose the conflict with their aggressors (Olweus, 1994; Perry, Williard, \& Perry, 1990). In contrast, passive victims are described as low-conflict victims; they tend to engage in withdrawn behaviors and respond to peer victimization 
through attempts to avoid conflict (Olweus, 1994; Perry, Kusel, \& Perry, 1988). Passive victims are also rarely successful at mitigating the frequency of their victimization experiences in part because they fail to demonstrate assertive behaviors necessary to alleviate peer conflict. For both aggressive and passive victims, the inability to regulate negative emotional arousal in situations involving peer threat likely interferes with the use of effective behavioral response strategies. Given that peer victimization often becomes chronic and stable, and has severe consequences for healthy child development (Crick, 1996; Crick \& Grotpeter, 1996), factors that may predispose children to peer victimization appear particularly necessary to identify in order to prevent future peer victimization experiences.

\section{Risk Factors for and Consequences Associated with Peer Victimization}

Numerous factors increase a child's risk for experiencing peer victimization. Most notably, children who are victimized are likely to be younger and physically weaker relative to their peer counterparts (see Smith, Shu, \& Madsen, 2001 for review). Additionally, children may be at a greater risk for peer victimization if they are described as being overweight, having a disability or chronic illness, or are rated lower on physical appearance (Callaghan \& Joseph, 1995; Griffiths \& Page, 2008; Pearce, Boergers, \& Prinstein, 2002; Rose, Monda-Amaya, \& Espelage, 2011; Sentenac et al., 2011). Child behavior also appears to play an influential role in determining which children will experience peer victimization, as aggressive behaviors, disruptive behaviors, and lack of prosocial behaviors have been linked to higher frequency of peer victimization experiences (Baumeister, Storch, \& Geffken, 2008; Hanish \& Guerra, 2000; Schwartz, McFadyen-Ketchum, Dodge, Pettit, \& Bates, 1999). 
Additional factors that increase the likelihood that a child will experience peer victimization include poor social skills and poor peer relations (Hawker \& Boulton, 2000; Hugh-Jones \& Smith, 1999; Salmon \& West, 2000). Specifically, children who have fewer friends (Perry, Hodges, \& Egan, 2001) and poorer friendships (Bollmer, Milich, Harris, \& Maras, 2005), as well as those who experience rejection from their peers (De Los Reyes \& Prinstein, 2004; Hodges \& Perry, 1999), are at an increased risk for peer victimization. Previous literature suggests high-quality positive friendships (Hodges, Boivin, Vitaro, \& Bukowski, 1999; Schmidt \& Bagwell, 2007) and peer acceptance (Demaray \& Malecki, 2003) decrease a child's risk for peer victimization. Therefore, children who demonstrate behavior considered aversive to peers may be more likely to experience peer victimization (Eisenberg et al., 1993) because they lack an ally in the presence of peer threat.

Children with deficits in emotional functioning are also predisposed to peer victimization (Hay, Payne, \& Chadwick, 2004; Olweus, 1994; Perry et al., 1988). Previous literature suggests that internalizing behaviors, such as anxiety and depression (Hawker \& Boulton, 2000; Siegel, La Greca, \& Harrison, 2009), and externalizing behaviors, including aggression (Hodges et al., 1999), increase the risk that a child will experience peer victimization. Internalizing and externalizing behaviors are known to be behavioral expressions of emotion regulation deficits (Zeman, Shipman, \& Suveg, 2002), suggesting that deficits in emotion regulation may be associated with increased peer victimization experiences. Prior research establishes this link, as emotion regulation deficits appear to play an influential role in the development of chronic peer victimization in children (Fogleman et al., 2016; Rosen et al., 2012). 
Several of the aforementioned risk factors for peer victimization appear to share a similar mechanism: the inability to regulate negative emotions. This likely interferes with the initiation of effective behavioral response strategies and leads to emotionally-driven behaviors, including aggression and avoidance (i.e., aggressive and passive victims). Thus, for a child to reduce their risk for peer victimization, use of active problem-solving approaches, in combination with suppressing negative emotional arousal (Perry et al., 2001), may allow a child to de-escalate and resolve episodes of peer conflict (Mahady Wilton, Craig, \& Pepler, 2000). Similarly, advice-seeking (e.g., asking an adult or friend for help; Kochenderfer \& Ladd, 1997), implementing conflict resolution strategies (e.g., trying to understand why the victimization happened and attempting to prevent it from happening again; Kochenderfer-Ladd, 2004), and engaging in prosocial behaviors (e.g., assertiveness, effective conflict management; Card \& Hodges, 2008; Mahady Wilton et al., 2000) may reduce a child's risk for peer victimization. These response strategies may lead to positive outcomes; however, when children fail to implement effective response strategies, peer victimization is likely to contribute to severe and long-lasting consequences.

Peer victimization is a distressing experience negatively associated with children's academic (Kochenderfer \& Ladd, 1996; Nakamoto \& Schwartz, 2010; Schwartz, Gorman, Nakamoto, \& Toblin, 2005), behavioral (Ewing Lee \& TroopGordon, 2011, Ji et al., 2019), emotional (Stadler, Feifel, Rohrmann, Vermeiren, \& Poustka, 2010), and social functioning (Bagwell \& Schmidt, 2011). Peer victimization is also positively associated with suicidal ideation and attempts (Dempsey, Haden, Goldman, Sivinski, \& Wiens, 2011; Van Geel, Vedder, \& Tanilon, 2014). While 
internalizing and externalizing behaviors have been shown to contribute to experiences of peer victimization (Jensen-Campbell, Knack, Waldrip, \& Ramirez, 2009; Reijntjes, Kamphuis, Prinzie, \& Telch, 2010; Reijntjes et al., 2011), numerous studies have documented that they may also be consequences of peer victimization (Hodges et al., 1999; Storch \& Ledley, 2005), suggesting experiences of peer victimization may further impair a child's ability to regulate their emotions. Thus, it is likely that emotion regulation deficits are both a risk factor for and consequence of peer victimization; these reciprocal influences likely lead to a cycle of peer victimization that remains stable over time. Conceptual and theoretical evidence for the process of peer victimization provides further insight into the relation between emotion regulation and peer victimization.

\section{Theories of Peer Victimization}

Numerous theories have been developed to conceptualize the process of peer victimization. Theories presented are intended to describe what predisposes children to peer victimization (Crick \& Dodge, 1994), how peer victimization affects children's cognitions, emotions and behaviors (Graham \& Juvonen, 2001), and how both theories may be integrated to describe peer victimization as cyclical and dynamic (Rosen et al., 2009, 2012; Rosen, Milich, \& Harris, 2007). The social information-processing theory, first developed by Dodge (1986) and reformulated by Crick and Dodge (1994), suggests that peer victimization is the result of how children encode and process information in their social environment. The social information-processing theory posits that in social environments, children receive and process social cues that affect their behavioral responses (Felix \& McMahon, 2007). The effectiveness with which a child is able to encode and interpret social information can be influenced by internal (e.g., emotional 
arousal) and external factors (e.g., behavior of others; Crick \& Dodge, 1994). The interpretations of these factors then alter which behavioral responses will be initiated (Crick \& Dodge, 1994). The social information-processing theory incorporates literature on the hostile attribution bias, defined as the tendency to interpret the intent of others as hostile, despite lack of environmental cues indicating clear and hostile intent (Milich \& Dodge, 1984). Oftentimes, the influence of internal factors (e.g., emotional arousal) may make it more likely that a child interprets external factors (e.g., peer's intent) as hostile, even if the intent is ambiguous, leading to increased demonstrations of negative affect (e.g., fear or anger; Crick \& Dodge, 1994). These emotional expressions are considered aversive to peers and may increase a child's risk for future victimization (Crick \& Dodge, 1994). Given that children who experience peer victimization often fail to use effective strategies in response to stressful social situations (Elledge et al., 2010) and frequently respond to peer provocation through actively engaging or avoiding conflict (Perry et al., 1988), the social information-processing theory appears to help to identify which children may be predisposed for subsequent victimization by peers; that is, children who inaccurately interpret social cues because they fail to reduce emotional arousal often respond with behaviors that are aversive to their peers (e.g., actively engaging or avoiding conflict; Perry et al., 1988), which increases their subsequent risk for peer victimization. The social information-processing theory provides evidence for why children may initially experience peer victimization. Once that peer victimization occurs, the attribution theory (Graham \& Juvonen, 2001) provides hypotheses for how peer victimization affects children. 
The attribution theory (Graham \& Juvonen, 2001) posits that the experience of peer victimization may further exacerbate a child's ability to initiate effective behavioral responses in socially distressing situations. Characterized as a social approach for understanding how children integrate how they think about themselves (i.e., personal motivation) with what others think about them (i.e., social motivation), the attribution theory argues that children make attributions, or inferences about why outcomes occur, about themselves and others; these attributions likely serve an important function in assisting children with imposing order in uncertain environments (Graham \& Juvonen, 2001). Graham and Juvonen (2001) propose two pathways to describe how peer victimization affects a child's self-attributions and attributions of others: (1) children who blame themselves for their peer victimization experiences are likely to develop intrapersonal consequences, such that the experience of peer victimization may cause internalizing behaviors, including anxiety and depression, which lead to the expression of maladaptive behaviors such as passivity and withdrawal, and (2) children who blame others for their peer victimization experiences are likely to develop interpersonal consequences, such that peer victimization causes anger and negative affect, which lead to rejection and withholding of help (Graham \& Juvonen, 2001). For both pathways, the attribution theory suggests that peer victimization results in negative attributions of self and others and leads to intrapersonal and interpersonal consequences.

Given prior research documenting that children who experience peer victimization may be more likely to demonstrate internalizing (Reijntjes et al., 2011) and externalizing (Reijntjes et al., 2010) behaviors, the attribution theory appears to describe the processes through which internalizing and externalizing behaviors emerge. As 
detailed in the social information-processing theory (Crick \& Dodge, 1994), the interpretation of situations involving peer threat may be influenced by emotional arousal; thus, it is also likely that attributions stem from subjective interpretations of peer victimization experiences. Social situations associated with significant emotional distress, such as in the context of peer victimization, may lead a child to make more negative attributions of self and others and identify as a victim. Additional evidence provided by Rosen, Milich, and Harris $(2007,2009,2012)$ appears to integrate the social informationprocessing theory (Crick \& Dodge, 1994) and the attribution theory (Graham \& Juvonen, 2001) by proposing a model that describes peer victimization as process which is cyclical and dynamic.

The victim schema model (Rosen et al., 2007, 2009) suggests that all children possess a schema for peer victimization experiences - labeled the victim schema - that develops from the interaction between biological factors (e.g., temperament) and early socialization experiences (e.g., parent-child interactions, early peer experiences). The victim schema model proposes that how victims view peer behavior varies based on victims' cognitions and emotions (Rosen et al., 2009). Victim schemas interact with social information-processing (i.e., peer threat perception) and emotion regulation strategies to determine the extent to which children will experience peer victimization (Rosen et al., 2009). Once a child experiences peer victimization, the victim schema model describes how implicit associations of oneself as a victim contribute to expectations of future peer victimization (Rosen et al., 2009). Integrating the social information-processing theory (Crick \& Dodge, 1994), the victim schema model posits that children who fail to regulate their emotions demonstrate greater deficits in processing 
social information because their emotional reactivity inhibits their ability to identify, encode, and interpret social information accurately. These deficits prevent the initiation of problem-solving approaches and lead to emotionally driven behaviors, including aggression and submission, which increase a child's risk for peer victimization (Rosen et al., 2009). Further, the victim schema model incorporates the attribution theory (Graham \& Juvonen, 2001) by suggesting that after children experience peer victimization, they develop negative attributions about themselves and others; these attributions lead to greater emotion regulation deficits in the presence of peer threat. Thus, Rosen et al. (2007, 2009) conceptualize peer victimization as cyclical and dynamic.

An additional model (Rosen et al., 2012), builds on the victim schema model (Rosen et al., 2007, 2009) and appears particularly relevant to the study of emotion regulation and peer victimization. In the proposed model of well-regulated and emotionally dysregulated responses to peer provocation in children, Rosen et al. (2012) suggest that a child's ability to regulate negative emotions in the presence of interpreted peer provocation substantially contributes to the child's risk of peer victimization. Rosen et al. (2012) identify two pathways for how children may respond to peer provocation. The first is the well-regulated response pathway. In this pathway, children respond to peer provocation with well-regulated emotion, which reduces distress and encourages effective problem solving skills and prosocial behaviors. This results in an outcome not associated with peer victimization. The second pathway is the emotionally dysregulated response pathway. In this pathway, children respond to peer provocation with dysregulated emotion, which causes emotional distress and emotionally-driven behaviors. This results in subsequent experiences of peer victimization. In both pathways proposed 
by Rosen et al. (2012), the outcome reinforces how children will interpret and respond to peer provocation moving forward. Children who experience peer victimization as a result of failing to manage negative emotions will be more likely to experience peer victimization in the future.

Broadly, the social information-processing-theory (Crick \& Dodge, 1994), attribution theory (Graham \& Juvonen, 2001), victim schema model (Rosen et al., 2007, 2009), and well-regulated and emotionally dysregulated model (Rosen et al., 2012) provide conceptual and theoretical hypotheses for the process of peer victimization. When integrating these theories, it is likely that the inability to regulate emotions in the presence of peer conflict or peer threat may interfere with a child's ability to effectively interpret and process social information correctly. This, in turn, may lead to considerable emotional distress, which overrides a child's ability to engage in effective problemsolving strategies, and ultimately may leads to the expression of emotionally reactive behaviors. These emotionally-driven behaviors increase the risk that a child will experience subsequent victimization by peers. Following experiences of peer victimization, children may make attributions (i.e., about self and others), identify as a victim and demonstrate further impairments in their abilities to regulate their emotional arousal and emotional reactivity in future stressful situations (i.e., peer conflict and peer threat). Therefore, emotion regulation deficits likely contribute to and are associated with peer victimization experiences; their reciprocal influences likely help to explain why many children experience chronic peer victimization (Hunter et al., 2007) that becomes increasingly stable over time (Scholte et al., 2007). 


\section{Measurement of Peer Victimization}

Parent report measures (Morelen, Southam-Gerow, \& Zeman, 2016), child selfreport measures (Becker, Mehari, Langberg, \& Evans, 2017), teacher report measures (Fite, Evans, Cooley, \& Rubens, 2014), peer report measures (Bacchini, Affuso, \& Trotta, 2008), observations (Godleski, Kamper, Ostrov, Hart, \& Blakely-McClure, 2015), and child tasks (Rosen et al., 2007) have been used to assess peer victimization among children. Child self-report, peer-report and teacher-report measures show moderate correlations (Crick \& Bigbee, 1998); however there is evidence that peer victimization often corresponds more with peer-report and teacher-report measures than with child selfreport measures (Pellegrini \& Bartini, 2000). Additional evidence suggests children and parents each have differing but valid perceptions of children's social functioning (Weissman, Orvaschel, \& Padian, 1980), and disparate methods of peer victimization assessment contribute valid and unique variance to the estimation of peer victimization (Ladd \& Kochenderfer-Ladd, 2002). Peer victimization is most stable during adolescence (Pellegrini \& Long, 2002) and assessment during this period may be particularly unique relative to other developmental stages (Troop-Gordon \& Ladd, 2005). Given the validity and unique variance associated with multiple peer victimization informants, Pellegrini (1998) recommends that peer victimization be assessed using a multi-informant approach. Through the assessment of peer victimization in children, multiple methods of measurement have demonstrated that peer victimization is often associated with deficits in emotion regulation (Camodeca \& Goossens, 2005; Toblin, Schwartz, Gorman, \& Abou-ezzeddine, 2005). 


\section{Relation Between Peer Victimization and Emotion Regulation Emotion Regulation}

Emotion regulation is a multifaceted and multidimensional process (Rosen \& Epstein, 2010) by which individuals control and modify the intensity of their emotional states to adapt to internal and external demands (Cole, Martin, \& Dennis, 2004). Broadly, emotion regulation is the ability to regulate physiological, behavioral, and emotional reactions to stimuli in order to meet the demands of a situation (Cole et al., 2004; Gross, 2002). Emotion regulation tends to be goal driven; that is, individuals often seek to decrease negative emotions and increase positive emotions (Gross, 1998). Often characterized as a crucial developmental skill (Cole, Michel, \& Teti, 1994) essential for children's positive development (Hastings et al., 2008), emotion regulation skills have been hypothesized to initially develop prenatally and continue developing throughout infancy, childhood, and adolescence (Dawson, Panagiotides, Klinger, \& Hill, 1992; Thompson \& Goodman, 2010; Thompson \& Meyer, 2007).

Previous literature suggests infants demonstrate emotion regulation strategies (Kochanska, Coy, \& Murray, 2001; Rothbart, Ziaie, \& O'boyle, 1992) which are thought to develop largely in the context of their relationships with their caregivers (Eisenberg, Fabes, Carlo, \& Karbon, 1992; Southam-Gerow \& Kendall, 2002). As children grow older and progress into childhood and adolescence, their emotion regulation skills become more complex and developed (Stegge \& Terwogt, 2007), and they often attempt to regulate their emotions independently in social situations (Zeman, Cassano, PerryParrish, \& Stegall, 2006). While many children will experience negative emotions, the ability to regulate negative emotional arousal and initiate assertive coping skills appears 
particularly necessary for the emotion regulation process (Eisenberg, et al., 1995). Numerous theoretical hypotheses attempt to explain how children regulate their emotions.

\section{Theories of Emotion Regulation}

The polyvagal theory (Porges, 1995, 2001; Porges, Doussard-Roosevelt, \& Maiti, 1994) posits that emotions are a physiological process, and the generation and regulation of emotion is dependent on the state of the nervous system. According to the polyvagal

theory (Porges et al., 1994), emotion regulation is the result of a hierarchically organized autonomic nervous system, composed of the sympathetic and parasympathetic nervous systems. These nervous systems are influenced by two vagal systems: (1) a phylogenetic relic of amphibia and reptilia (i.e., ventral vagal complex), and (2) an evolutionary modification unique to mammals (i.e., dorsal vagal complex), both of which regulate heart rate in response to a variety of stressors and are programmed with disparate response strategies (Porges, 1995). The ventral and dorsal vagal systems were hypothesized to develop among mammals due to increasing metabolic demands that are unique relative to amphibians and reptiles (Porges, 1995), and their hierarchical organization is necessary to understand the process of emotion regulation.

When children experience stressful situations, the more primitive ventral vagal complex acts first, followed by the evolutionary developed dorsal vagal complex. More specifically, the ventral vagal complex is initiated to inhibit input to the heart through activating the parasympathetic nervous system (Porges, 2001). Activation of the parasympathetic nervous system has been shown to reduce emotional distress and restore autonomic homeostasis (Porges, 1992). However, if the ventral vagal complex is unable 
to provide inhibitory input to the heart via the parasympathetic nervous system, the dorsal vagal complex activates the sympathetic nervous system (Porges, 2001). Unlike the parasympathetic nervous system, the sympathetic nervous system does not restore autonomic homeostasis; rather, it increases heart rate, stimulates sweat glands, and inhibits the gastrointestinal tract to prepare the body for emergency (Porges, 2001). Therefore, for children to maintain autonomic homeostasis during stressful situations, the ventral vagal complex must be able to activate the parasympathetic nervous system to initiate the emotion regulation process. Disruptions in autonomic functioning will likely lead to the inability to effectively regulate emotions in response to threat and precede the expression of maladaptive coping skills. Thus, the polyvagal theory provides theoretical rationale for how children physiologically regulate their emotions (Porges, 2011).

Complementing this work on physiological regulation of emotion is a model of neuroanatomical regions involved in the emotion regulation process. The model of the cognitive control of emotion (Ochsner \& Gross, 2007) proposes that emotions can be generated and regulated either by bottom-up or top-down neuroanatomical processes. Both processes play an influential role in the emotion regulation process; bottom-up processes alert a child about potentially threatening situations and top-down processes regulate emotional and behavioral responses. Bottom-up processes for emotionally generated responses are triggered by the perception of stimuli with intrinsic or learned affective value (Ochsner \& Gross, 2007). For bottom-up processes, limbic structures (e.g., amygdala, insula) encode the affective properties of stimuli and send outputs to the hypothalamic nuclei that control autonomic and behavioral responses (Ochsner \& Gross, 2007). The generation of emotion through bottom-up processes likely leads to the 
initiation of the ventral vagal complex as proposed in the polyvagal theory (Porges, 1995, 2001; Porges et al., 1994). Once bottom-up generation has begun, top-down processes can regulate, redirect and alter the way in which triggering stimuli are being appraised (Ochsner \& Gross, 2007).

Top-down processes involve the lateral and medial prefrontal cortex, and are triggered by beliefs which lead one to appraise an otherwise neutral stimulus as emotionally evocative (Ochsner \& Gross, 2007). Top-down processes allow for a child to actively control the appraisal process through implementing higher cognitive processes (Ochsner \& Gross, 2007). These higher cognitive processes enable a child to deliberately attend to and appraise a situation in different ways (Ochsner \& Gross, 2007). Given that top-down processes regulate bottom-up processes for emotion generation, children who fail to initiate top-down processes are likely to demonstrate deficits in the emotion regulation process. If bottom-up processes override higher cognitive processes, children will fail to regulate their emotional arousal, and express maladaptive coping strategies. While bottom-up and top-down processes may provide theoretical evidence that emotion is generated and regulated by unique neuroanatomical processes, the model of emotion regulation based on principles of executive function (Zelazo \& Cunningham, 2007) describes how neuroanatomical regions involved in the emotion regulation process may contribute to the subjective experience of complex emotions (Zelazo \& Cunningham, 2007).

Executive function refers to attention shifting, working memory, and inhibitory control processes that are used in goal-directed activities (Miyake et al., 2000). Zelazo and Cunningham (2007) argue that these processes are recruited for the deliberate self- 
regulation of emotion, and propose theoretical evidence for two types of executive functions: "hot" (i.e., control processes involved in emotion and reward representation) and "cool" (i.e., higher-order processes involved in relatively abstract and decontextualized information; Zelazo \& Müller, 2002). "Hot" executive functions operate in motivationally and emotionally significant situations (e.g., when a child really cares about the problems they are attempting to solve), whereas "cool" executive functions operate in more motivationally and emotionally neutral situations (e.g., when a child is categorizing shapes by color; Zelazo \& Cunningham, 2007). While "hot” executive functions are characterized by the presence of more emotion and motivation, both "hot" and "cool" are likely involved in regulating motivation and emotion (Zelazo \& Cunningham, 2007).

To provide neuroanatomical evidence for the differentiation between "hot" and "cool" aspects of executive function, Zelazo and Cunningham (2007) suggest that "hot" aspects are associated with the ventral prefrontal cortex, and "cool" aspects are associated with the lateral prefrontal cortex. Specifically, "hot" executive functions involve the orbitofrontal cortex (i.e., ventral prefrontal cortex region), which has strong connections to limbic structures and integrates affective and nonaffective information (Zelazo \& Cunningham, 2007). "Cool" executive functions involve the lateral prefrontal cortex, which is connected to a variety of brain regions (e.g., thalamus, basal ganglia, and hippocampus) and plays an important role in the regulation of sensory information, intellectual functioning, and action (Zelazo \& Cunningham, 2007). Similar to the model of the cognitive control of emotion (Ochsner \& Gross, 2007), which proposes emotions are regulated by top-down neuroanatomical processes, Zelazo and Cunningham (2007) 
propose that "hot" and "cool" aspects of executive function involve different top-down neuroanatomical processes (Zelazo \& Carlson, 2012). These top-down neuroanatomical processes are initiated by either the orbitofrontal cortex (i.e. "hot" executive functions) or the lateral prefrontal cortex (i.e. "cool" executive functions) to inform goal-directed activities. Thus, children who have difficulties regulating their emotions may have challenges with "hot" executive functions and top-down neuroanatomical processes involved in down-regulating limbic regions. While Zelazo and Cunningham (2007) provide theoretical evidence that executive functions are involved in emotion regulation, Cyders and Smith (2008) describe why some children may have more difficulty regulating their emotions than others.

The theory of urgency (Cyders \& Smith, 2008) proposes that under heightened emotional states, children are more likely to engage in ill-considered or rash actions than at other times. Cyders and Smith (2008) suggest that the experience of emotion facilitates a child's action to meet their needs; these actions can be fundamentally adaptive (i.e. problem-solving) or maladaptive (i.e. internalizing and externalizing behaviors). Generally, more intense needs are associated with more intense emotional states and more extreme behavioral choices (Cyders \& Smith, 2008). Thus, Cyders and Smith (2008) propose urgency traits (i.e., positive and negative urgency) to describe a specific process by which emotionality is tied to ill-advised, rash action. Positive urgency refers to the tendency to engage in rash action in response to extreme positive affect, and negative urgency refers to the tendency to engage in rash action in response to extreme negative affect (Cyders \& Smith, 2008). Positive and negative urgency are positively correlated and provide theoretical evidence for how maladaptive levels of emotionality 
lead to the demonstration of problematic behaviors (Cyders \& Smith, 2008). For example, a child who experiences more intense emotions (both positive and negative) may be more likely to demonstrate problematic behaviors because they fail to inhibit and regulate their emotional arousal.

Evidence for the urgency theory stems from literature in temperament and neuroscience (Cyders \& Smith, 2008). Cyders and Smith (2008) suggest that genetic polymorphisms in the serotonin transporter gene (5HTTLPR) and dopamine receptor genes (DRD2, DRD3, and DRD4) contribute to variation in levels of serotonin and dopamine in the amygdala and orbitofrontal cortex pathway (i.e., neuroanatomical regions associated with "hot" executive functions). These variations, in turn, affect child temperament, and Cyders and Smith (2008) propose two distinct pathways to describe how predispositions in temperament affect the demonstration of adaptive or maladaptive behaviors: (1) children who are predisposed to act rashly perform rash actions, leading to the development of urgency traits and the demonstration of more rash actions and problematic behaviors, and (2) children who not predisposed to act rashly will not perform rash actions, leading to the child refraining from rash actions and learning adaptive means for addressing emotions. Broadly, Cyders and Smith (2008) suggest there are individual differences in the propensity to engage in ill-considered behaviors when experiencing intense emotions; these differences are reflected in a broad trait called urgency. The theory of urgency (Cyders \& Smith, 2008) provides additional evidence for the process of emotion regulation, and the process model of emotion regulation (Gross, 1998) describes how environmental mechanisms contribute to a child's ability to regulate their emotions. 
The process model of emotion regulation (Gross, 1998) proposes that children attempt to modify their emotions, and emotion regulation may occur at five points in the emotion generative process: (1) selection of the situation, (2) modification of the situation, (3) deployment of attention, (4) change of cognitions, and (5) modulation of responses. According to Gross (1998), at the first point in the emotion generative process, situation selection, children have the ability to approach or avoid certain people, places, or objects to reduce emotional distress. Unfortunately, children may not always be able to control situations in which they choose to engage, and when situations arise unexpectedly, they may attempt situation modification, or the ability to directly modify the situation in order to decrease negative emotional arousal. During this time, children may choose to deploy focused attention; that is, they may attempt to disengage from emotionally arousing situations by using strategies such as distraction, concentration, and rumination. Following focused attention, children may also evaluate their capacity to manage the situation though engaging in strategies such as cognitive reframing, and/or social comparisons or reappraisal. Response modulation, hypothesized to occur late in the emotion generative process after response tendencies have been initiated, refers to directly influencing physiological, experiential, or behavioral responding. During this stage of the emotion regulation process, parents or caregivers often become involved. Medications, therapy, and exercise are all ways in which parents or caregivers may choose to improve children's emotion regulation strategies to decrease emotional distress. Therefore, the process model of emotion regulation provides several opportunities through which children and their parents or caregivers may attempt to regulate emotional distress. 
Broadly, the polyvagal theory (Porges, 1995, 2001; Porges et al., 1994), the model of cognitive control of emotion (Ochsner \& Gross, 2007), the model of emotion regulation based on principles of executive function (Zelazo \& Cunningham, 2007), and the theory of urgency (Cyders \& Smith, 2008) describe biological, physiological and neurological mechanisms involved in emotion regulation. The social process model of emotion regulation (Gross, 1998) provides additional behavioral, cognitive, and social processes of emotion regulation. Each theory attempts to provide unique insight for the process of emotion regulation in children. Given that emotion regulation is a multidimensional construct (Rosen \& Epstein, 2010), disparate methods may be used to assess how children regulate their emotions.

\section{Measurement of Emotion Regulation}

Parent-report measures (Factor, Rosen, \& Reyes, 2016), child-report measures (Bunford, Evans, \& Langberg, 2018), teacher-report measures (McCandless \& O’Laughlin, 2007), child observations (Shields \& Cicchetti, 2001) and child tasks (Bollmer, Harris, \& Milich, 2006) have been shown to represent valid methods for assessing the behavioral and emotional dimensions of emotion regulation in children (Hessler \& Fainsilber Katz, 2007). Emotion regulation appears relatively stable across teacher and parent measures (Hanish et al., 2004); however, discrepant findings have been identified among child-report and parent-report measures (Hourigan, Goodman, Southam-Gerow, 2011). Although differences have emerged in perceptions of emotion regulation between children and their parents, Hourigan et al. (2011) argue that differing perceptions provide meaningful and useful information about the nature of emotion regulation. Additionally, the employment of ecological momentary assessment methods 
may not be valid among children, as children may be less likely to complete emotion regulation measures when emotionally distressed (Rosen, Epstein, \& Van Orden, 2013; Rosen \& Factor, 2015). Given the use of multiple methods of measurement for emotional and behavioral dimensions of emotion regulation in children, Morelen et al. (2016) recommend using multi-informant approaches.

Neuroimaging measures (McRae et al., 2012), physiological measures (Musser et al., 2011), neurophysiological measures (Dennis \& Hajcak, 2009; Lewis, Lamm, Segalowitz, Stieben, \& Zelazo, 2006), and molecular genetic measures (Kochanska, Philibert, \& Barry, 2009) have demonstrated validity in assessing biological dimensions of emotion regulation in children (see Goldsmith, Pollak, \& Davidson, 2008 for review). Unfortunately, there remains a lack of literature incorporating multiple biological assessment methods to describe emotion regulation in children; thus, the incorporation of multi-method approaches also appears warranted to identify which biological assessments are more or less accurate in assessing children's emotion regulation abilities.

\section{Emotion Regulation and Social Functioning}

Emotion regulation skills are necessary for social functioning (see Rose-Krasnor, 1997 for review), as the inability to regulate emotions is associated with greater social impairment (Bunford et al., 2018; Hubbard \& Dearing, 2004), including lower social status (Maszk, Eisenberg, \& Guthrie, 1999), poor social skills (Eisenberg et al., 2000), poor friendship quality (McDowell, O’Neil, \& Parke, 2000), and peer rejection (Bierman, 2004). Based on evidence that children tend to prefer peers who demonstrate fewer negative emotions (Hay et al., 2004; Smith et al., 2001), and evidence that peers find emotionally dysregulated behavior aversive (Hubbard \& Coie, 1994), the inability to 
regulate negative emotions appears particularly detrimental to children's social functioning, especially given evidence that deficits in emotion regulation are associated with increased aggressive behaviors (Röll, Koglin, \& Petermann, 2012). Eisenberg et al. (1997) suggested that emotion regulation abilities are not only linked to social impairments but are also predictive of future social impairments; children who demonstrated more negative emotions at four years of age were more likely to experience greater social impairment four years later. Extending emotion regulation into the peer victimization literature, previous research suggests that emotion regulation plays an influential role in the development of chronic peer victimization (Hanish et al., 2004; Rosen et al., 2012).

\section{Emotion Regulation and Peer Victimization}

Emotion regulation deficits have long been associated with peer victimization. In a study by Rosen et al. (2012), children who demonstrated emotion regulation deficits were more likely to experience peer victimization, and Fogleman et al. (2016) observed that children who fail to regulate and cope with negative emotions experience a greater frequency of peer victimization experiences. Even in situations when children were asked to recount experiences of peer victimization, children who experienced more peer victimization demonstrated more sympathetic nervous system reactivity (Kliewer, Dibble, Goodman, \& Sullivan, 2012), negative affect (Bollmer et al., 2006), and emotional distress (Rosen et al., 2012). Given that children who effectively regulate their emotions are less likely to be victimized by their peers (Kaynak, Lepore, Kliewer, \& Jaggi, 2015), effective emotion regulation and conflict resolution skills appear critical for 
reducing the frequency with which children experience peer victimization (KochenderferLadd, 2004).

It has been hypothesized that the inability to regulate emotions may interfere with use of learned prosocial behaviors and conflict resolution skills (Fogleman et al., 2016), which may put a child at risk for peer victimization because they respond to peer provocation with aggressive or withdrawn behaviors (Olweus, 1994; Schwartz et al., 2001). Many children who experience peer victimization respond emotionally to adverse situations and interpret ambiguous situations as hostile (Camodeca \& Goossens, 2005). Mahady Wilton et al. (2000) found that children who experience peer victimization demonstrate maladaptive emotion regulation strategies and are likely to respond to peer provocation with physical or verbal aggression. Moreover, children who fail to regulate negative emotions in the presence of peer threat often exhibit aggressive attitudes (Terranova, 2009), revenge-seeking behaviors (Kochenderfer-Ladd, 2004), emotionallyreactive behaviors (Toblin et al., 2005), and fewer assertive behaviors and social strategies (Toblin et al., 2005). Thus, children who are unable to control their emotional arousal to implement assertive and effective conflict management strategies instead resort to emotionally-driven fear or anger responses, increasing their risk for peer victimization (Hanish et al., 2004). Coping with peer conflict requires children to monitor and control their own emotions and behavior to execute effective coping strategies (Mahady Wilton et al., 2000) and engage in assertive conflict resolution behaviors (Kopp, 1989). However, children who experience peer victimization tend to implement similar coping strategies over time (Terranova, 2009), many of which have been shown to be ineffective (Kochenderfer-Ladd \& Skinner, 2002). While emotion regulation and coping strategies 
are useful in mitigating peer victimization experiences (Cooley \& Fite, 2016), peer victimization may also exacerbate a child's ability to regulate their emotions in future social situations (Iyer, Kochenderfer-Ladd, Eisenberg, \& Thompson, 2010).

The experience of peer victimization has been shown to uniquely impair children's emotion regulation abilities (Cuevas, Finkelhor, Clifford, Ormrod, \& Turner, 2010). McLaughlin, Hatzenbuehler, and Hilt (2009) demonstrated that peer victimization was associated with more emotion regulation deficits over a four-month period, and Cooley and Fite (2016) found that peer victimization predicted more physical aggression over time. Thus, the experience of peer victimization likely interferes with the initiation of effective emotion regulation and coping strategies. Therefore, peer victimization and emotion regulation appear to share a reciprocal relationship (Reijntjes et al, 2010; Reijntjes et al., 2011), such that children with emotion regulation deficits are at an increased risk for peer victimization, and the experience of peer victimization likely influences the development of maladaptive emotion regulation strategies and coping skills. Given that emotion regulation begins developing prenatally and during infancy (Dawson et al., 1992; Thompson \& Goodman, 2010), and the earliest documentation of peer victimization is in toddlerhood (Bonica et al., 2003), it is likely that emotion regulation deficits initially lead to peer victimization experiences, which, in turn, further affect a child's emotion regulation abilities.

Given the link between emotion regulation and peer victimization, it appears necessary to integrate theories to better understand the relation between the two multidimensional constructs. Incorporating the social information-processing theory (Crick \& Dodge, 1994), children who fail to regulate their emotions are likely to 
demonstrate an impaired ability to encode and interpret social information effectively. This inability to encode social information accurately may lead to peer victimization, which, in turn, may affect how children make attributions of themselves and others (Graham \& Juvonen, 2001), further impairing deficits in social information-processing (Camodeca \& Goossens, 2005). Models proposed by Rosen et al. (2007, 2009, 2012) incorporate emotion regulation and peer victimization by demonstrating that each construct likely influences the other. If peer victimization is attributable to emotion regulation deficits in children, emotion regulation theories may argue that children with neuroanatomical deficits (Ochsner \& Gross, 2007; Zelazo \& Cunningham, 2007), deficits in their physiological responses to stress (Porges, 1995), genetic polymorphisms associated with temperament and urgency traits (Cyders \& Smith, 2008), and who fail to initiate environmentally-driven emotion regulation strategies (Gross, 1998) may be more likely to experience peer victimization.

Certain neurodevelopmental disorders, such as ADHD, are associated with neuroanatomical deficits (Shaw et al., 2012), impaired physiological arousal (Musser, Galloway-Long, Frick, \& Nigg, 2013), genetic predispositions for urgency traits (Faraone \& Mick, 2010), and maladaptive emotion regulation responses (Shaw et al., 2014). Previous literature also demonstrates that children with ADHD are more likely to experience social dysfunction (Hoza et al., 2005) and peer victimization (Wiener \& Mak, 2009). When incorporating evidence that emotion regulation is linked to peer victimization (Fogleman et al., 2016), emotion regulation deficits among children with ADHD may make them more susceptible to experiencing victimization from their peers. 


\title{
Relation Between Emotion Regulation and ADHD
}

\author{
ADHD \\ ADHD is mainly characterized by symptoms of impulsivity, inattention, and \\ hyperactivity (American Psychiatric Association, 2013). Affecting between five and \\ seven percent of children worldwide (Polanczyk, de Lima, Horta, Biederman, \& Rohde, \\ 2007; Thomas, Sanders, Doust, Beller, \& Glasziou, 2015), ADHD is highly heritable (see \\ Faraone \& Biederman, 2000 for review; Rhee, Waldman, Hay, \& Levy, 1999), more \\ prevalent among males than females (American Psychiatric Association, 2013; DuPaul et \\ al., 1997; DuPaul et al., 1998), and often persists into adulthood (Barkley, Murphy, \& \\ Fischer, 2008; Faraone, Biederman, \& Mick, 2006). For a child to receive a diagnosis of \\ ADHD, symptoms of impulsivity, inattention, and hyperactivity must be present prior to \\ the age of twelve, occur for at least six months, impact a child functioning in multiple \\ domains (e.g. home and school), and cannot be attributable to a co-occurring medical \\ condition (American Psychiatric Association, 2013). ADHD may be diagnosed as \\ predominantly inattentive presentation, predominantly hyperactive/impulsive \\ presentation, or predominantly combined presentation (i.e., combination of inattentive \\ and hyperactive/impulsive presentations), with diagnoses characterized as mild, \\ moderate, or severe (American Psychiatric Association, 2013). \\ In children with ADHD, brain maturation is delayed, on average, by about three \\ years (Shaw et al., 2007). Children with ADHD show morphometric differences in the \\ right prefrontal cortex and amygdala (Clark et al., 2007; Frodl et al., 2010) and delayed \\ cortex maturation (Shaw et al., 2012). Additional research suggests that children with \\ ADHD may demonstrate distinct patterns of autonomic functioning, including
}


impairments in parasympathetic and sympathetic nervous systems (Musser et al., 2011; Musser et al., 2013). Often associated with comorbid psychiatric disorders (Barkley \& Murphy, 2006; Barkley et al., 2008), deficits in executive functioning (Barkley, 1997), and impairments in academic, behavioral, and social functioning (DuPaul, McGoey, Eckert, \& VanBrakle, 2001; DuPaul \& Stoner, 2014; Loe \& Feldman, 2006), ADHD is also a disorder associated with emotion regulation difficulties (Berlin, Bohlin, Nyberg, \& Janols, 2004; Braaten \& Rosén, 2000; Wehmeier, Schacht, \& Barkley, 2010).

\section{Measures of ADHD Diagnostic Status}

ADHD assessment requires a comprehensive evaluation by a licensed clinician, who often employs the use of parent-report measures (Bunford et al. 2018) and teacherreport measures (Bagwell, Molina, Pelham, \& Hoza, 2001). Although previous studies have implemented child-report measures in older children (Spencer et al., 2011), these methods may not provide an accurate assessment of ADHD as children with ADHD tend to underreport ADHD symptoms (Loeber, Green, Lahey, \& Stouthamer-Loeber, 1991; Sibley, Campez, \& Raiker, 2019) and overestimate their abilities in several functional domains (Hoza, Pelham, Dobbs, Owens, \& Pillow, 2002). Interestingly, although studies have documented the reliability of parent-report (Wolraich et al., 2003) and teacherreport methods (Wolraich, Bard, Neas, Doffing, \& Beck, 2013) for assessing ADHD in children, use of parent-report and teacher-report measures each appear to influence the rate of ADHD diagnoses (Jarratt, Riccio, \& Siekierski, 2005), and teacher-report measures may provide a more accurate ADHD subtype diagnosis (Power et al., 1998). Additionally, ADHD symptom agreement between parents and teachers is relatively low, and the use of multiple informants significantly decreases the prevalence of ADHD 
(Mitsis, McKay, Schulz, Newcorn, \& Halperin, 2000; Wolraich et al., 2004). Therefore, a multi-informant approach, incorporating parent and teacher measures, likely leads to a more accurate evaluation of child ADHD symptoms.

\section{ADHD and Emotion Regulation}

Emotion regulation deficits frequently co-occur with ADHD (Crundwell, 2005; Jensen \& Rosen, 2004; Linder, Kroyzer, Maeir, Wertman-Elad, \& Pollak, 2010), and have been shown to be present in infancy and early childhood (Gurevitz, Geva, Varon, Leitner, 2014; Martel, Roberts, Gremillion, 2013). Emotion regulation deficits among children with ADHD may include poor self-regulation of emotion (Graziano \& Garcia, 2016), excessive emotional expressions (Sobanski et al., 2010), and greater problems coping with negative emotions (Melnick \& Hinshaw, 2000). Although emotion regulation difficulties are not currently described as a core deficit among children with ADHD (American Psychiatric Association, 2013), previous research suggests nearly 45 percent of children with ADHD demonstrate deficits in emotion regulation (Shaw et al., 2014), with higher rates among children with ADHD combined presentation (Wheeler Maedgen \& Carlson, 2000) and in children with comorbid psychiatric disorders (Factor, Reyes, Rosen, 2014). Although the influence of sex characteristics on emotion regulation is relatively unknown (Becker et al., 2006; Bubier \& Drabick, 2008; Sjöwall, Roth, Lindqvist, \& Thorell, 2013), emotion regulation deficits among children with ADHD have been linked to functional impairments (Anastopoulos et al., 2011).

Previous studies have recommended that emotion regulation deficits be incorporated into conceptualizations of ADHD (see Martel, 2009 for review). Neuroanatomical regions (Cyders \& Smith, 2008; Ochsner \& Gross, 2007; Zelazo \& 
Cunningham, 2007) and autonomic functioning (Porges, 1995) hypothesized to influence the emotion regulation process may provide insight into why children with ADHD demonstrate more emotion regulation deficits relative to unaffected children. Given ADHD is a neurodevelopmental disorder associated with neuroanatomical and physiological impairments (Musser et al., 2011; Shaw et al., 2007), emotion regulation deficits among children with ADHD may be attributable to neural dysfunction (Nigg \& Casey, 2005) and/or abnormal autonomic functioning (Musser et al., 2013). Furthermore, the top-down and bottom-up processes associated with emotion regulation may be impaired in children with ADHD due to deficits in the frontal-limbic-amygdala circuit (Nigg \& Casey, 2005) and abnormal connectivity between the amygdala and prefrontal cortex (Plessen et al., 2006). Thus, children with ADHD may demonstrate an inability to regulate their emotions at an early age (Sullivan et al., 2015) due to neuroanatomical and physiological impairments inherent to the disorder.

While neuroanatomical and physiological impairments may make it more difficult for children with ADHD to regulate their emotions, high levels of behavioral and attentional impulsivity common among children with ADHD (American Psychiatric Association, 2013) may cause emotion regulation deficits to be particularly impairing. Poor impulse control and executive function among children with ADHD (Barkley, 1997) may make children more likely to act on negative emotions, amplifying the impact of negative emotions. Given theoretical evidence that executive functions are involved in the emotion regulation process (Zelazo \& Cunningham, 2007), poor executive functioning among children with ADHD may make it more difficult to inhibit and regulate negative emotional arousal during stressful situations. 
Additional evidence suggests children with ADHD may experience emotions more intensely (Fogleman, Leaberry, Rosen, Walerius, \& Slaughter, 2018a; Scime \& Norvilitis, 2006), react more impulsively to negative events, and demonstrate a lower capacity to regulate negative emotions (Barkley, 2014). These characteristics appear similar to Cyders and Smith's (2008) theoretical conceptualization of negative urgency. Therefore, excessive emotional expressions, including emotional reactivity (Walerius, Reyes, Rosen, \& Factor, 2014), impulsivity (Rosen \& Factor, 2015) and lability (Rosen, Walerius, Fogleman, \& Factor, 2015; Sobanski et al., 2010; Stringaris \& Goodman, 2009), may be more common among children with ADHD due to an inability to inhibit and regulate intense feelings of negative emotions. More specifically, during stressful situations, children with ADHD may fail to initiate effective emotion regulation strategies because they demonstrate urgency traits (Roberts, Peters, Adams, Lynam, \& Milich, 2014), and their experiences of intense negative emotions make it difficult for them to inhibit feelings of negative emotions. This inability to manage intense negative emotions leads to the demonstration of greater negative emotional reactivity (Walcott \& Landau, 2004). Difficulties inhibiting negative emotions among children with ADHD may prevent children from initiating effective coping strategies, which are known as the behavioral outcome of the emotion regulation process (Eisenberg et al., 1995), and may even increase a child's risk for developing comorbid psychiatric disorders (Seymour et al., 2012). Unfortunately for children with ADHD, peers find negative emotional expressions aversive (Hay et al., 2004), and children with ADHD who fail to regulate their emotions may experience greater social dysfunction (Bunford, Evans, \& Wymbs, 2015) and peer victimization (Fogleman et al., 2016). 


\section{Relation Between ADHD and Peer Victimization}

\section{ADHD and Social Functioning}

ADHD is associated with impairments in social functioning (see Hoza et al., 2007 for review). For children with ADHD, initial negative peer impressions may form very quickly (Diener \& Milich, 1997) and remain stable into adolescence (Bagwell et al., 2001). When compared to unaffected children, children with ADHD are less well-liked (Bacchini et al., 2008; Hoza et al., 2005), more disliked (Sciberras, Ohan, \& Anderson, 2011), and more likely to be rejected by their peers (Bagwell et al., 2001). Additional evidence suggests children with ADHD are involved in more peer conflict (Strine et al., 2006) and have poorer peer relations (Hoza et al., 2005) and fewer close friendships (Redmond, 2011). Albeit in a small sample, Shea and Wiener (2003) observed that children with ADHD often perceive themselves as being more socially isolated and different from other children, and perceptions of being different from other children was associated with greater social functioning deficits. Given previous literature suggesting that having fewer friends (Perry et al., 2001) and poorer friendships (Boulton \& Underwood, 1992) are associated with increased peer victimization, even among children with ADHD (Redmond, 2011), children with ADHD appear at a much greater risk for experiencing peer victimization relative to their unaffected peers.

\section{ADHD and Peer Victimization}

Children with ADHD are frequently victimized by their peers through overt and relational forms of victimization. Nearly 60 percent of children with ADHD report experiencing at least one episode of peer victimization per week (Becker et al., 2017), which greatly exceeds estimates among unaffected children (Nansel et al., 2001). 
Additional evidence suggests children with ADHD are twice as likely to experience peer victimization (Redmond, 2011); however, this estimate may be relatively low as Holmberg and Hjern (2008) and Wiener and Mak (2009) demonstrate that children with ADHD report experiencing peer victimization between seven and 10 times more frequently than children without ADHD. Although experiences of peer victimization may be more common among children with ADHD and comorbid psychiatric disorders (Taylor, Saylor, Twyman, \& Macias, 2010), there are inconsistent findings regarding whether the presence of core ADHD symptoms (i.e., inattention, hyperactivity, and impulsivity) is directly associated with increased peer victimization experiences in children with ADHD.

Initially, studies noted that ADHD symptoms were associated with peer victimization (Bacchini et al., 2008; Wiener \& Mak, 2009), but more recent literature fails to substantiate these findings (Chou et al., 2014; Fite et al., 2014). Fite et al. (2014) found that ADHD symptoms were not associated with overt victimization; yet, relational victimization was present across both high and low levels of ADHD symptoms. Additional literature by Mitchell, Cooley, Evans, and Fite (2015) found that ADHD symptoms were associated with more overt victimization, but they did not find differences for relational victimization. Thus, it is difficult to determine whether the presence of ADHD symptoms linearly coincides with increased rates of peer victimization among children with ADHD.

The relation between ADHD symptoms and peer victimization may also be influenced by child sex characteristics and peer victimization assessment methods. Examination of sex characteristics and ADHD symptoms suggest peer victimization may 
be more prevalent among females than males (Bacchini et al., 2008; Wiener \& Mak, 2009); however, these findings have been disputed in recent literature (Becker et al., 2017). Additionally, according to Sciberras et al. (2012), parent-report measures of peer victimization were associated with more ADHD than oppositional defiant disorder (ODD) symptoms; however, according to child-report measures of peer victimization, peer victimization was associated with more ODD than ADHD symptoms. While evidence suggests that the use of child-report measures among children with ADHD remains questionable (Hoza et al., 2002; Hoza et al., 2004), and previous studies have documented that children with ADHD may provide more optimistic reports of their peer victimization experiences than their parents (Fogleman et al., 2016), it is difficult to draw the conclusion that ADHD symptoms are directly related to the frequency with which a child with ADHD experiences peer victimization.

Generally, if ADHD symptoms are directly related to experiences of peer victimization, the use of stimulant medications, often prescribed to reduce core symptoms of ADHD (i.e., inattention, hyperactivity, and impulsivity; Pelham \& Fabiano, 2008), may modulate the frequency with which a child with ADHD experiences peer victimization. Unfortunately, previous studies have demonstrated this is not the case, and children with ADHD taking stimulant medications consistently report more peer victimization experiences relative to their unaffected peers (Unnever \& Cornell, 2003). Additionally, in a sample of children with ADHD who were recently prescribed stimulant medications, children on stimulant medications reported similar peer victimization relative to children with ADHD not on stimulant medications; it is important to highlight that both groups of children (i.e., children on and off stimulant medications) reported 
more peer victimization than children without ADHD. Although stimulant medications are effective at reducing core symptoms of ADHD (MTA Cooperative Group, 2004), they have not been shown to reduce emotion regulation deficits (Shaw et al., 2014). This may help to explain why children with ADHD on stimulant medication continue to experience peer victimization. Together, these findings suggest that ADHD symptoms of inattention, hyperactivity, and impulsivity may not be directly associated with the increased rates of peer victimization among children with $\mathrm{ADHD}$, further warranting an investigation into the role of emotion regulation.

\section{Relation Between ADHD, Emotion Regulation, and Peer Victimization}

There have been few studies examining the relation between emotion regulation and peer victimization among children with ADHD. Prior research by Fogleman et al. (2016) demonstrated that the relation between emotion regulation and peer victimization was moderated by ADHD diagnostic status. More specifically, children who had more difficulties regulating their emotions were more likely to experience peer victimization if they had also been diagnosed with ADHD. Additional studies have suggested that emotion regulation deficits (Fogleman, Slaughter, Rosen, Leaberry, \& Walerius, 2018), and internalizing behaviors (Fogleman, Leaberry, Rosen, Walerius, \& Slaughter, 2018b) are each uniquely associated with increased peer victimization experiences among children with ADHD. Given internalizing behaviors are often characterized as behavioral expressions of emotion regulation deficits (Zeman et al., 2002), there is substantial evidence that emotion regulation plays an influential role in experiences of peer victimization among children with ADHD. 


\section{Current Study}

Although emotion regulation and peer victimization likely share a reciprocal relationship (Rosen et al., 2012), the current study examines the concurrent associations between ADHD symptoms, emotion regulation, and peer victimization among children with ADHD. Children with ADHD demonstrate emotion regulation deficits (Shaw et al., 2014), and given that emotion regulation deficits are linked to peer victimization concurrently (Fogleman et al., 2016; Fogleman et al., 2018; Fogleman et al., 2018b; Hanish et al., 2004) and longitudinally (Rosen et al., 2012), the current study proposes that deficits in emotion regulation, rather than the severity of core ADHD symptoms (i.e., inattention, hyperactivity, and impulsivity), is associated with experiences of peer victimization among children with ADHD. Previous studies have demonstrated that children with ADHD experience emotions more intensely and have difficulties regulating their negative emotional arousal (Barkley, 2014; Shaw et al., 2014). Furthermore, children with ADHD are more likely to react impulsively to negative situations (Barkley, 2014) and engage in emotionally-reactive and emotionally-driven behaviors (Walcott \& Landau, 2004). During stressful situations (e.g., peer conflict or peer threat), children with ADHD may experience intense negative emotions and may be unable to regulate their negative emotional arousal effectively. The inability for a child with ADHD to regulate negative emotional arousal likely interferes with effective problem-solving and conflict resolution strategies necessary to reduce peer conflict, and may ultimately lead to behavioral expressions (i.e., negative emotional reactivity) considered aversive to peers (Eisenberg, 1993). These emotionally-driven behaviors likely increase a child's risk for experiencing peer victimization. 
While previous literature has established a link between ADHD and peer victimization (Unnever \& Cornell, 2003; Wiener \& Mak, 2009), few studies have investigated why children with ADHD experience higher rates of peer victimization relative to unaffected children. Thus, the current study aims to identify factors associated with peer victimization among children with ADHD. Examining the relation between ADHD symptoms, emotion regulation, and peer victimization will provide initial insight into whether ADHD symptoms and/or emotion regulation is associated with peer victimization among children with ADHD. Additionally, given the prevalence of ADHD in the worldwide population (Polanczyk et al., 2007) and the detrimental outcomes associated with peer victimization (Dempsey et al., 2011; Hawker \& Boulton, 2000), findings from the current study may also provide evidence for effective interventions for peer victimization among children with ADHD. Emotion regulation was not assessed in previous investigations examining the relation between ADHD symptoms and peer victimization (Wiener \& Mak, 2009), and given that emotion regulation deficits are often associated with increased ADHD symptomatology (Wheeler Maedgen \& Carlson, 2000), it is possible that emotion regulation deficits among children with ADHD are accounting for the observed relation between ADHD symptoms and peer victimization.

\section{Hypotheses}

The current study utilized a multi-informant approach (i.e., children and their parents) to examine the concurrent associations between ADHD symptoms, emotion regulation, and peer victimization among children with ADHD. Given evidence that children and parents provide unique and valid perspectives of emotion regulation and peer victimization, the following hypotheses were posited: 
1a) The primary hypothesis of this study is that poorer emotion regulation will be uniquely associated with peer victimization above and beyond the effect of ADHD symptoms.

1b) Based on extant literature (Fogleman et al., 2016; Fogleman et al., 2018b), it was hypothesized that within-rater and cross-rater effects will be observed for child-report and parent-report of emotion regulation on childreport and parent-report of peer victimization above and beyond the effect of ADHD symptoms.

1c) Exploratory analyses will examine the interaction between emotion regulation and ADHD symptoms on peer victimization. Analyses will investigate whether the relation of emotion regulation to peer victimization is moderated by the presence of ADHD symptoms. Although exploratory in nature, given previous research demonstrating ADHD symptoms are associated with peer victimization experiences (Ji et al., 2019; Rosen et al., 2012; Wiener \& Mak, 2009), and that emotion regulation is more strongly related to peer victimization in children with ADHD relative to children without ADHD (Fogleman et al., 2016), it was hypothesized that the relation of emotion regulation to peer victimization will be exacerbated by a greater frequency of ADHD symptoms.

2) Given evidence that experiences of peer victimization may bias how negative social situations are interpreted (Ruggieri, Bendixen, Gabriel, Alsaker, 2013), and evidence that children who experience peer victimization are more emotionally affected by laboratory tasks that 
simulate negative social experiences (Iffland, Sansen, Catani, \& Neuner, 2014; Ruggieri et al., 2013), it was hypothesized that greater emotional responses to a laboratory-based peer stressor task (i.e., Cyberball) will be associated with peer victimization.

3) Although there is a link between the regulation of negative emotions and peer victimization among children with ADHD (Fogleman et al., 2016), it is relatively unknown how the regulation of specific negative emotions affects peer victimization. Given that internalizing behaviors and externalizing behaviors are each associated with peer victimization (Reijntjes et al, 2010; Reijntjes et al., 2011), it is possible that the inability to regulate specific negative emotions, such as anger, sadness, and worry, will be associated with a greater frequency of peer victimization. Thus, exploratory analyses will assess the regulation of anger, sadness, and worry on the estimation of peer victimization among children with ADHD. Although exploratory in nature, it was hypothesized that poorer regulation of anger, sadness, and worry will each be uniquely associated with peer victimization. 


\section{CHAPTER II}

\section{METHOD}

\section{Recruitment}

Study hypotheses examined the effects of ADHD symptoms and emotion regulation on peer victimization among children with ADHD. Given the low base rates of ADHD in the general population (Polanczyk et al., 2007; Thomas et al., 2015), the current study recruited primarily from a pre-existing participant database at the Research in ADHD and Children's Emotion Regulation (RACER) Laboratory at the University of Louisville. When parents and children participated in previous research studies at the RACER Laboratory (Rosen et al., 2015), they were asked the following question: "May we contact you to provide information about other studies occurring at University of Louisville that you and your child may be eligible for?" If parents had responded 'yes' and their child had a previous diagnosis of ADHD and were within the study's targeted age range, parents were contacted via email and/or telephone and were provided information regarding the study.

Children who had been diagnosed with ADHD or were showing clinically concerning symptoms of ADHD were also recruited through community events throughout Louisville, Kentucky, and advertisements in the University of Louisville email notification system. Flyers describing the study were initially distributed to child and family community-based organizations/events and school counselors, and then disseminated to parents of children within the study's targeted age range and range of 
clinical difficulty. Parents interested in the study were instructed to contact study staff directly to receive additional information regarding the study. Similar recruitment methods have been documented in previous research studies (Fogleman et al., 2016; Rosen et al., 2015).

\section{Participants}

Fifty-four children (36 males, 18 females), ages $10-15$ years $(M$ age $=12.24 \pm$ 1.77), and their parents were enrolled in the present study. The age range of the sample was recruited/selected a priori due to previous evidence that experiences of peer victimization occur most frequently during the transition between elementary and middle school (see Troop-Gordon, 2017 for review) and are particularly common among children with ADHD throughout middle school and into early high school (Becker et al., 2017). Moreover, emotion regulation strategies are often used independently during this age range in social situations (Zeman et al., 2006). Eligibility was limited to children who met criteria for age, ADHD diagnostic status, and had an IQ greater than or equal to 70, as measured by the Wechsler Abbreviated Scale of Intelligence, Second Edition (WASIII; Wechsler, 2011). Additional eligibility was limited to families in which both the parent or caregiver and the child were able to attend the session. Five children did not meet diagnostic criteria for ADHD (as outlined in more detail below) and were excluded from the study, leaving a total 49 children diagnosed with ADHD in the final sample (32 males, 17 females; $M$ age $=12.22 \pm 1.71$; see Appendix B, Table 1).

The Diagnostic Structured Interview for Children ADHD module, Parent Version (DISC-P; Shaffer, Fisher, Lucas, Dulcan, \& Schwab-Stone, 2000), Vanderbilt ADHD Parent Rating Scale (VAPRS; Wolraich et al., 2003), and the Vanderbilt ADHD Teacher 
Report Scale (VATRS; Wolraich, Feurer, Hannah, Baumgaertel, \& Pinnock, 1998) were used to assess ADHD in children. Each assessment measure has shown to be a reliable method for assessing ADHD in children (Shaffer et al., 2000, Wolraich et al., 2003; Wolraich et al., 2013). Given evidence the DISC-P assesses behavior across multiple settings (i.e., home and school; Shaffer et al., 2000), children were diagnosed with ADHD if they met the following criteria: (1) met full criteria for ADHD on the DISC-P or (2) met intermediate criteria for ADHD on the DISC-P and met full criteria for ADHD on the completed parent (i.e., VAPRS) and/or teacher (i.e., VATRS) rating scale(s).

A child met criteria for ADHD when his or her parent/caregiver or teacher endorsed at least six of the nine inattentive symptoms (ADHD predominantly inattentive presentation; ADHD-I), at least six of nine hyperactive and impulsive symptoms (ADHD predominantly hyperactive/impulsive presentation; ADHD-H/I), or at least six of nine inattentive and six of nine hyperactive/impulsive symptoms (ADHD combined presentation; ADHD-C) on the DISC-P or combination on the DISC-P, VAPRS, and VATRS. Among all participants, 24 children met diagnostic criteria for ADHD-I, one child met diagnostic criteria for ADHD-H/I, and 24 children met diagnostic criteria for ADHD-C. The ADHD module of the DISC-P contained a question related to current use of psychiatric medications to manage symptoms of ADHD. This question was used to assess active ADHD medication treatment; 28 of the 49 children (57.1\%) were receiving medication treatment at the time of study.

The ethnic composition of the sample was reflective of the area from which the population was collected (U.S. Census Bureau, 2016), with 77.6\% European-American (n $=38), 12.0 \%$ African-American $(n=6), 2.0 \%$ Hispanic-American $(n=1), 2.0 \%$ Asian- 
American $(n=1)$, and $6.1 \%$ as having more than one racial/ethnic background $(n=3)$.

The median family income for children in the sample was greater than would be expected in the area from which the population was collected (U.S. Census Bureau, 2016), such that $2.0 \%$ were lower to middle income ( $\$ 0-\$ 25,000 ; n=1), 40.8 \%$ were middle to high income $(\$ 25,001-\$ 75,000 ; n=20)$, and $57.2 \%$ were high income (above $\$ 75,000 ; n=$ 28; see Appendix B, Table 1).

\section{Procedures}

The current study was approved by the Institutional Review Board at the University of Louisville. Parents of children completed an initial phone screening assessing for the presence of ADHD or clinically concerning symptoms of ADHD. Eligible parents and children were then scheduled for a visit at the University of Louisville to be consented for the study. Parents of children provided informed consent and children provided assent prior to initiation of any study procedures. During this time, parents were given the option to sign a release of information form authorizing communication between the investigator and the child's primary classroom teacher, or in the case of children with multiple teachers, a teacher with sufficient contact with the child to provide an accurate report of the child's ADHD symptoms. All parents in the present study signed a release of information to authorize communication between the investigator and the child's primary teacher. Of the 54 children who were enrolled in the current study, 72.2\% ( $n=39)$ of teachers returned measures assessing ADHD.

After obtaining informed consent and child assent, parents and children were escorted to separate rooms within the research laboratory. Parents were administered a highly structured diagnostic interview (DISC-P; Shaffer, 2000) to assess for ADHD 
diagnostic status while children completed a laboratory task and self-report measures assessing emotion regulation and experiences of peer victimization. Children did not complete measures assessing ADHD symptoms due to previous evidence that children with ADHD underreport their ADHD symptoms (Loeber et al., 1991; Sibley et al., 2019). After completing the diagnostic structured interview, parents completed measures assessing their child's ADHD symptoms, emotion regulation, and experiences of peer victimization. Children were compensated five dollars and provided with a small prize for their participation; parents were provided an ADHD screening evaluation at their request summarizing results of the study.

\section{Measures}

Multi-informant approaches were employed to assess a child's ADHD symptoms, emotion regulation, and peer victimization. Multi-informant approaches were selected to increase the accuracy of ADHD diagnoses (Mitsis et al., 2000; Wolraich et al., 2004), and to incorporate unique and valid estimates of emotion regulation (Hourigan et al., 2011) and peer victimization (Ladd \& Kochenderfer-Ladd, 2002; Putallaz et al., 2007).

\section{ADHD Diagnostic Status}

The Diagnostic Interview Schedule for Children-Version IV, Parent Report (DISC-P; Shaffer et al., 2000) was used as the primary method to determine ADHD diagnostic status for children in the study. This approach is consistent with previous literature suggesting the DISC-P provides greater specificity of questions with respect to time relative to ADHD rating scales (Owens, Zalecki, Gillette, \& Hinshaw, 2017). The DISC-P is a structured diagnostic interview that assesses mood and behavior across multiple settings (i.e. home and school), generates psychiatric diagnoses for children 
based on the American Psychiatric Association's Diagnostic and Statistical Manual, Fourth Edition (DSM-IV; American Psychiatric Association, 1994), and is designed for lay population use in diagnosing ADHD (Shaffer et al., 2000). All diagnostic structured interviews were conducted by a doctoral student in clinical psychology trained on DISCP administration. To determine a child's ADHD diagnostic status, parents answered 'yes' or 'no' forced choice questions assessing for the presence of inattentive, hyperactive, and impulsive symptoms, as well as the degree of impairment caused by symptoms. The DISC-P generated three diagnoses for ADHD (i.e., full criteria, intermediate criteria, and did not meet criteria). Of the entire sample, 45 children met full criteria for ADHD, seven children met intermediate criteria for ADHD, and two children did not meet criteria for ADHD. Of the seven children that met intermediate criteria for ADHD on the DISC-P, the VAPRS and VATRS were used to determine ADHD diagnostic status. Four children met full diagnostic criteria on either the VAPRS or VATRS, and three children did not meet full diagnostic criteria on the VAPRS or VATRS. The DISC-P contained a question related to the current use of psychiatric medications to treat ADHD (i.e., stimulant and non-stimulant). This question was used to assess active medication usage. Children were included if they met criteria for ADHD-I, ADHD-H/I, or ADHD-C. The DISC-P demonstrated acceptable internal consistency $(\alpha=0.77)$.

\section{ADHD Symptoms}

The Vanderbilt ADHD Parent Rating Scale (VAPRS; Wolraich et al., 2003) was used to assess a child's ADHD symptoms. The VAPRS is a 55-item DSM-IV-based scale; the first 18 items comprise the ADHD subscale and include nine items assessing for ADHD inattentive symptoms and nine items assessing for ADHD 
hyperactive/impulsive symptoms. Parents rated their child on a four-point Likert scale ( 0 $=$ Never, $1=$ Occasionally, $2=$ Often, $3=$ Very Often). A child's total ADHD symptoms was determined by combining the nine inattentive symptoms with the nine hyperactive/impulsive symptoms. Higher scores on the VAPRS indicated a greater severity of ADHD symptoms. Previous research supports the reliability and validity of the ADHD subscales of the VAPRS (Wolraich et al., 2003). Internal consistencies for the total ADHD symptom scale was calculated $(\alpha=.87)$ and mean scale scores were included in analyses.

\section{Emotion Regulation}

The Emotion Regulation Index for Children and Adolescents (ERICA;

MacDermott, Gullone, Allen, King, \& Tonge, 2010) was used to assess children's selfreport of their emotion regulation abilities. The ERICA is a 16-item child self-report measure designed to assess children's self-perceptions of their ability to regulate emotions. The ERICA is an adaptation of the Emotion Regulation Q-Sort (Biesecker \& Easterbrooks, 2001; Shields \& Cicchetti, 1995). Children rated their emotion regulation on a five-point Likert scale $(1=$ Strongly Disagree, $2=$ Disagree, $3=$ Neither Agree or Disagree, $4=$ Agree, $5=$ Strongly Agree). The ERICA yielded three subscales: Emotional Control, Emotional Self-Awareness, and Situational Responsiveness. Items assessing positive emotion regulation strategies were inversely scored so that they would be positively correlated with items assessing negative emotion regulation strategies, and could be combined to form a single child-report construct of emotion regulation. Thus, higher scores on the ERICA indicate poorer emotion regulation. The ERICA has demonstrated reliability and validity in previous studies (MacDermott et al., 2010). 
Internal consistency was acceptable $(\alpha=.70)$ and mean scale scores were used in analyses.

The Emotion Regulation Checklist (ERC; Shields \& Cicchetti, 1997) was used to assess parent perceptions of their child's overall emotion regulation abilities. The ERC is a 24-item measure that assesses emotionally dysregulated behavior in children (Shields \& Cicchetti, 1997), including emotional negativity, emotional lability, and emotion regulation. Similar to the ERICA, the ERC was originally adapted from the Emotion Regulation Q-Sort (Shields \& Cicchetti, 1995). Parents rated their child on a four-point Likert scale $(1=$ Never, $2=$ Sometimes, $3=$ Often, $4=$ Almost Always $)$ regarding the child's general emotional states and reactions. Responses yielded two subscales: Lability/Negativity and Emotion Regulation. The Lability/Negativity subscale assesses dysregulated negative affect and mood lability and the Emotion Regulation subscale assesses situationally appropriate displays of affect (Shields \& Cicchetti, 1997). As described previously by Bunford, Evans, Zoccola, Owens, Flory, and Spiel (2016), higher scores on the Lability/Negativity subscale indicate poorer emotion regulation whereas lower scores on the Emotion Regulation subscale indicate poorer emotion regulation. In order to be consistent with previous studies (Chang, Schwartz, Dodge, \& McBrideChang, 2003; Rosen et al., 2012; Schwartz \& Proctor, 2000), and to better capture a child's emotion regulation abilities, the Emotion Regulation subscale was inversely scored so that it would be positively correlated with the Lability/Negativity subscale, and combined to form a single parent-report construct of emotion regulation; higher scores on the ERC indicate poorer emotion regulation. The ERC has demonstrated reliability and validity (Molina et al., 2014; Shields \& Cicchetti, 1997). In the current study, the ERC 
demonstrated good internal consistency $(\alpha=.88)$. Mean scale scores were calculated and included in analyses.

The Children's Emotion Management Scales (CEMS; Zeman, Shipman, \& PenzaClyve, 2001) was used to assess child and parent perceptions of children's ability to regulate specific negative emotions, including anger, sadness, and worry. The CEMS consists of an 11-item Anger scale, a 12-item Sadness scale, and a 10-item Worry scale. Children and their parents rated how the child regulates specific emotions (i.e., anger, sadness, and worry) on a three-point Likert scale $(1=$ Hardly Ever, $2=$ Sometimes, $3=$ Often). The CEMS yielded three subscales for each emotion scale: Inhibition, Dysregulation, and Coping. Items included in the Inhibition and Coping subscales were inversely scored to be positively correlated with the Dysregulation subscale and to form a single child-report or parent-report of the regulation of specific negative emotions (i.e., anger, sadness, and worry). Therefore, higher scores on the CEMS indicate poorer anger, sadness, and worry regulation. The CEMS has demonstrated reliability and validity in previous studies for both children and parents (Zeman, Cassano, Suveg \& Shipman, 2010; Zeman et al., 2001). Internal consistencies for children (parents) were: anger regulation $\alpha=.82(.90)$, sadness regulation $\alpha=.58(.80)$, and worry regulation $\alpha=.59$ (.78). Due to the unacceptably low reliability of the child CEMS sadness regulation and worry regulation scales, the child CEMS sadness and worry regulation scales were not included in analyses. Mean scale scores were calculated for child CEMS anger regulation, and parent CEMS anger regulation, sadness regulation, and worry regulation, and included in analyses. 


\section{Emotional Response to a Discrete Peer Stressor}

Cyberball (Williams, Yeager, Cheung, \& Choi, 2012) is a laboratory-based task that was used to simulate a stressful peer interaction. Cyberball is a computerized balltossing game that manipulates the degree of social inclusion or ostracism (i.e., being excluded or ignored) by changing the frequency with which a participant is passed a ball by study confederates (Hartgerink, van Beest, Wicherts \& Williams, 2015). Prior to beginning Cyberball, children were informed they would be playing an online balltossing game with two other same-sex peers. In reality, the two other "same-sex peers" were computer-generated confederates who were represented by names and avatars. For male participants, computer-generated confederates were labeled with common male names. For female participants, computer-generated confederates were labeled with common female names. Children completed three conditions of Cyberball (i.e., Condition 1, Condition 2, and Condition 3), each composed of 30 throws between the child and the two computer-generated confederates, with the child choosing the recipient of their throws; throws by computer-generated confederates were predetermined. In Condition 1, the basal inclusion condition, children were passed the ball an equal number of times $(n=$ 10) relative to the other two confederates $(n=20)$. In Condition 2 , the exclusion condition, children were initially passed the ball two times $(n=2)$ and then were not passed the ball again for the remainder of the condition. In Condition 3, the postexclusion inclusion condition, children were passed the ball an equal number of times ( $n$ $=10)$ relative to the other two players $(n=20)$. Condition 1 (basal inclusion) and Condition 3 (post-exclusion inclusion) were referred to as inclusion conditions; Condition 2 was referred to as an exclusion condition. Given previous research documenting the 
exclusion condition may elicit negative emotions (Beekman, Stock, \& Marcus, 2016; Boyes \& French, 2009), conditions were not randomized and the exclusion condition was intentionally placed between the two inclusion conditions. This methodology is consistent with approaches described in previous studies (Yeager, Trzesniewski, \& Dweck, 2013). Immediately after completing all three conditions of Cyberball, children were fully debriefed and provided an honest and accurate description of Cyberball to be consistent with recommendations in prior literature (Zadro et al., 2013). During this time, children were also provided with two brief relaxation exercises to help each child return to baseline following completion of the task. Although previous literature suggests many children may have suspicions that Cyberball is a computerized task, Zadro, Williams, and Richardson (2004) provided evidence that similar negative emotional responses were observed regardless of whether a child believes they are playing against a computer or real children. Cyberball has been shown to elicit strong negative emotions and has demonstrated an effective means for studying the effects of negative peer interactions, including social ostracism and peer exclusion (Iffland et al., 2014).

The Positive and Negative Affect Schedule (PANAS; Laurent et al., 1999) was used to assess a child's emotional response to a discrete peer stressor (i.e., Cyberball). Immediately following each condition of Cyberball (Condition 1, Condition 2, and Condition 3; Williams, et al., 2012), children completed PANAS ratings. The PANAS is a child self-report measure that assesses the frequency with which children are experiencing various emotional states on a five-point Likert scale $(1=$ Very slightly or not at all, $2=$ A little, $3=$ Moderately, $4=$ Quite a bit, $5=$ Extremely). The PANAS is composed of 20 items; ten items assess for positive affect (e.g., excited, proud) and ten 
items assess for negative affect (e.g., upset, irritable). The PANAS yielded two subscales: Positive Affect and Negative Affect. Given evidence that the exclusion condition of Cyberball is more strongly associated with increased negative affect (Ruggieri et al., 2013) and reduced positive affect (Iffland et al., 2014) among children who experience peer victimization, the current study examined both the PANAS Positive Affect scale and the Negative Affect scale separately. Higher scores on the Positive Affect and Negative Affect scales indicate higher positive or negative affect. Previous literature has documented that the PANAS is a reliable, valid, and efficient means for measuring positive and negative emotions in children, and when used with short-term instructions (e.g., right now), has been shown to be sensitive to fluctuations in emotional states (Watson, Clark, \& Tellegen, 1988). Because parents did not observe their child completing Cyberball, the parent version of the PANAS was not included in the present study (Phillips, Lonigan, Driscoll, \& Hooe, 2002). To calculate a child's emotional response to a discrete peer stressor (i.e., Cyberball), two calculations were conducted: 1) the Positive Affect scale for Condition 1 (i.e., basal inclusion) was subtracted from Condition 2 (i.e., exclusion), and 2) the PANAS Negative Affect scale for Condition 1 (i.e., basal inclusion) was subtracted from Condition 2 (i.e., exclusion). These separate calculations yielded a total change in a child's emotional response for both positive affect ( $\Delta$ Positive Affect) and negative affect ( $\Delta$ Negative Affect) following the exclusion condition of Cyberball. Therefore, the $\Delta$ Positive Affect represented a child's change in positive affect from Condition 1 to Condition 2; the $\Delta$ Negative Affect represented a child's change in negative affect from Condition 1 to Condition 2. Condition 3 (postexclusion inclusion) was not examined given study hypotheses sought to investigate a 
child's emotional response to a discrete peer stressor. Internal consistencies for the Positive Affect scale were: Condition $1 \alpha=.89$ and Condition $2 \alpha=.89$. Internal consistencies for the Negative Affect scale were Condition $1 \alpha=.61$ and Condition $2 \alpha=$ .76. Mean scale scores were used in analyses.

\section{Peer Victimization}

The Multisource Peer Victimization Inventory (MPVI; Ladd \& KochenderferLadd, 2002) was used to assess child and parent perceptions of peer victimization experiences. The child version of the MVPI (MVPI-C) consists of 12 items (See Appendix A); children rated themselves on a three-point Likert scale $(1=$ Never, $2=$ Sometimes, 3 = A lot) regarding how often they experience positive and negative social behaviors from their peers. The MVPI-C comprises four items that measure frequency of peer victimization (Does anyone in your class pick on you at school? Does anyone in your class say mean things to you? Does anyone in your class say bad things about you to other kids? Does anyone in your class hit or kick you?). The parent version of the MVPI (MPVI-P) consists of 13 items (See Appendix A); parents rated their child on a three-point Likert scale $(1=$ Seldom, 2 = Sometimes, $3=$ Often $)$ regarding how often their child experiences positive and negative social behaviors from peers. The MVPI-P comprises five items that measure frequency of peer victimization (My child is picked on by other children. My child is called names by peers. My child has peers who say negative things about him or her to other children. My child is hit or kicked by other children. My child is teased or made fun of by peers.). Higher scores on the MVPI-C and the MVPI-P indicate a greater frequency of peer victimization experiences. Similar measures to the MVPI have been used in multiple studies among children with ADHD in 
younger, but overlapping, age ranges (ages 8-12 years; Fogleman et al., 2016, Fogleman

et al., 2018, Fogleman et al. 2018b). Previous findings suggest the MVPI has

demonstrated reliability and validity for both children and parents (Ladd \&

Kochenderfer-Ladd, 2002). In the present study, internal consistencies were calculated

(MPVI-C: $\alpha=.69 ;$ MPVI-P $\alpha=.88$ ) and mean scale scores were included in analyses.

\section{Power Analyses}

Power analyses were examined using G*Power (Faul, Erdfelder, Lang, \&

Buchner, 2007), a power analysis program commonly used in social and behavioral sciences (Faul et al., 2007). Post hoc sensitivity analyses were conducted to determine effect sizes based on hypotheses of the study (Faul, Erdfelder, Buchner, \& Lang, 2009), using sample size $(n=49)$, significance level $(\alpha=.05)$, and statistical power $(1-\beta=.80$; Cohen, 1992). Hierarchical linear regression analyses for all hypotheses included three to seven parameters in the overall models, and the effect sizes detectable ranged from $\mathrm{f}^{2}=$ .24 to $\mathrm{f}^{2}=.35$. For hypothesis 1 , the model included a total of seven parameters: two covariates in the first step (i.e., race/ethnicity and ADHD medication), one main effect in the second step (i.e., ADHD symptoms), two main effects in the third step (i.e., childreport of emotion regulation and parent-report of emotion regulation), and two interaction effects in the fourth step (i.e., child-report of emotion regulation x ADHD symptoms and parent-report of emotion regulation $\mathrm{x}$ ADHD symptoms). The effect sizes detectable at step $1\left(f^{2}=.21\right)$, step $2\left(f^{2}=.17\right)$, step $3\left(f^{2}=.21\right)$, and step $4\left(f^{2}=.21\right)$ were all moderate. Hypothesis 2 was not examined using hierarchical linear regression analyses given evidence that independent variables (i.e., $\Delta$ Positive Affect and $\Delta$ Negative Affect) were not significantly correlated with dependent variables (i.e., child-report of peer 
victimization and parent-report of peer victimization). For hypothesis 3 , the model included a total of three parameters: two covariates in the first step (i.e., race/ethnicity and ADHD medication) and one main effect in the second step (i.e., child-report of anger regulation or parent-report of sadness regulation). The effect sizes detectable at step 1 ( $\mathrm{f}^{2}$ $=.22)$ and step $2\left(f^{2}=.17\right)$ were each moderate. 


\section{CHAPTER III}

\section{RESULTS}

\section{Data Analytic Plan}

The current study conducted analyses to examine the associations between ADHD symptoms, emotion regulation, and peer victimization among children with ADHD. A significant strength of this study was the ability to use both child and parent ratings for emotion regulation and peer victimization so as to assess relations within and across raters. Children and their parents were each selected as informants of emotion regulation and peer victimization due to previous studies demonstrating that they both have unique and valid perspectives of emotion regulation and peer victimization (Hourigan et al., 2011; Ladd \& Kochenderfer-Ladd, 2002; Putallaz et al., 2007). Given evidence children with ADHD underreport their ADHD symptoms (Loeber et al., 1991; Sibley et al., 2019), ADHD symptoms were assessed exclusively through parent ratings.

Within-rater and cross-rater effects were independently examined to identify differential and unique relations between independent and dependent variables. Withinrater effects raised the issue of shared-rater variance, which is known to result in larger effects between independent and dependent variables relative to cross-rater estimates (Saudino, 2005). Cross-rater effects provided evidence that associations between independent and dependent variables were observed across raters (i.e., children and their parents) and are generally more conservative and robust relative to within-rater effects. Based on prior literature examining associations between ADHD symptoms and peer 
victimization (Fogleman et al., 2016; Wiener \& Mak, 2009), and associations between emotion regulation and peer victimization (Camodeca \& Goossens, 2005; Cooley \& Fite, 2016), it was likely that within-rater effects and cross-rater effects would be observed.

All questionnaire and task data were manually entered and examined using frequency statistics for unusual responses. As noted above, mean scaled scores for all child-report and parent-report measures were included in analyses. A summary mean composite scale for child-report and parent-report of emotion regulation was considered to minimize the number of potential independent variables included within analyses. However, bivariate correlations were modest $(\mathrm{r}[49]=.25, p=.08)$ and did not warrant compositing child-report and parent-report of emotion regulation into a single construct. Therefore, child-report and parent-report of emotion regulation were examined separately within analyses. Given there are no known studies investigating associations between ADHD symptoms, emotion regulation, and peer victimization among children with ADHD, all data were analyzed using an exploratory approach (Yu, 1977).

To determine if the final sample was representative of all children enrolled in the study, one-way analyses of variance (ANOVA) were calculated for all demographic variables. Pearson bivariate correlations (two-tailed) were conducted to assess for significant relations between potential covariates, independent variables, and dependent variables. A correlation of .10 is considered a small effect, .30 is considered a medium effect, and .50 is considered a large effect (Cohen, Cohen, West, \& Aiken, 2003). If a potential covariate was significantly correlated with a dependent variable (i.e., childreport of peer victimization or parent-report of peer victimization), it was retained for inclusion in hierarchical linear regression analyses. Exploration of potential covariates 
was intended to account for several possible variables that may influence the relation between ADHD symptoms, emotion regulation, and peer victimization. Potential covariates included biological sex, age, race/ethnicity [dummy-coded as White/Caucasian and non-White/Caucasian], IQ, and active ADHD medication use. Family income was also considered as a potential covariate; however, given the majority of the sample reported a family income greater than $\$ 75,000$ (higher than would be expected in the area from which the population was collected; U.S. Census Bureau, 2016), it was not included as a potential covariate because there was not sufficient variability. Race/ethnicity was dummy coded as White/Caucasian and non-White/Caucasian due to the low percentage of participants that were not White/Caucasian. Previous studies have documented a significant relation between biological sex (Callahan \& Joseph, 1995; Craig et al., 2009; Kochenderfer-Ladd \& Skinner, 2002), age (Troop-Gordon, 2017), race/ethnicity (Nansel et al., 2001; Spriggs, Iannotti, Nansel, \& Haynie, 2007), IQ (Didden et al., 2009), active ADHD medication use (Epstein-Ngo et al., 2015; Unnever \& Cornell, 2003), and peer victimization.

An exploratory approach was also implemented to determine relations between independent and dependent variables. If a proposed independent variable was not significantly correlated with a dependent variable, the variable was not included in hierarchical linear regression analyses. This methodological approach was intended to increase statistical power (VanVoorhis \& Morgan, 2007) and reduce multiple comparisons, which decreases the likelihood of making a Type I error, or incorrectly rejecting the null hypothesis (Meyers, Gamst, \& Guarino, 2016). Although an exploratory approach to data analysis can be particularly useful in small sample sizes (VanVoorhis \& 
Morgan, 2007) and when examining relationships relatively unknown in the current literature (Fogleman et al., 2016), it may result in identifying significant effects that are not present. Due to concerns about making a Type II error, or not finding an effect that is present (Meyers et al., 2016), analyses were not corrected for Type I error. Effect sizes and significance testing were used to assess statistical results.

For all hierarchical linear regression analyses, potential covariates were entered into the first step of the model to control for factors known to be associated with peer victimization. Coefficient of determination $\left(R^{2}\right)$ was examined at each step of the hierarchical linear regression model to determine the total proportion of variance attributed to the independent variable(s). Additionally, Akaike Information Criteria (AIC) was examined at each step of the model to assess model fit. Change in AIC ( $\triangle$ AIC) signified the difference between the AIC at each step of the model; negative $\triangle \mathrm{AIC}$ scores indicated lower AIC and thus improved the model fit for the inclusion of the main effect(s) and/or the interaction terms. Standardized coefficients $(\beta)$ and t-statistics $(t)$ were also examined at each step of the model to determine the unique variance attributed to each independent variable. All data were analyzed using SPSS Version 25.0 statistical software (IBM Corp., 2017).

\section{Hypothesis 1}

To assess hypothesis 1 , two hierarchical linear regression analyses were conducted to examine the effects of ADHD symptoms, child-report of emotion regulation, and parent-report of emotion regulation on child-report and parent-report of peer victimization. Both child-report of peer victimization and parent-report of peer victimization were regressed on ADHD symptoms, child-report of emotion regulation, 
and parent-report of emotion regulation. Race/ethnicity and ADHD medication were entered into the first step of the model as covariates. ADHD symptoms were entered into the second step of the model to assess the main effects of ADHD symptoms in the estimation of child-report and parent-report of peer victimization when controlling for race/ethnicity and active ADHD medication use. Child-report of emotion regulation and parent-report of emotion regulation were entered into the third step of the model to assess whether there was a main effect of child-report of emotion regulation and parent-report of emotion regulation above and beyond the impact of ADHD symptoms in the estimation of child-report and parent-report of peer victimization when controlling for race/ethnicity and active ADHD medication use. ADHD symptoms by child-report of emotion regulation and ADHD symptoms by parent-report of emotion regulation interaction terms were entered into the fourth and final step of the model to assess whether or not ADHD symptoms moderated the effect of child-report of emotion regulation or parent-report of emotion regulation in the estimation of child-report and parent-report of peer victimization.

\section{Hypothesis 2}

To assess hypothesis 2, initial bivariate correlations were conducted to examine associations between a child's emotional response to a discrete peer stressor (i.e., Cyberball) and child-report and parent-report of peer victimization. As noted above, a child's emotional response to a discrete peer stressor was measured separately by the change in the Positive Affect scale ( $\Delta$ Positive Affect) and the change in the Negative Affect scale ( $\Delta$ Negative Affect) from Condition 1 (i.e., basal inclusion) to Condition 2 (i.e., exclusion) of Cyberball. Independent variables (i.e., $\Delta$ Positive Affect and 
$\Delta$ Negative Affect) were not significantly associated with either child-report or parentreport of peer victimization. Therefore, hierarchical linear regression analyses were not conducted.

\section{Hypothesis 3}

To assess hypothesis 3, a total of four hierarchical linear regression analyses were conducted to explore the effects of child-report and parent-report of regulation anger, sadness, and worry on child-report and parent-report of peer victimization. Given the unacceptably low reliability of the child-report sadness regulation and worry regulation scales, they were not included in statistical analyses. Additionally, parent-report of anger regulation and worry regulation were not significantly correlated with child-report or parent-report of peer victimization and were removed prior to hierarchical linear regression analyses. Two hierarchical linear regression analyses were conducted to explore the effects of child-report of anger regulation on child-report and parent-report of peer victimization. Child-report of peer victimization and parent-report of peer victimization were each independently regressed on child-report of anger regulation. Race/ethnicity and active ADHD medication use were entered into the first step of the models as covariates, and child-report of anger regulation was entered into the second step of each model to assess the main effects of child-report of anger regulation in the estimation of child-report and parent-report of peer victimization when controlling for race/ethnicity and active ADHD medication use. Two additional hierarchical linear regression analyses were conducted to explore the effects of parent-report of sadness regulation on child-report and parent-report of peer victimization. Child-report of peer victimization and parent-report of peer victimization were each independently regressed 
on parent-report of sadness regulation. Race/ethnicity and active ADHD medication use were entered into the first step of each model as covariates. Parent-report of sadness regulation was entered into the second step of each model to assess the main effects of parent-report of sadness regulation in the estimation of child-report and parent-report of peer victimization when controlling for race/ethnicity and active ADHD medication use.

\section{Preliminary Analyses}

The assumption of normal distribution of variables was evaluated by examining boxplots, histograms, and skewness and kurtosis statistics (George \& Mallery, 2010). Skewness and kurtosis statistics for all independent and dependent variables, with the exception of the $\Delta$ Negative Affect variable, were between recommended thresholds of -2 and +2 (Field, 2009; George \& Mallery, 2010). The $\Delta$ Negative Affect variable was nonnormally distributed (i.e., positively skewed) and was log-transformed to satisfy assumptions of normality (Curran-Everett, 2018). Collinearity diagnostics were included in hierarchical linear regression analyses and multicollinearity was not identified across any of the analyses, as evidenced by a Variance Inflation Factor (VIF) of less than 10 $($ Range $=1.01-1.81 ;$ Marquaridt, 1970 $)$.

\section{Sample Comparisons}

Of the 54 children who enrolled in the study, five children were excluded from the study because they did not meet diagnostic criteria for ADHD according to the DISCP, VAPRS, and VATRS. This resulted in a total of 49 children with ADHD in the final sample. No significant differences were observed for $\operatorname{sex}(F(1,53)=.43, p=.52)$, age $(F(1,53)=.04, p=.84), \operatorname{IQ}(F(1,53)=.2 .01, p=.16)$, race/ethnicity $(F(1,53)=1.39, p=$ 
$.24)$, and active ADHD medication use $(F(1,53)=.02, p=.90)$ between children who were included in the study and children who were excluded from the study.

\section{Covariates}

Bivariate correlation analyses were conducted to assess the relation of potential covariates to child-report and parent-report of peer victimization. Race/ethnicity was negatively correlated with child-report of peer victimization $(\mathrm{r}[49]=-.31, p=.03)$, such that children who were non-White/Caucasian reported significantly more peer victimization relative to children who were White/Caucasian. Additionally, ADHD medication was significantly positively correlated with parent-report of peer victimization $(\mathrm{r}[49]=.34, p=.02)$; children who were taking ADHD medication at the time of the study were rated by their parents as experiencing a greater frequency of peer victimization relative to children who were not taking ADHD medication. Therefore, race/ethnicity and ADHD medication were included in all hierarchical linear regression analyses as covariates. Biological sex, age, and IQ were not significantly associated with either child-report or parent-report of peer victimization.

\section{Hypothesis 1}

Hypothesis 1a: Poorer emotion regulation will be associated with peer victimization above and beyond the effect of ADHD Symptoms

Hypothesis 1b: Within-rater and cross-rater effects will be observed for childreport and parent-report of emotion regulation on child-report and parent-report of peer victimization above and beyond the effect of ADHD symptoms 
Hypothesis 1c: The relation of child-report of emotion regulation and parentreport of emotion regulation to child-report and parent-report of peer victimization will be exacerbated by a greater frequency of ADHD symptoms

\section{Bivariate correlations}

Bivariate correlations assessed the relation between ADHD symptoms, childreport of emotion regulation, and parent-report of emotion regulation to child-report and parent-report of peer victimization (See Appendix B, Table 2). ADHD symptoms were significantly positively correlated with child-report $(\mathrm{r}[49]=.36, p=.01)$ and parentreport of peer victimization $(\mathrm{r}[49]=.38, p=.008)$, suggesting that children who were rated by their parents as demonstrating more severe ADHD symptoms experienced more frequent peer victimization. Poorer child-report of emotion regulation was significantly positively correlated with child-report of peer victimization $(\mathrm{r}[49]=.32, p=.03)$; children who rated themselves as having greater difficulties regulating their emotions also reported experiencing more frequent peer victimization. Poorer child-report of emotion regulation was not significantly correlated with parent-report of peer victimization $(\mathrm{r}[49]=.22, p=.12)$. Poorer parent-report of emotion regulation was significantly positively correlated with child-report $(\mathrm{r}[49]=.38, p=.008)$ and parentreport of peer victimization $(\mathrm{r}[49]=.53, p<.001)$, such that parent ratings of emotion regulation deficits were significantly associated with increased child and parent ratings of peer victimization.

Hierarchical Linear Regression Analyses

Relation of ADHD symptoms, child-report of emotion regulation, and parentreport of emotion regulation to child-report of peer victimization 
Results supported the hypothesis that poorer emotion regulation is associated with child-report of peer victimization above and beyond the effect of ADHD symptoms (See Appendix B, Table 3). In step one of the model, race/ethnicity and ADHD medication did not contribute significant variance to the model fit for child-report of peer victimization, $\Delta R^{2}=.10, \mathrm{AIC}=-75.69, p=.09$. Step two of the model containing the main effects of ADHD symptoms contributed significant variance to child-report of peer victimization, $\Delta R^{2}=.07, \mathrm{AIC}=-77.78, \Delta \mathrm{AIC}=-2.09, p=05$, such that children with greater $\mathrm{ADHD}$ symptoms self-reported more frequent peer victimization experiences $(\beta=.31 t=1.98, p$ $=.05)$. Step three containing poorer child-report and parent-report of emotion regulation contributed significantly to the model fit for child-report of peer victimization, $\Delta R^{2}=.11$, $\mathrm{AIC}=-80.72, \Delta \mathrm{AIC}=-2.92, p=.05$. Specifically, children who had higher self-report ratings of emotion regulation deficits had higher self-report ratings of peer victimization above and beyond their frequency of ADHD symptoms $(\beta=.27, t=2.01, p=.05)$; poorer parent-report of emotion regulation was not uniquely associated with child-report of peer victimization above and beyond ADHD symptoms $(\beta=.17, t=1.09, p=.28)$. Step four of the model indicated that the effect of poorer parent-report of emotion regulation on the estimation of child-report of peer victimization was moderated by ADHD symptoms, $\Delta R^{2}$ $=.12, \mathrm{AIC}=-85.52, \Delta \mathrm{AIC}=-4.80, p=.03$, such that poorer parent-report of emotion regulation deficits was more strongly related to child-report of peer victimization in children exhibiting more ADHD symptoms $(\beta=.37, t=2.62, p=.01$; see Appendix C, Fig. 1). An interaction between poorer child-report of emotion regulation and ADHD symptoms on child-report of peer victimization was not observed $(\beta=.06, t=.44, p=$ .76). Results supported the overall model with interaction included, $R^{2}=.40, F(7,48)=$ 
$3.90, p=.002$. Results suggested that greater child-report of emotion regulation deficits was related to greater child-report of peer victimization above and beyond the effect of ADHD symptoms, and that the relation between parent-report of emotion regulation deficits and child-report of peer victimization was moderated by the frequency of ADHD symptoms.

\section{Relation of ADHD symptoms, child-report of emotion regulation, and parent-} report of emotion regulation to parent-report of peer victimization

Results supported the hypothesis that poorer emotion regulation is associated with parent-report of peer victimization above and beyond the effect of ADHD symptoms (See Appendix B, Table 4). Step one containing race/ethnicity and ADHD medication was significantly associated with parent-report of peer victimization, $\Delta R^{2}=.17$, $\mathrm{AIC}=-73.15$, $p=.01$; children who were taking ADHD medication were rated by their parents as experiencing a greater frequency of peer victimization $(\beta=.32, t=2.36, p=.02)$. Results did not indicate a significant contribution of the step containing a main effects of ADHD symptoms to the estimation of parent-report of peer victimization, $\Delta R^{2}=.05$, $\mathrm{AIC}=-$ 73.95, $\Delta \mathrm{AIC}=-.80, p=.11$. Step three of the model containing poorer child-report and parent-report of emotion regulation contributed significant variance to parent-report of peer victimization, $\Delta R^{2}=.17$, $\mathrm{AIC}=-82.28, \Delta \mathrm{AIC}=-8.33, p=.004$. Specifically, parents who rated their child as having greater emotion regulation deficits also rated their child as experiencing a greater frequency of peer victimization experiences above and beyond their ADHD symptoms $(\beta=.44, t=3.05, p=.004)$. Poorer child-report of emotion regulation was not uniquely associated with parent-report of peer victimization above and beyond ADHD symptoms $(\beta=.12, t=.99, p=.33)$. Furthermore, results did not support 
an interaction of poorer child-report $(\beta=-.04, t=-.31, p=.76)$ or parent-report $(\beta=.19, t$ $=1.38, p=.17$ ) of emotion regulation and ADHD symptoms in the estimation of parentreport of peer victimization, $\Delta R^{2}=.03, \mathrm{AIC}=-80.51, \Delta \mathrm{AIC}=1.77, p=.39$, suggesting the model was best fit by a main effects of poorer parent-report of emotion regulation, $R^{2}$ $=.39, F(7,48)=5.52, p=.001$, on parent-report of peer victimization. Overall, results suggested that greater parent-report of emotion regulation deficits was associated with parent-report of peer victimization above and beyond the effect of ADHD symptoms.

\section{Hypothesis 2: Greater Emotional Responses to a Discrete Peer Stressor will be}

\section{Associated with a Greater Frequency of Peer Victimization Experiences}

\section{Bivariate correlations}

Initial bivariate correlations assessed the relation between a child's emotional response to a discrete peer stressor, as measured separately by changes in positive affect ( $\Delta$ Positive Affect) and negative affect ( $\Delta$ Negative Affect) from Condition 1 (i.e., basal inclusion condition) to Condition 2 (i.e., exclusion condition) of Cyberball, and childreport and parent-report of peer victimization (See Appendix B, Table 5). The change in positive affect ( $\Delta$ Positive Affect) from Condition 1 to Condition 2 was not significantly associated with child-report $(\mathrm{r}[49]=-.01, p=.95)$ or parent-report $(\mathrm{r}[49]=.04, p=.79)$ of peer victimization. Likewise, the change in negative affect ( $\Delta$ Negative Affect) from Condition 1 to Condition 2 was not significantly associated with child-report $(\mathrm{r}[49]=.10$, $p=.49)$ or parent-report $(\mathrm{r}[49]=.21, p=.15)$ of peer victimization. Results suggested that a child's emotional response to a laboratory-based stressor task (i.e., Cyberball), as measured separately by changes in positive affect and negative affect across the inclusion 
and exclusion conditions, was not associated with child-report or parent-report of peer victimization. Therefore, hierarchical linear regression analyses were not conducted.

\section{Hypothesis 3: Poorer regulation of anger, sadness, and worry will each be uniquely associated with child-report and parent-report of peer victimization}

\section{Bivariate correlations}

Bivariate correlations assessed the relation between child-report of anger regulation, and parent-report of anger regulation, sadness regulation, and worry regulation to child-report and parent-report of peer victimization (See Appendix B, Table 6). Poorer child-report of anger regulation was significantly positively correlated with child-report $(\mathrm{r}[49]=.32, p=.02)$ and parent-report of peer victimization $(\mathrm{r}[49]=.42, p=$ .003 ); children who self-reported greater anger regulation deficits experienced a greater frequency of peer victimization. Additionally, poorer parent-report of sadness regulation was significantly positively correlated with child-report $(\mathrm{r}[49]=.31, p=.03)$ and parentreport of peer victimization $(\mathrm{r}[49]=.35, p=.02)$, such that parents who rated their child as having more difficulties regulating their sadness experienced more frequent peer victimization. Significant correlations were not observed for poorer parent-report of anger regulation and child-report $(\mathrm{r}[49]=.18, p=.22)$ or parent-report of peer victimization $(\mathrm{r}[49]=.23, p=.11)$. Furthermore, poorer parent-report of worry regulation was not significantly correlated with child-report $(\mathrm{r}[49]=.11, p=.45)$ or parent-report of peer victimization $(\mathrm{r}[49]=.21, p=.15)$. Therefore, parent-report of anger regulation and worry regulation were not included in hierarchical linear regression analyses. 


\section{Hierarchical linear regression analyses}

\section{Relation of child-report of anger regulation to child-report and parent-report of}

\section{peer victimization}

Results suggested that poorer child-report of anger regulation is significantly associated with greater child-report and parent-report of peer victimization (See Appendix B, Table 7; See Appendix B, Table 8). Race/ethnicity and ADHD medication were entered in the first step of each model. Step two containing poorer child-report of anger regulation contributed significant variance to child-report of peer victimization, $\Delta R^{2}=.08, \mathrm{AIC}=-78.00, \Delta \mathrm{AIC}=-2.31, p=.05$, and parent-report of peer victimization, $\Delta R^{2}=.16, \mathrm{AIC}=-81.74, \Delta \mathrm{AIC}=-8.59, p=.002$. Specifically, children who self-reported greater deficits regulating their anger self-reported more frequent peer victimization $(\beta=$ $.28, t=2.03, p=.05)$ and were rated by their parents as experiencing more frequent peer victimization $(\beta=.41, t=3.30, p=.002)$. Overall, the model with child-report of peer victimization, $R^{2}=.18, F(3,48)=3.19, p=.03$, and the model of parent-report of peer victimization, $R^{2}=.33, F(3,48)=7.45, p<.001$, were best fit by a main effects of poorer child-report of anger regulation. Overall, results from both the child-report and the parent-report of peer victimization models indicated that poorer child-report of anger regulation is significantly associated with a greater frequency of peer victimization experiences.

\section{Relation of parent-report of sadness regulation to child-report and parent-}

\section{report of peer victimization}

Results indicated that parent-report of sadness regulation is significantly associated with a greater frequency of child-report and parent-report of peer victimization 
(See Appendix B, Table 9; See Appendix B, Table 10). Race/ethnicity and ADHD medication were entered in the first step of each model. Step two containing poorer parent-report of sadness regulation contributed significant variance to child-report of peer victimization, $\Delta R^{2}=.08, \mathrm{AIC}=-78.29, \Delta \mathrm{AIC}=-2.60, p=.04$, and parent-report of peer victimization, $\Delta R^{2}=.07, \mathrm{AIC}=-75.70, \Delta \mathrm{AIC}=-2.55, p=.04$. Specifically, children who were rated by their parents as demonstrating greater deficits regulating their sadness selfreported more peer victimization $(\beta=.29, t=2.10, p=.04)$ and were rated by their parents as experiencing more peer victimization $(\beta=.28, t=2.09, p=.04)$. Overall, the model with child-report of peer victimization, $R^{2}=.18, F(3,48)=3.30, p=.03$, and the model of parent-report of peer victimization, $R^{2}=.24, F(3,48)=4.84, p=.005$, were best fit by a main effects of poorer parent-report of sadness regulation. Overall, results suggested that poorer parent-report of sadness regulation is significantly associated with more frequent peer victimization experiences. 


\section{CHAPTER IV}

\section{DISCUSSION}

The present study provides an initial examination of the concurrent relations between ADHD symptoms, emotion regulation, and peer victimization among children with ADHD. Consistent with study hypotheses, results supported the association of poorer emotion regulation to both child-report and parent-report of peer victimization above and beyond the effect of ADHD symptoms. Results also suggested that ADHD symptoms moderated the impact of parent-report of emotion regulation on child-report of peer victimization, such that poorer parent-report of emotion regulation was more strongly associated with child-report of peer victimization in the presence of a greater severity of ADHD symptoms. Results did not support the hypothesis that a child's emotional response to a discrete peer stressor, as simulated in a laboratory setting, would be associated with more frequent peer victimization experiences. With regard to exploratory analyses, results indicated that poorer regulation of anger and sadness were associated with increased peer victimization experiences among children with ADHD. Overall, the current findings support the assertion that emotion regulation deficits play an important role in the estimation of concurrent peer victimization among children with ADHD.

\section{Theoretical Implications}

The current study adds to a growing body of literature suggesting emotion regulation deficits are associated with peer victimization among children with ADHD 
(Fogleman et al., 2016; Fogleman et al., 2018a; Fogleman et al., 2018b), and is the first study to demonstrate that emotion regulation deficits are uniquely linked to peer victimization experiences among children with $\mathrm{ADHD}$, even after accounting for core ADHD symptoms of inattention, hyperactivity, and impulsivity. The current study supports previous findings indicating that a greater severity of ADHD symptoms are associated with increased child-report (Wiener \& Mak, 2009) and parent-report (Sciberras et al., 2012) of peer victimization experiences, while also advancing the current literature on peer victimization among children with ADHD by demonstrating the role of emotion regulation deficits. Broadly, findings are consistent with prior research suggesting that the inability to regulate emotions is particularly important for the social functioning of children with ADHD (Bunford et al., 2018), and is necessary to consider when attempting to understand why children with ADHD experience higher rates of peer victimization $(\approx 60 \%$; Becker et al., 2017$)$ relative to their unaffected peers $(\approx 10 \%$; Hunter et al., 2007).

Emotion regulation deficits co-occur with ADHD (Crundwell, 2005; Jensen \& Rosen, 2004) and have been hypothesized to be associated with delayed brain maturation (Shaw et al., 2007; Shaw et al., 2012) and distinct patterns of autonomic functioning, characterized by impairments in parasympathetic and sympathetic nervous systems (Musser et al., 2011; 2013). Emotion regulation deficits among children with ADHD may increase their risk for experiencing peer victimization because children with ADHD often fail to respond effectively to stressful social situations (e.g., peer conflict and peer provocation). Given the effectiveness with which a child is able to encode and interpret social situations is associated with their subsequent risk for peer victimization, and is 
influenced by both internal (e.g., emotional arousal) and external factors (e.g., behavior of others; Crick \& Dodge, 1994), children with ADHD may be more likely to experience peer victimization because they have greater difficulty regulating their emotional arousal (Graziano \& Garcia, 2016) and are more likely to perceive ambiguous provocation as threatening (King et al., 2009), which, in turn, leads to extreme emotional distress. This extreme emotional distress in children with ADHD likely overrides their ability to engage in effective problem-solving, conflict resolution, and prosocial behaviors necessary to reduce stressful peer interactions, and leads to the expression of emotionally-driven behaviors that are considered aversive to peers (e.g., actively engaging or avoiding conflict; Perry et al., 1988; Rosen et al., 2012). Overall, the current findings suggest that children with ADHD who are unable to regulate negative emotions and inhibit emotionally-driven behaviors in stressful social situations may be at greater risk of experiencing peer victimization due to the link observed between emotion regulation and peer victimization.

For children with ADHD, responding to peer conflict and peer provocation with emotionally-driven behaviors may reward their victimizers and increase their risk for experiencing peer victimization in the future. Unfortunately, the experience of peer victimization may also further exacerbate a child's ability to initiate effective behavioral responses in future social situations and may make it more likely that they again respond with emotionally-driven behaviors. Once peer victimization occurs, children with ADHD may make negative inferences about themselves (i.e., blame themselves for their peer victimization experiences) and others (i.e., blame others for their peer victimization experiences; Graham \& Juvonen, 2001), resulting in increased negative emotions (e.g., 
anger, anxiety, sadness). These negative emotions may ultimately make it more likely that a child with ADHD identifies as a victim and demonstrates an even greater difficulty regulating their emotions in future stressful social situations (Rosen et al., 2012). Given evidence that children with ADHD experience emotions more intensely (Barkley, 2014) and engage in more emotionally-driven behaviors (Walcott \& Landau, 2004), experiences of peer victimization may further impair their ability to effectively regulate emotions and respond to peer conflict or provocation with effective prosocial behaviors. The reciprocal influences of emotion regulation deficits and peer victimization may help to explain why peer victimization is among the most robust difficulties faced by children with ADHD (Hoza et al., 2007) and often becomes chronic and stable over time (Rosen et al., 2012).

The current study may also help to explain why stimulant medications, designed to reduce symptoms of inattention, hyperactivity, and impulsivity (MTA Cooperative Group, 2004), are not effective at reducing peer victimization experiences among children with ADHD. As documented by Unnever and Cornell (2003), children with ADHD taking stimulant medications continued to report more experiences of peer victimization relative to unaffected peers. Additionally, Epstein-Ngo et al., (2015) demonstrated that among children with ADHD, children taking stimulant medications reported similar peer victimization experiences relative to children who were not taking stimulant medications, and regardless of medication use, children with ADHD were more likely to experience peer victimization relative to unaffected peers. Given evidence stimulant medications do not improve emotion regulation deficits among children with ADHD (Shaw et al., 2014), children with ADHD likely experience peer victimization because they fail to regulate their negative emotional arousal, and, in turn, respond 
inappropriately to stressful social situations. Therefore, core symptoms of ADHD may be associated with peer victimization experiences simply because children with ADHD demonstrate deficits regulating their emotions, not because there is a true association between ADHD symptoms and peer victimization.

The relation of parent-report of emotion regulation to child-report of peer victimization was moderated by ADHD symptoms, such that children with greater parent-report of emotion regulation deficits were more likely to self-report experiences of peer victimization if they also were rated by their parents as exhibiting a greater severity of ADHD symptoms. Previous evidence suggests that emotion regulation deficits among children with ADHD are associated with a greater severity of ADHD symptoms (Sobanski et al., 2010). More specifically, hyperactive and impulsive symptoms are linked to increased deficits regulating negative emotions of anger and frustration (Crundwell, 2005), and inattentive and hyperactive symptoms are associated with greater deficits regulating both positive and negative emotions (Sjöwall, Backman, \& Thorell, 2015). Further, in a sample of children with ADHD, Wåhlstedt, Thorell, and Bohlin (2008) observed that ADHD symptoms were associated with greater deficits in emotion regulation and lower social competence. Since core symptoms of ADHD are associated with greater emotion regulation deficits, and emotion regulation deficits are linked to more frequent experiences of peer victimization, it appears plausible that the severity of ADHD symptoms may differentially affect the relation between emotion regulation deficits and peer victimization among children with ADHD. Given ADHD is largely known to be a disorder of inhibition (Barkley, 1997), the link between emotion regulation and peer victimization is likely exacerbated in children with more severe ADHD because 
these children are less able to inhibit their emotional reactions to stressful social situations, and more likely to impulsively act on negative emotions, increasing their risk for peer victimization experiences.

The discussion above focuses on the relation between ADHD symptoms, emotion regulation, and peer victimization among children with ADHD; however, this study also implemented a laboratory-based task to examine associations between a child's emotional reaction to a discrete peer stressor and their peer victimization experiences. More specifically, the current study exposed children with ADHD to a stressful peer interaction and examined whether their changes in self-reported mood states were associated with peer victimization. Although previous studies have documented the relation of reduced positive emotions (Iffland et al., 2014) and increased negative emotions (Ruggieri et al., 2013) in response to computer-simulated tasks involving stressful peer interactions to increased peer victimization experiences among unaffected children, significant findings were not observed in the current sample of children with ADHD; self-reported positive and negative emotional reactions to the exclusion condition of Cyberball were not associated with peer victimization experiences. Although Cyberball simulates a stressful peer interaction and often elicits negative emotions (Beekman et al., 2016; Boyes \& French, 2009), it does not involve direct peer conflict or provocation. Rather, the Cyberball task focuses on peer rejection and ostracism (i.e., being excluded or ignored). Peer rejection/ostracism and peer victimization are highly correlated constructs (Salmivalli \& Isaacs, 2005), such that children who are more ostracized or rejected by their peers are also more likely to be victimized (Cullerton-Sen \& Crick, 2005). However, social ostracism/peer rejection and peer victimization are similar but unique constructs 
(Morrow, Hubbard, Rubin, \& McAuliffe, 2008). Given peer victimization is characterized as the experience of being exposed, repeatedly and over time, to aggressive behavior or intentional acts from one's peers (Olweus, 1999), peer victimization is intended to cause harm. In contrast, peer rejection and ostracism are intended to exclude. Because children with ADHD experience high rates peer victimization, in which they are actively targeted in harmful ways, including physical, relational, and reputational forms of victimization (Becker et al., 2017), social ostracism and peer rejection may not elicit extreme negative emotions among children with ADHD because the experience of peer victimization is more distressing in comparison.

The current study also examined whether the regulation of specific negative emotions was associated with peer victimization experiences among children with ADHD. Specifically, the study explored whether deficits in anger regulation, sadness regulation, and/or worry regulation would be linked to peer victimization experiences. In previous literature, the inability to regulate anger, sadness, and worry have each been linked to increased peer victimization experiences among unaffected children (Morelen et al., 2016), and this is the first study to examine the relation between these emotions and peer victimization among children with ADHD.

The study provided initial evidence that anger regulation is uniquely associated with increased experiences of peer victimization among children with ADHD. Specifically, deficits in anger regulation were linked to increased peer victimization experiences, suggesting that a child's inability to regulate anger plays a powerful role in determining their risk for experiencing peer victimization. Children with ADHD have specific challenges regulating their anger (Braaten \& Rosén, 2000; Sjöwall et al., 2013) 
and are more likely to impulsively act on negative emotions (Barkley, 2014). In the presence of peer conflict, the inability to regulate anger likely leads to behavioral responses that are emotionally-driven and aversive to peers, which may decrease a child's ability to implement effective coping strategies and may increase a child's subsequent risk for peer victimization. Given that anger is an externalizing emotion, the behavioral expression of anger may be more likely to escalate peer conflict and, in turn, increase a child's risk for peer victimization. These findings are consistent with previous literature. In a sample of similar-aged children, expressions of anger were associated with increased peer victimization experiences (Camodeca \& Goossens, 2005), and children who demonstrated the ability to regulate their anger experienced fewer instances of peer victimization (Cooley \& Fite, 2016; Kaynak et al., 2015). Additionally, in longitudinal studies among younger children, deficits in regulating anger were associated with peer victimization experiences (Hanish et al., 2004), and anger served as a risk factor for subsequent peer victimization (Hanish et al., 2004). Overall, as observed in studies among unaffected children (Camodeca \& Goosens, 2005), the inability to regulate anger among children with ADHD is common and appears particularly important when considering their risk for experiencing peer victimization.

The current study also demonstrated that sadness regulation is uniquely associated with increased experiences of peer victimization among children with ADHD. More specifically, the inability to regulate sadness was associated with a greater frequency of peer victimization experiences. This is not the first study to find a connection between the regulation of sadness and peer victimization, as previous literature has demonstrated that children who have difficulties regulating their sadness experience a greater frequency of 
peer victimization (Hanish et al., 2004; Morelen et al., 2016). Given evidence that children who demonstrate more difficulties regulating their sadness may become less desirable as a friend (Shields \& Cicchetti, 2001), and evidence that children prefer peers who demonstrate more positive emotions and fewer negative emotions (Hay et al., 2004; Smith et al., 2001), children who fail to regulate their sadness effectively may be more likely to experience peer victimization because they lack high-quality positive friendships known to reduce peer victimization experiences (Cardoos \& Hinshaw, 2011; Hodges et al., 1999). For children with ADHD, the inability to regulate sadness, in particular, has been well-documented (Braaten \& Rosén, 2000; Sjöwall et al., 2013). Therefore, in response to stressful social situations, children with ADHD who have difficulties regulating their sadness may be more likely to experience peer victimization because they fail to assert effective prosocial skills necessary to alleviate peer conflict, and respond with withdrawn behaviors and attempts to avoid conflict. Overall, the inability to regulate sadness among children with ADHD plays an important role in determining their risk for experiencing peer victimization.

\section{Clinical Implications}

The current study demonstrated the powerful effect emotion regulation deficits have on peer victimization experiences among children with ADHD, and has important clinical implications for informing the assessment and treatment of emotional and social functioning among children with ADHD. Children with ADHD who exhibited greater difficulties regulating their emotions were more likely to experience peer victimization, and assessment of emotion regulation deficits may provide an important indicator for how often a child is victimized by their peers. Given theoretical evidence that emotion 
regulation deficits are risk factors for subsequent peer victimization (Olweus, 1994; Perry et al., 1988), and evidence that peer victimization further impairs a child's emotion regulation abilities (Stadler et al., 2010), initial assessment of emotion regulation deficits among children with ADHD appears warranted, especially given the long-term negative outcomes associated with peer victimization, including poorer academic (Nakamoto \& Schwartz, 2010), behavioral (Ewing Lee \& Troop-Gordon, 2011), and social functioning (Bagwell \& Schmidt, 2011).

In addition to implications for assessment, the current study also has important clinical implications for informing treatment and interventions among children with ADHD. Although previous research has supported the efficacy of stimulant medications (MTA Cooperative Group, 2004; see Swanson, McBurnett, Christian, \& Wigal, 1995 for review) and behavioral parent training for the treatment of the core symptoms of ADHD (Pelham \& Fabiano, 2008), these approaches have failed to effectively address peer victimization (Epstein-Ngo et al., 2015; Unnever \& Cornell, 2003). The current study provides a possible explanation for why: these treatments fail to help children regulate their negative emotions (Shaw et al., 2014), which, as suggested by the current study, are linked to peer victimization above and beyond ADHD symptoms. It is important to note that stimulant medications may help to reduce some negative behaviors that peers find aversive; however, they do not normalize the social functioning of children with ADHD (see Hoza, 2007 for review).

Treatment interventions for children with ADHD who demonstrate deficits in emotion regulation should focus on teaching effective ways to respond to emotionallydriven stimuli and manage feelings of negative emotions (Waxmonsky et al., 2013). A 
recent study by Rosen et al. (2018) demonstrated that group treatments for children with ADHD that are focused on helping children manage negative emotions, particularly frustration, have demonstrated promise for improving a child's emotion regulation. The study examined the effects of a treatment intervention called the Managing Frustration for Children Group Intervention for ADHD, which was specifically designed to help children with ADHD learn strategies to be more effective at regulating negative emotions. This program teaches children how to recognize their emotions in the moment and initiate effective coping strategies before negative behavioral responses occur. The study provided initial evidence that emotion regulation skills among children can be remediated. Specifically, in a sample of children ages nine to 11 years of age, Rosen et al. (2018) demonstrated that more than half of children who completed the treatment intervention experienced clinically meaningful improvements in their daily functioning. The treatment was designed for children younger than those in the current study's sample; similar interventions developed to assist children between the ages of 10 to 15 appear warranted. Although the Managing Frustration for Children Group Intervention for ADHD improved emotion regulation, information on peer victimization was not collected, so it is unknown how the treatment affected the frequency of peer victimization experiences among its participants. However, based on the results of the current study, one could hypothesize that children who benefited from the program with regards to their emotional functioning also likely benefited in their social functioning.

Regarding treatment for children who already experience peer victimization, as noted by Card and Hodges (2008), there is a paucity of research guiding peer victimization treatment. Of the few studies which have attempted to evaluate the 
effectiveness of peer victimization interventions, many are methodologically flawed. More recent evidence suggests that school-based interventions are effective at reducing a child's peer victimization experiences (Ttofi \& Farrington, 2011); however, the effectiveness of an anti-bullying intervention likely depends on the age of the child. A recent meta-analysis by Yeager, Fong, Lee, and Espelage (2015) found that anti-bullying interventions are more effective for children in seventh grade and below (i.e., 13 years old and younger); results from interventions among children in eighth grade and beyond are not effective. Given peer victimization becomes chronic and increasingly stable over time (Scholte et al., 2007), it appears that peer victimization interventions among children with ADHD should be developed for children younger than seventh grade. Previous studies have argued that through identifying risk factors for peer victimization, research can seek to develop more effective interventions (Saarento, Kärnä, Hodges, \& Salmivalli, 2013). The current study identifies deficits in emotion regulation as a risk factor and therefore has implications for interventions for peer victimization among children with ADHD.

Treatment interventions for children with ADHD who experience frequent peer victimization also should focus on teaching effective ways to respond to emotionallydriven stimuli and initiate prosocial behaviors, especially in the presence of peer conflict. Situations involving peer conflict are likely to provoke extreme distress in children with ADHD. Through therapeutic treatment initiatives to improve a child's emotion regulation and coping skills, especially in the presence of peer conflict, a child who experiences frequent victimization may learn how to appropriately assert themselves in social situations and reduce their risk for victimization. Interventions aimed at decreasing 
aggressive behaviors in children have demonstrated efficacy for reducing the frequency with which a child experiences peer victimization (Olweus, 1994). Similar interventions may be particularly beneficial for children with ADHD and should focus primarily on helping children regulate anger, given evidence that children who exhibit challenges regulating this emotion are at the greatest risk of experiencing peer victimization. An intervention similar to the Managing Frustration for Children Group Intervention for ADHD, but with a focus on children who experience frequent victimization, may be an effective way to help these children learn to manage negative emotions including anger and, subsequently, reduce their risk of future victimization episodes. Like the current Managing Frustration for Children Group Intervention for ADHD, similar interventions should include only children with ADHD, given that children with ADHD are more likely to accept other children with ADHD relative to unaffected peers (Hinshaw \& Melnick, 1995). Future studies may seek to examine the effects of such treatments on emotion regulation among children with ADHD to identify whether decreases in emotion regulation deficits are associated with decreases in peer victimization either concurrently or over time.

\section{Limitations and Future Research}

The current study employed a multi-informant approach to examine associations between ADHD symptoms, emotion regulation, and peer victimization among children with ADHD. Although this study demonstrated a robust main effect of emotion regulation deficits in the estimation of peer victimization above and beyond ADHD symptoms, an interaction effect between emotion regulation deficits and peer victimization by ADHD symptoms, and robust main effects of anger and sadness 
regulation deficits in the estimation of peer victimization among children with ADHD, several limitations must be acknowledged. Each limitation is intended to provide additional insight into why the current findings may have been observed, as well as how future studies may seek to add to the growing body of literature on peer victimization among children with ADHD.

First, the present study was cross-sectional and all data were obtained concurrently. Therefore, it is not possible to determine causality or deconstruct the direction of effects demonstrated in the current study. As conceptualized by Rosen et al. (2012), it is likely that a dynamic bidirectional effect exists between emotion regulation deficits and peer victimization, such that each influences the other. More specifically, deficits in emotion regulation increase a child's risk for peer victimization, and experiences of peer victimization further increase a child's risk that they will become more emotionally dysregulated (Rosen et al., 2012). Although this study was unable to examine longitudinal associations between ADHD symptoms, emotion regulation, and peer victimization, previous studies have provided evidence that emotion regulation deficits are longitudinally associated with increased peer victimization experiences (Hanish et al., 2004). However, this has yet to be examined specifically among children with ADHD and warrants further exploration. Additionally, of the few studies that have examined the direct associations between emotion regulation and peer victimization among children with ADHD (Fogleman et al., 2016; Fogleman et al., 2018b), in addition to the current study, all rely on cross-sectional analyses. Future studies should seek to explore the longitudinal direction of the relation between emotion regulation and peer 
victimization among children with ADHD and aim to determine whether emotion regulation deficits are a cause or result of peer victimization.

The current study also examined the relation between ADHD symptoms, emotion regulation, and peer victimization among a small sample of children diagnosed with ADHD. Of the 54 children enrolled in the present study, 49 children were included in the study sample. The small sample size in the current study limits the statistical power necessary to detect small to moderate effects. In this study, there were several results that were not statistically significant (e.g., a child's emotional responses to a discrete peer stressor and peer victimization); however, based on the interpretation of effect sizes, in a larger sample, significant effects may have been observed. Due to the current sample size, all hypotheses were examined using an exploratory approach to data analysis, such that covariates were only included in models if they were significantly correlated with measures of peer victimization. A larger sample size would allow for using a priori covariates known to be associated with peer victimization, including age, sex, race/ethnicity, IQ, family income, and active ADHD medication use (Callahan \& Joseph, 1995; Craig et al., 2009; Didden et al., 2009; Epstein-Ngo et al., 2015; Nansel et al., 2001; Troop-Gordon, 2017), and would likely provide a more comprehensive investigation of the relation between ADHD symptoms, emotion regulation, and peer victimization among children with ADHD. Given family income was removed from analyses due to the insufficient variability in income reported by families in the current study, particular attention to family income as a covariate in future studies appears necessary; this appears especially important given previous evidence that lower family income is associated with increased peer victimization experiences in children (Barker et 
al., 2008). Therefore, future studies using a larger sample size are warranted to substantiate and expand upon the current findings.

Another limitation of the study is the use of multiple statistical analyses. This is a limitation because multiple comparisons, especially in a small sample size, increase the likelihood of making a type I error. Given the exploratory approach to analyses, alpha correction procedures were not included. Although the current study demonstrated a significant relation between emotion regulation and peer victimization above and beyond symptoms of ADHD, future studies should seek to use a priori hypotheses and correct for multiple comparisons.

Shared-rater variance is an additional limitation to the current study. For both children with ADHD and their parents, within-rater effects were observed, such that child-report and parent-report of emotion regulation deficits were associated with childreport and parent-report of peer victimization, above and beyond the influence of ADHD symptoms. Given evidence shared-rater variance, relative to cross-rater variance, may overestimate relations between independent and dependent variables (Saudino, 2017), the concurrent relations between ADHD symptoms, emotion regulation, and peer victimization observed in the current study may be an overestimate of the true relation between variables. Future studies should continue to explore both within-rater and crossrater effects for the relation between ADHD symptoms, emotion regulation, and peer victimization among children with ADHD while also being aware that cross-rater effects reduce shared-rater variance and are generally more conservative and robust.

The use of DISC-P for ADHD diagnostic status is another potential limitation of this study. The DISC-P requires report of symptoms and impairment across multiple 
settings (i.e., home and school; Shaffer et al., 2000). Although the DISC-P is a structured diagnostic interview that has demonstrated reliability and validity in the assessment of ADHD (Shaffer et al., 2000), previous studies suggest that the DISC-P may inflate diagnostic rates of psychiatric disorders relative to other assessment techniques (Cohen, O'connor, Lewis, Velez, \& Malachowski, 1987; Kaufman et al., 1997), meaning that it is possible that some children in this study were characterized as having ADHD when they, in fact, did not.

For children who met an intermediate diagnostic criteria for ADHD on the DISC$\mathrm{P}$, the current study also incorporated the reliable and valid measures of VAPRS (Wolraich et al., 2003) and VATRS (Wolraich et al., 1998) to attempt to ensure the accuracy of ADHD diagnoses (Mitsis et al., 2000; Wolraich et al., 2004). Given the VATRS was completed by most, but not all, teachers of children in the study, the inclusion of a teacher-report measure for ADHD diagnostic status for all children was not possible. This is a limitation because rates of ADHD decrease substantially when parents and teachers are both included in the diagnostic process. Therefore, it is possible that ADHD diagnoses were inflated because all teachers in the study $(n=39,79.6 \%)$ did not complete ADHD rating scales. Future studies would benefit from incorporating a multiinformant approach, including collecting information from both parents and teachers, to improve accuracy of ADHD diagnosis.

A lack of teacher measures also limits the scope of the current study. As envisioned, the study would have incorporated a multi-informant approach, including children, parents, and teachers, for examining the relation between ADHD symptoms, emotion regulation, and peer victimization. However, because several teachers did not 
complete or return measures, this significantly reduced power to detect significant effects. Additionally, teacher ratings of ADHD symptoms may have provided an additional perspective and may have influenced the relation between ADHD symptoms, emotion regulation, and peer victimization. Future studies should seek to incorporate a multi-informant approach for all children to determine if the relation between ADHD symptoms, emotion regulation, and peer victimization remains consistent across reporters. Given previous evidence that ADHD symptom agreement between parents and teachers is relatively low (Mitsis et al., 2000), it is possible that different findings will be observed.

The present study did not examine the relation between ADHD symptoms, emotion regulation, and peer victimization among children with different presentations of ADHD (i.e., ADHD-I, ADHD-H/I, and ADHD-C). There is evidence to suggest that deficits in emotion regulation are more common among children diagnosed with ADHDC relative to children diagnosed with ADHD-I (Maedgen \& Carlson, 2000; SemrudClikeman, Walkowiak, Wilkinson, \& Butcher, 2010); however, there are some studies that have not observed this finding (Bunford et al., 2018). Given evidence that ADHD presentation may affect social functioning (Wheeler \& Carlson, 1994), future studies should seek to explore the relation between ADHD symptoms, emotion regulation, and peer victimization in children diagnosed with ADHD-I, ADHD-H/I, and ADHD-C to determine whether findings are consistent across diagnostic presentations of ADHD.

Although the current study utilized a reliable and valid measure of peer victimization (Ladd \& Kochenderfer-Ladd, 2002), the measure was not able to examine differing forms of peer victimization (i.e., overt and relational). Although the measure of 
peer victimization in the current study was initially developed for children in elementary school, it was selected for the current study because it assessed child and parent perceptions of peer victimization using similar items. Previous studies have demonstrated a strong positive correlation between overt and relational forms of peer victimization, and each have been concurrently and longitudinally associated with deficits in emotion regulation (McLaughlin et al., 2009). However, there is evidence that a child may experience one form of peer victimization (i.e., overt or relational) but not the other (Card \& Hodges, 2008). Because this study did not investigate differing forms of victimization, the current study is limited in its ability to inform intervention programs. Future studies should analyze the relation between ADHD symptoms, emotion regulation, and differing forms of peer victimization among children with ADHD. When doing so, it may be particularly important to select biological sex as an a priori covariate given evidence that males and females may be more likely to experience different forms of peer victimization. Specifically, previous studies have provided evidence that males may be more likely to experience overt victimization and females may be more likely to experience relational victimization (Crick \& Bigbee, 1998; Klomek, Marrocco, Kleinman, Schonfeld, \& Gould, 2008; Putallaz et al., 2007).

A multi-informant approach (i.e., child-report and parent-report) was employed to assess peer victimization. Although this is consistent with recommendations from previous studies (Card \& Hodges, 2008; Pellegrini, 1998), the limitation of this approach is that peer-nomination strategies, often referred to as the most reliable assessment of peer victimization in children (Pellegrini, 2001), were not collected, and peers were not included in the study as informants of peer victimization experiences. In children with 
ADHD, peer victimization experiences may be affected by the positive illusory bias, a well-known finding among children with ADHD describing the disparity between perceived and actual competence (Hoza, Pelham, Milich, Pillow, \& McBride, 1993). Therefore, it is possible that children with ADHD in the sample may have overestimated their social functioning and reported fewer experiences of peer victimization than were actually occurring (Hoza, et al., 2004; McQuade et al., 2011). Given additional evidence that some children may over-report victimization, under-report victimization, or be unaware of victimization (Card \& Hodges, 2008), the use of child-report methods may not have been the most accurate method of assessing peer victimization in children with ADHD. Though this is a limitation of the current study, previous literature does suggest that child-report and parent-report of peer victimization contribute valid and unique variance towards the assessment of peer victimization (Ladd \& Kochenderfer-Ladd, 2002; Putallaz et al., 2007). However, future studies should seek to examine the relation between ADHD symptoms, emotion regulation, and peer victimization employing peer nominations to determine whether these results generalize across peer reporters of peer victimization.

The current study also utilized a multi-informant approach to assess emotion regulation. Although child-report and parent-report of emotion regulation have demonstrated acceptable reliability and validity in numerous studies (Hessler \& Fainsilber Katz, 2007; Hourigan et al., 2011; MacDermott et al., 2010; Shields \& Cicchetti, 1997), Bunford et al. (2015), recommends additional methods to assess emotion regulation in children. These methods include assessing changes in physiology (i.e., autonomic nervous system), observing children during experimental tasks, and 
examining neuropsychological indices and ecological momentary assessment. Biological responses and in-the-moment assessments provide real-time snapshots of how children emotionally respond to different situations. Since this study used a multi-informant approach and not these additional modes of assessment, future studies should seek to examine the relations between ADHD symptoms, emotion regulation and peer victimization among children with ADHD using disparate methodology to determine whether these results generalize across multiple measurements of emotion regulation.

The low reliability of the child CEMS sadness and worry scales is also a limitation of the current study. Reliability is necessary for validity, and fidelity of measures allowed for an initial examination of the relation between ADHD symptoms, emotion regulation, and peer victimization among children with ADHD. The CEMS sadness and worry scales have each demonstrated acceptable reliability in previous studies for both children and their parents (Zeman et al., 2010; Zeman et al., 2001), and it is not known why low reliability estimates were observed in the current study. Low reliability estimates of the child CEMS sadness and worry regulation scales did, however, affect how analyses were conducted. It is possible that child self-perceptions of sadness and worry regulation are linked to peer victimization among children with ADHD, as evidenced by previous literature documenting similar findings among unaffected children who were in a younger but overlapping age range (ages 7-12 years; Morelen et al., 2016). Future studies should seek to examine the child version of the CEMS sadness and worry scales among children with ADHD to identify whether there are additional interventions that can be implemented to improve a child's emotion regulation abilities and decrease their risk for experiencing peer victimization. 
The current study also did not delineate dimensions of emotion regulation (e.g., recognition, awareness, impulsivity, lability, and reactivity) to identify aspects that are more or less associated with peer victimization among children with ADHD. This appears warranted in future studies. Although the present study examined the regulation of specific emotions, emotion regulation is a multidimensional and multifaceted process (Rosen \& Epstein, 2010), and this study only examined the construct of emotion regulation broadly, not the different dimensions. Given that ADHD is associated with emotional impulsivity (Rosen \& Factor, 2015), lability (Sobanski et al., 2010), and reactivity (Rosen et al., 2014), attempts to identify which aspects of emotion regulation are driving the observed relation between ADHD symptoms, emotion regulation, and peer victimization among children with ADHD should be investigated. Specific attention to neuroanatomical (Shaw et al., 2007), physiological (Musser et al., 2011), and/or genetic (Rhee et al., 1999) factors associated with emotion regulation and ADHD also appears warranted as there is currently a lack of literature incorporating multiple biological methodologies in the assessment of emotion regulation in children. It may be hypothesized that these factors influence one another (as proposed by Cyders \& Smith, 2008) and contribute to the observed relation between ADHD symptoms, emotion regulation, and peer victimization among children with ADHD.

The method for assessing a child's emotional response to Cyberball (Williams et al., 2012), as measured by the PANAS, may also have affected the observed relation between a child's emotional response to a discrete peer stressor and experiences of peer victimization. Although the PANAS is sensitive to assessing fluctuations in mood states (Watson et al., 1988), children completed PANAS ratings following each condition of 
Cyberball (i.e., basal inclusion, exclusion, and post-exclusion inclusion) and baseline measurement of a child's emotional state was not collected. This is a limitation to the current study because a child's emotional response to Cyberball was assessed from the basal inclusion condition (Condition 1) to the exclusion condition (Condition 2), and it is unknown how a child's baseline emotional state was associated with their emotional responses to the exclusion condition of Cyberball. Therefore, future studies should collect baseline measures of a child's emotional state prior to beginning and administering Cyberball. This method of data collection will help to provide additional information for how a child's emotional changes from baseline to the exclusion condition is associated with experiences of peer victimization. It is quite possible that the current study failed to replicate previous literature demonstrating a relation between emotional responses to Cyberball and peer victimization experiences (Iffland et al., 2014; Ruggieri et al., 2013) due to the method of data collection and administration.

Another limitation of the current study is that the study was conducted on children between the ages of 10-15 years, and the findings may not apply to children who are younger or older, so the scope of application is relatively limited. The current study selected this age range because there is evidence that while peer victimization affects young children (Bonica et al., 2003), peer victimization often becomes most prevalent during the transition to adolescence (Troop-Gordon, 2017). This appears especially true for children with ADHD (Becker et al., 2017). Additional evidence for the development of emotion regulation suggests that although children regulate their emotions at an early age (Kochanska et al., 2001), their emotion regulation strategies may become more developed during adolescence (Stegge \& Terwogt, 2007). Because the age group 
investigated in the current study is unique, future studies should examine whether the results of the study also apply to children with ADHD of all ages or are unique to adolescence.

The current study did not assess for the co-occurrence of psychiatric disorders with ADHD, as this was beyond the scope of the present study. Future studies should attempt to examine whether the relation between ADHD symptoms, emotion regulation, and peer victimization is similar for children with ADHD with and without co-occurring psychiatric disorders. ADHD is often associated with co-occurring psychiatric disorders (American Psychiatric Association, 2013), and co-occurring psychiatric disorders among children with ADHD are associated with greater emotion regulation deficits (Leaberry, Rosen, Fogleman, Walerius, \& Slaughter, 2018; Sobanski et al., 2010) and peer victimization experiences (Becker et al., 2017; Humphrey, Storch, \& Geffken, 2007). Previous evidence suggests psychiatric disorders are broadly associated with deficits in emotion regulation (Sheppes, Suri, \& Gross, 2015), and children with ADHD who have a co-occurring psychiatric disorder may be at a greater risk for experiencing peer victimization because they have more difficulties regulating their emotions during stressful situations (i.e. peer conflict or peer threat). Therefore, future studies should seek to examine whether the presence of co-occurring psychiatric disorders influence findings from the current study. Independent evaluation of co-occurring internalizing and externalizing disorders appears warranted, especially given evidence that internalizing and externalizing disorders may be associated with unique emotion regulation profiles (Steinberg \& Drabick, 2015). 


\section{Conclusion}

This study examined the concurrent relations between ADHD symptoms, emotion regulation, and peer victimization among children with ADHD. Deficits in emotion regulation appear to uniquely affect peer victimization among children with ADHD, such that the inability to regulate and control negative emotions inhibits a child's ability to cope with distress, initiate effective coping strategies, and engage in prosocial behaviors. Children with ADHD who have difficulties regulating their emotions may be more likely to experience peer victimization because they are emotionally impulsive and respond to stimuli with excessive emotional reactions, leading to a pattern of emotionally-driven processing and behavior (Rosen et al., 2012). This pattern of impairment is differentially related to peer victimization by the frequency of ADHD symptoms, such that the relation of emotion regulation deficits to peer victimization was exacerbated by ADHD symptoms. Results did not reveal that a child's emotional response to a discrete peer stressor was associated with experiences of peer victimization. Furthermore, the regulation of anger and sadness appear particularly important in understanding peer victimization among children with ADHD, such that children in the current study who demonstrated more difficulties regulating their anger or sadness experienced a greater frequency of peer victimization experiences. Overall, children with ADHD who are unable to effectively regulate and manage their emotions may experience more frequent peer victimization not because they demonstrate core ADHD symptoms of inattention, hyperactivity, and impulsivity, but rather because they fail to effectively regulate their emotions in social settings. Though the study has several limitations, it has important implications for the assessment and treatment of emotional and social functioning among 
children with ADHD. Future studies are warranted to continue investigating the relation between ADHD symptoms, emotion regulation, and peer victimization to improve the lives of children with ADHD. 


\section{REFERENCES}

American Psychiatric Association. (1994). Diagnostic and statistical manual of mental disorders (DSM-IV). Washington, DC: American Psychiatric Association Publishing.

American Psychiatric Association. (2013). Diagnostic and statistical manual of mental disorders (DSM-5). Washington, DC: American Psychiatric Association Publishing.

Anastopoulos, A. D., Smith, T. F., Garrett, M. E., Morrissey-Kane, E., Schatz, N. K., Sommer, J. L., Sommer, S.C., \& Ashley-Koch, A. (2011). Self-regulation of emotion, functional impairment, and comorbidity among children with AD/HD. Journal of Attention Disorders, 15(7), 583-592.

Bacchini, D., Affuso, G., \& Trotta, T. (2008). Temperament, ADHD and peer relations among schoolchildren: the mediating role of school bullying. Aggressive Behavior, 34(5), 447-459.

Bagwell, C. L., Molina, B. S., Pelham, W. E., \& Hoza, B. (2001). Attention-deficit hyperactivity disorder and problems in peer relations: Predictions from childhood to adolescence. Journal of the American Academy of Child \& Adolescent Psychiatry, 40(11), 1285-1292.

Bagwell, C. L., \& Schmidt, M. E. (2011). The friendship quality of overtly and relationally victimized children. Merrill-Palmer Quarterly, 57(2), 158-185. 
Barker, E. D., Boivin, M., Brendgen, M., Fontaine, N., Arseneault, L., Vitaro, F., Bissonnette, C., \& Tremblay, R. E. (2008). Predictive validity and early predictors of peer-victimization trajectories in preschool. Archives of General Psychiatry, 65(10), 1185-1192.

Barkley, R. A. (1997). Behavioral inhibition, sustained attention, and executive functions: constructing a unifying theory of ADHD. Psychological Bulletin, 121(1), 65.

Barkley, R. A. (2014). Attention-deficit hyperactivity disorder: A handbook for diagnosis and treatment. New York, NY: Guilford Publications.

Barkley, R. A., \& Murphy, K. R. (2006). Attention-deficit hyperactivity disorder: A clinical workbook. New York, NY: Guilford Press.

Barkley, R. A., Murphy, K. R., \& Fischer, M. (2008). ADHD in adults: What the science says. New York, NY: Guilford Press.

Baumeister, A. L., Storch, E. A., \& Geffken, G. R. (2008). Peer victimization in children with learning disabilities. Child and Adolescent Social Work Journal, 25(1), 1123.

Becker, S. P., Mehari, K. R., Langberg, J. M., \& Evans, S. W. (2017). Rates of peer victimization in young adolescents with $\mathrm{ADHD}$ and associations with internalizing symptoms and self-esteem. European Child \& Adolescent Psychiatry, 26(2), 201-214.

Becker, A., Steinhausen, H. C., Baldursson, G., Dalsgaard, S., Lorenzo, M. J., Ralston, S. J., Döpfner, M., Rothenberger, A., \& ADORE Study Group. (2006). Psychopathological screening of children with ADHD: Strengths and Difficulties 
Questionnaire in a pan-European study. European Child \& Adolescent Psychiatry, 15(1), i56-i62.

Beekman, J. B., Stock, M. L., \& Marcus, T. (2016). Need to belong, not rejection sensitivity, moderates cortisol response, self-reported stress, and negative affect following social exclusion. The Journal of Social Psychology, 156(2), 131-138.

Berlin, L., Bohlin, G., Nyberg, L., \& Janols, L. O. (2004). How well do measures of inhibition and other executive functions discriminate between children with ADHD and controls?. Child Neuropsychology, 10(1), 1-13.

Betts, L. R., Houston, J. E., \& Steer, O. L. (2015). Development of the multidimensional peer victimization scale-revised (MPVS-R) and the multidimensional peer bullying scale (MPVS-RB). The Journal of Genetic Psychology, 176(2), 93-109.

Bierman, K. L. (2004). Peer rejection: Developmental processes and intervention strategies. New York, NY: Guilford Press.

Biesecker, G. E., \& Easterbrooks, M. A. (2001). Emotion Regulation Checklist for Adolescents. Adapted from Shields, A.M. \& Cicchetti, D. (1997). Unpublished manuscript, Tufts University.

Bollmer, J. M., Harris, M. J., \& Milich, R. (2006). Reactions to bullying and peer victimization: Narratives, physiological arousal, and personality. Journal of Research in Personality, 40(5), 803-828.

Bollmer, J. M., Milich, R., Harris, M. J., \& Maras, M. A. (2005). A friend in need: The role of friendship quality as a protective factor in peer victimization and bullying. Journal of Interpersonal Violence, 20(6), 701-712. 
Bonica, C., Arnold, D. H., Fisher, P. H., Zeljo, A., \& Yershova, K. (2003). Relational aggression, relational victimization, and language development in preschoolers. Social Development, 12(4), 551-562.

Boulton, M. J., \& Underwood, K. (1992). Bully/victim problems among middle school children. British Journal of Educational Psychology, 62(1), 73-87.

Boyes, M. E., \& French, D. J. (2009). Having a Cyberball: Using a ball-throwing game as an experimental social stressor to examine the relationship between neuroticism and coping. Personality and Individual Differences, 47(5), 396-401.

Braaten, E. B., \& Rosén, L. A. (2000). Self-regulation of affect in attention deficithyperactivity disorder (ADHD) and non-ADHD boys: differences in empathic responding. Journal of consulting and clinical psychology, 68(2), 313.

Bradshaw, C. P., Waasdorp, T. E., \& O’Brennan, L. M. (2013). A latent class approach to examining forms of peer victimization. Journal of Educational Psychology, $105(3), 839$.

Brendgen, M., Boivin, M., Vitaro, F., Girard, A., Dionne, G., \& Pérusse, D. (2008).

Gene-environment interaction between peer victimization and child aggression. Development and Psychopathology, 20(02), 455-471.

Bubier, J. L., \& Drabick, D. A. (2008). Affective decision-making and externalizing behaviors: The role of autonomic activity. Journal of Abnormal Child Psychology, 36(6), 941.

Bunford, N., Evans, S. W., \& Langberg, J. M. (2018). Emotion dysregulation is associated with social impairment among young adolescents with ADHD. Journal of Attention Disorders, 22(1), 66-82. 
Bunford, N., Evans, S. W., \& Wymbs, F. (2015). ADHD and emotion dysregulation among children and adolescents. Clinical Child and Family Psychology Review, $18(3), 185-217$.

Bunford, N., Evans, S. W., Zoccola, P. M., Owens, J. S., Flory, K., \& Spiel, C. F. (2017). Correspondence between heart rate variability and emotion dysregulation in children, including children with ADHD. Journal of Abnormal Child Psychology, 45(7), 1325-1337.

Callaghan, S., \& Joseph, S. (1995). Self-concept and peer victimization among schoolchildren. Personality and Individual Differences, 18(1), 161-163.

Camodeca, M., \& Goossens, F. A. (2005). Aggression, social cognitions, anger and sadness in bullies and victims. Journal of Child Psychology and Psychiatry, 46(2), 186-197.

Card, N. A., \& Hodges, E. V. (2008). Peer victimization among schoolchildren: Correlations, causes, consequences, and considerations in assessment and intervention. School Psychology Quarterly, 23(4), 451.

Cardoos, S. L., \& Hinshaw, S. P. (2011). Friendship as protection from peer victimization for girls with and without ADHD. Journal of Abnormal Child Psychology, 39(7), 1035-1045.

Census Bureau, U.S. (2010). State and county QuickFacts. (Retrieved from) https://www.census.gov/quickfacts.

Chang, L., Schwartz, D., Dodge, K. A., \& McBride-Chang, C. (2003). Harsh parenting in relation to child emotion regulation and aggression. Journal of Family Psychology, 17(4), 598. 
Chou, W. J., Liu, T. L., Yang, P., Yen, C. F., \& Hu, H. F. (2014). Bullying victimization and perpetration and their correlates in adolescents clinically diagnosed with ADHD. Journal of Attention Disorders, 22(1), 25-34.

Clark, L., Blackwell, A. D., Aron, A. R., Turner, D. C., Dowson, J., Robbins, T. W., \& Sahakian, B. J. (2007). Association between response inhibition and working memory in adult ADHD: a link to right frontal cortex pathology?. Biological Psychiatry, 61(12), 1395-1401.

Cohen, J. (1992). A power primer. Psychological bulletin, 112(1), 155.

Cohen, J., \& Cohen, P. West, S. G, \& Aiken, L. S. (2003). Applied multiple regression/correlation analysis for the behavioral sciences. Hillsdale, NJ: Erlbaum.

Cohen, P., O'connor, P., Lewis, S., Velez, C. N., \& Malachowski, B. (1987). Comparison of DISC and K-SADS-P interviews of an epidemiological sample of children. Journal of the American Academy of Child \& Adolescent Psychiatry, 26(5), 662667.

Cole, P. M., Martin, S. E., \& Dennis, T. A. (2004). Emotion regulation as a scientific construct: Methodological challenges and directions for child development research. Child Development, 75(2), 317-333.

Cole, P. M., Michel, M. K., \& Teti, L. O. D. (1994). The development of emotion regulation and dysregulation: A clinical perspective. Monographs of the Society for Research in Child Development, 59(2-3), 73-102. 
Cooley, J. L., \& Fite, P. J. (2016). Peer victimization and forms of aggression during middle childhood: the role of emotion regulation. Journal of Abnormal Child Psychology, 44(3), 535-546.

Craig, W., Harel-Fisch, Y., Fogel-Grinvald, H., Dostaler, S., Hetland, J., Simons-Morton, B., Molcho, M., Gaspar de Mato, M., Overpeck, M., Due, P., \& Pickett, W. (2009). A cross-national profile of bullying and victimization among adolescents in 40 countries. International Journal of Public Health, 54, 216-224.

Crick, N. R. (1996). The role of overt aggression, relational aggression, and prosocial behavior in the prediction of children's future social adjustment. Child Development, 67(5), 2317-2327.

Crick, N. R., \& Bigbee, M. A. (1998). Relational and overt forms of peer victimization: a multiinformant approach. Journal of Consulting and Clinical Psychology, 66(2), 337.

Crick, N. R., Casas, J. F., \& Ku, H. (1999). Physical and relational peer victimization in preschool. Developmental Psychology, 35(2), 376-385.

Crick, N. R., Casas, J. F., \& Nelson, D. A. (2002). Toward a more comprehensive understanding of peer maltreatment: Studies of relational victimization. Current Directions in Psychological Science, 11(3), 98-101.

Crick, N. R., \& Dodge, K. A. (1994). A review and reformulation of social informationprocessing mechanisms in children's social adjustment. Psychological Bulletin, 115(1), 74 .

Crick, N. R., \& Grotpeter, J. K. (1995). Relational aggression, gender, and socialpsychological adjustment. Child Development, 66(3), 710-722. 
Crick, N. R., \& Grotpeter, J. K. (1996). Children's treatment by peers: Victims of relational and overt aggression. Development and Psychopathology, 8(02), 367380.

Crick, N. R., \& Nelson, D. A. (2002). Relational and physical victimization within friendships: Nobody told me there'd be friends like these. Journal of Abnormal Child Psychology, 30(6), 599-607.

Crundwell, R. M. A. (2005). An initial investigation of the impact of self-regulation and emotionality on behavior problems in children with ADHD. Canadian Journal of School Psychology, 20(1-2), 62-74.

Cuevas, C. A., Finkelhor, D., Clifford, C., Ormrod, R. K., \& Turner, H. A. (2010). Psychological distress as a risk factor for re-victimization in children. Child Abuse \& Neglect, 34(4), 235-243.

Cullerton-Sen, C., \& Crick, N. R. (2005). Understanding the effects of physical and relational victimization: The utility of multiple perspectives in predicting socialemotional adjustment. School Psychology Review, 34(2), 147-160.

Curran-Everett, D. (2018). Explorations in statistics: the log transformation. Advances in Physiology Education, 42(2), 343-347.

Cyders, M. A., \& Smith, G. T. (2008). Emotion-based dispositions to rash action: positive and negative urgency. Psychological Bulletin, 134(6), 807.

Dawson, G., Panagiotides, H., Klinger, L. G., \& Hill, D. (1992). The role of frontal lobe functioning in the development of infant self-regulatory behavior. Brain and Cognition, 20(1), 152-175. 
De Los Reyes, A., \& Prinstein, M. J. (2004). Applying depression-distortion hypotheses to the assessment of peer victimization in adolescents. Journal of Clinical Child and Adolescent Psychology, 33(2), 325-335.

Demaray, M. K., \& Malecki, C. K. (2003). Perceptions of the frequency and importance of social support by students classified as victims, bullies, and bully/victims in an urban middle school. School Psychology Review, 32(3), 471-490.

Dempsey, A. G., Haden, S. C., Goldman, J., Sivinski, J., \& Wiens, B. A. (2011). Relational and overt victimization in middle and high schools: Associations with self-reported suicidality. Journal of School Violence, 10(4), 374-392.

Dennis, T. A., \& Hajcak, G. (2009). The late positive potential: a neurophysiological marker for emotion regulation in children. Journal of Child Psychology and Psychiatry, 50(11), 1373-1383.

Didden, R., Scholte, R. H., Korzilius, H., De Moor, J. M., Vermeulen, A., O’Reilly, M., Lang, R., \& Lancioni, G. E. (2009). Cyberbullying among students with intellectual and developmental disability in special education settings. Developmental Neurorehabilitation, 12(3), 146-151.

Diener, M. B., \& Milich, R. (1997). Effects of positive feedback on the social interactions of boys with attention deficit hyperactivity disorder: A test of the self-protective hypothesis. Journal of Clinical Child Psychology, 26(3), 256-265.

Dodge, K. A. (1986). A social information processing model of social competence in children. In M. Perlmutter (Ed.), The Minnesota Symposium on Child Psychology (Vol. 18, pp. 77-125). Hillsdale, NJ: Erlbaum. 
Due, P., Holstein, B. E., Lynch, J., Diderichsen, F., Gabhain, S. N., Scheidt, P., \& Currie, C. (2005). Bullying and symptoms among school-aged children: international comparative cross sectional study in 28 countries. The European Journal of Public Health, 15(2), 128-132.

DuPaul, G. J., Anastopoulos, A. D., Power, T. J., Reid, R., Ikeda, M. J., \& McGoey, K. E. (1998). Parent ratings of attention-deficit/hyperactivity disorder symptoms: Factor structure and normative data. Journal of Psychopathology and Behavioral Assessment, 20(1), 83-102.

DuPaul, G. J., McGoey, K. E., Eckert, T. L., \& VanBrakle, J. (2001). Preschool children with attention-deficit/hyperactivity disorder: impairments in behavioral, social, and school functioning. Journal of the American Academy of Child \& Adolescent Psychiatry, 40(5), 508-515.

DuPaul, G. J., Power, T. J., Anastopoulos, A. D., Reid, R., McGoey, K. E., \& Ikeda, M. J. (1997). Teacher ratings of attention deficit hyperactivity disorder symptoms: Factor structure and normative data. Psychological Assessment, 9(4), 436.

DuPaul, G. J., \& Stoner, G. (2014). ADHD in the schools: Assessment and intervention strategies. New York, NY: Guilford Publications.

Eisenberg, N., Fabes, R. A., Bernzweig, J., Karbon, M., Poulin, R., \& Hanish, L. (1993). The relations of emotionality and regulation to preschoolers' social skills and sociometric status. Child Development, 64(5), 1418-1438.

Eisenberg, N., Fabes, R. A., Carlo, G., \& Karbon, M. (1992). Emotional responsivity to others: Behavioral correlates and socialization antecedents. New Directions for Child and Adolescent Development, (55), 57-73. 
Eisenberg, N., Fabes, R. A., Murphy, B., Maszk, P., Smith, M., \& Karbon, M. (1995).

The role of emotionality and regulation in children's social functioning: A longitudinal study. Child Development, 66(5), 1360-1384.

Eisenberg, N., Fabes, R. A., Shepard, S. A., Murphy, B. C., Guthrie, I. K., Jones, S., Friedman, J., Poulin, R., \& Maszk, P. (1997). Contemporaneous and longitudinal prediction of children's social functioning from regulation and emotionality. Child Development, 68(4), 642-664.

Eisenberg, N., Guthrie, I. K., Fabes, R. A., Shepard, S., Losoya, S., Murphy, B., Jones, S., Poulin, R., \& Reiser, M. (2000). Prediction of elementary school children's externalizing problem behaviors from attentional and behavioral regulation and negative emotionality. Child Development, 71(5), 1367-1382.

Elledge, L. C., Cavell, T. A., Ogle, N. T., Malcolm, K. T., Newgent, R. A., \& Faith, M. A. (2010). History of peer victimization and children's response to school bullying. School Psychology Quarterly, 25(2), 129-141.

Epstein-Ngo, Q. M., McCabe, S. E., Veliz, P. T., Stoddard, S. A., Austic, E. A., \& Boyd, C. J. (2015). Diversion of ADHD stimulants and victimization among adolescents. Journal of Pediatric Psychology, 41(7), 786-798.

Espelage, D. L., Mebane, S. E., \& Swearer, S. M. (2004). Gender differences in bullying: Moving beyond mean level differences. In D. L. Espelage \& S. M. Swearer (Eds.), Bullying in American schools: A social-ecological perspective on prevention and intervention (pp. 15-35). Mahwah: NJ: Erlbaum. 
Ewing Lee, E. A., \& Troop-Gordon, W. (2011). Peer socialization of masculinity and femininity: Differential effects of overt and relational forms of peer victimization. British Journal of Developmental Psychology, 29(2), 197-213.

Factor, P. I., Reyes, R. A., \& Rosen, P. J. (2014). Emotional impulsivity in children with ADHD associated with comorbid—not ADHD—symptomatology. Journal of Psychopathology and Behavioral Assessment, 36(4), 530-541.

Factor, P. I., Rosen, P. J., \& Reyes, R. A. (2016). The relation of poor emotional awareness and externalizing behavior among children with ADHD. Journal of Attention Disorders, 20(2), 168-177.

Faraone, S. V., \& Biederman, J. (2000). Nature, nurture, and attention deficit hyperactivity disorder. Developmental Review, 20(4), 568-581.

Faraone, S. V., Biederman, J., \& Mick, E. (2006). The age-dependent decline of attention deficit hyperactivity disorder: a meta-analysis of follow-up studies. Psychological Medicine, 36(02), 159-165.

Faraone, S. V., \& Mick, E. (2010). Molecular genetics of attention deficit hyperactivity disorder. Psychiatric Clinics of North America, 33(1), 159-180.

Faul, F., Erdfelder, E., Buchner, A., \& Lang, A. G. (2009). Statistical power analyses using G* Power 3.1: Tests for correlation and regression analyses. Behavior Research Methods, 41(4), 1149-1160.

Faul, F., Erdfelder, E., Lang, A. G., \& Buchner, A. (2007). G* Power 3: A flexible statistical power analysis program for the social, behavioral, and biomedical sciences. Behavior Research Methods, 39(2), 175-191. 
Felix, E. D., \& McMahon, S. D. (2007). The role of gender in peer victimization among youth: A study of incidence, interrelations, and social cognitive correlates. Journal of School Violence, 6(3), 27-44.

Field, A. (2009). Discovering statistics using SPSS. London: Sage publications.

Fite, P. J., Evans, S. C., Cooley, J. L., \& Rubens, S. L. (2014). Further evaluation of associations between attention-deficit/hyperactivity and oppositional defiant disorder symptoms and bullying-victimization in adolescence. Child Psychiatry \& Human Development, 45(1), 32-41.

Fogleman, N. D., Leaberry, K. D., Rosen, P. J., Walerius, D. M., \& Slaughter, K. (2018a). How do children with and without ADHD talk about frustration?: Use of a novel emotion narrative recall task. ADHD Attention Deficit and Hyperactivity Disorders, 10(4), 297-307.

Fogleman, N. D., Leaberry, K. D., Rosen, P. J., Walerius, D. M., \& Slaughter, K. E. (2018b). Relation between internalizing behaviors, externalizing behaviors, and peer victimization among children with and without ADHD. ADHD Attention Deficit and Hyperactivity Disorders, 10(3), 209-222.

Fogleman, N. D., Slaughter, K. E., Rosen, P. J., Leaberry, K. D., \& Walerius, D. M. (2018). Emotion regulation accounts for the relation between ADHD and peer victimization. Journal of Child and Family Studies, 1-14.

Fogleman, N. D., Walerius, D. M., Rosen, P. J., \& Leaberry, K. D. (2016). Peer victimization linked to negative affect in children with and without ADHD. Journal of Applied Developmental Psychology, 46, 1-10. 
Frodl, T., Stauber, J., Schaaff, N., Koutsouleris, N., Scheuerecker, J., Ewers, M., Omerovic, M., Opgen-Rhein, M., Hampel, H., Reiser, M., \& Möller, H. J. (2010). Amygdala reduction in patients with ADHD compared with major depression and healthy volunteers. Acta Psychiatrica Scandinavica, 121(2), 111-118.

George, D., \& Mallery, P. (2010). SPSS for Windows step by step. A simple study guide and reference. Boston, MA: Pearson Education Incorporated.

Godleski, S. A., Kamper, K. E., Ostrov, J. M., Hart, E. J., \& Blakely-McClure, S. J. (2015). Peer victimization and peer rejection during early childhood. Journal of Clinical Child \& Adolescent Psychology, 44(3), 380-392.

Goldsmith, H. H., Pollak, S. D., \& Davidson, R. J. (2008). Developmental neuroscience perspectives on emotion regulation. Child Development Perspectives, 2(3), 132140.

Graham, S., \& Juvonen, J. (2001). An attributional approach to peer victimization. In J. Juvonen \& S. Graham (Eds.), Peer harassment in school: The plight of the vulnerable and victimized (pp. 49-72). New York: Guilford Press.

Graziano, P. A., \& Garcia, A. (2016). Attention-deficit hyperactivity disorder and children's emotion dysregulation: A meta-analysis. Clinical Psychology Review, $46,106-123$.

Griffiths, L. J., \& Page, A. S. (2008). The Impact of Weight-related Victimization on Peer Relationships: The Female Adolescent Perspective. Obesity, 16(S2).

Gross, J. J. (1998). The emerging field of emotion regulation: An integrative review. Review of General Psychology, 2(3), 271. 
Gross, J. J. (2002). Emotion regulation: Affective, cognitive, and social consequences. Psychophysiology, 39(3), 281-291.

Gurevitz, M., Geva, R., Varon, M., \& Leitner, Y. (2014). Early markers in infants and toddlers for development of ADHD. Journal of Attention Disorders, 18(1), 14-22.

Hanish, L. D., Eisenberg, N., Fabes, R. A., Spinrad, T. L., Ryan, P., \& Schmidt, S. (2004). The expression and regulation of negative emotions: Risk factors for young children's peer victimization. Development and Psychopathology, 16(02), 335-353.

Hanish, L. D., \& Guerra, N. G. (2000). Predictors of peer victimization among urban youth. Social Development, 9(4), 521-543.

Hanish, L. D., Kochenderfer-Ladd, B., Fabes, R. A., Martin, C. L., \& Denning, D. (2004). Bullying among young children: The influence of peers and teachers. In D.L. Espelage \& S.M. Swearer (Eds.). Bullying in American schools: A socialecological perspective on prevention and intervention (pp. 141-159). Mahwah, NJ: Erlbaum.

Hartgerink, C. H., van Beest, I., Wicherts, J. M., \& Williams, K. D. (2015). The ordinal effects of ostracism: A meta-analysis of 120 Cyberball studies. PloS One, 10(5), e0127002.

Hastings, P. D., Nuselovici, J. N., Utendale, W. T., Coutya, J., McShane, K. E., \& Sullivan, C. (2008). Applying the polyvagal theory to children's emotion regulation: Social context, socialization, and adjustment. Biological Psychology, 79(3), 299-306. 
Hawker, D. S., \& Boulton, M. J. (2000). Twenty years' research on peer victimization and psychosocial maladjustment: A meta-analytic review of cross-sectional studies. Journal of Child Psychology and Psychiatry, 41(4), 441-455.

Hay, D. F., Payne, A., \& Chadwick, A. (2004). Peer relations in childhood. Journal of Child Psychology and Psychiatry, 45(1), 84-108.

Haynie, D. L., Nansel, T., Eitel, P., Crump, A. D., Saylor, K., Yu, K., \& Simons-Morton, B. (2001). Bullies, victims, and bully/victims: Distinct groups of at-risk youth. The Journal of Early Adolescence, 21(1), 29-49.

Hessler, D. M., \& Fainsilber Katz, L. (2007). Children's emotion regulation: Self-report and physiological response to peer provocation. Developmental Psychology, $43(1), 27$.

Hinshaw, S. P., \& Melnick, S. M. (1995). Peer relationships in boys with attention-deficit hyperactivity disorder with and without comorbid aggression. Development and psychopathology, 7(04), 627-647.

Hodges, E. V., Boivin, M., Vitaro, F., \& Bukowski, W. M. (1999). The power of friendship: protection against an escalating cycle of peer victimization. Developmental Psychology, 35(1), 94.

Hodges, E. V., \& Perry, D. G. (1999). Personal and interpersonal antecedents and consequences of victimization by peers. Journal of Personality and Social Psychology, 76(4), 677.

Holmberg, K., \& Hjern, A. (2008). Bullying and attention-deficit-hyperactivity disorder in 10-year-olds in a Swedish community. Developmental Medicine \& Child Neurology, 50(2), 134-138. 
Hoover, J. H., Oliver, R., \& Hazler, R. J. (1992). Bullying: Perceptions of adolescent victims in the Midwestern USA. School Psychology International, 13(1), 5-16.

Hourigan, S. E., Goodman, K. L., \& Southam-Gerow, M. A. (2011). Discrepancies in parents' and children's reports of child emotion regulation. Journal of Experimental Child Psychology, 110(2), 198-212.

Hoza, B. (2007). Peer functioning in children with ADHD. Journal of Pediatric Psychology, 32(6), 655-663.

Hoza, B., Gerdes, A. C., Hinshaw, S. P., Arnold, L. E., Pelham Jr, W. E., Molina, B. S., Abikoff, H. B., Epstein, J. N., Greenhill, L. L., Hechtman, L., Odbert, C., Swanson, J. M., \& Wigal., T. (2004). Self-perceptions of competence in children with ADHD and comparison children. Journal of Consulting and Clinical Psychology, 72(3), 382.

Hoza, B., Mrug, S., Gerdes, A. C., Hinshaw, S. P., Bukowski, W. M., Gold, J. A., Kraemer, H.C., Pelham, W.E., Wigal, T., \& Arnold, L. E. (2005). What aspects of peer relationships are impaired in children with attention-deficit/hyperactivity disorder?. Journal of Consulting and Clinical Psychology, 73(3), 411.

Hoza, B., Pelham Jr, W. E., Dobbs, J., Owens, J. S., \& Pillow, D. R. (2002). Do boys with attention-deficit/hyperactivity disorder have positive illusory self-concepts?. Journal of Abnormal Psychology, 111(2), 268.

Hoza, B., Pelham, W. E., Milich, R., Pillow, D., \& McBride, K. (1993). The selfperceptions and attributions of attention deficit hyperactivity disordered and nonreferred boys. Journal of Abnormal Child Psychology, 21(3), 271-286. 
Hubbard, J. A., \& Coie, J. D. (1994). Emotional correlates of social competence in children's peer relationships. Merrill-Palmer Quarterly, 40, 1-20.

Hubbard, J. A., \& Dearing, K. F. (2004). Children's understanding and regulation of emotion in the context of their peer relations. In J. B. Kupersmidt \& K. A. Dodge (Eds.), Children's Peer Relations: From Development to Intervention, (pp. 81-99. Washington D.C.: American Psychological Association Press.

Hugh-Jones, S., \& Smith, P. K. (1999). Self-reports of short-and long-term effects of bullying on children who stammer. British Journal of Educational Psychology, 69(2), 141-158.

Humphrey, J. L., Storch, E. A., \& Geffken, G. R. (2007). Peer victimization in children with attention-deficit hyperactivity disorder. Journal of Child Health Care, 11(3), 248-260.

Hunter, S. C., Boyle, J. M., \& Warden, D. (2007). Perceptions and correlates of peervictimization and bullying. British Journal of Educational Psychology, 77(4), 797-810.

IBM Corp. (2017). IBM SPSS Statistics for Windows (Version 25.0) [Computer software]. Armonk, NY: Author.

Iffland, B., Sansen, L. M., Catani, C., \& Neuner, F. (2014). The trauma of peer abuse: Effects of relational peer victimization and social anxiety disorder on physiological and affective reactions to social exclusion. Frontiers in Psychiatry, $5,26$. 
Iyer, R. V., Kochenderfer-Ladd, B., Eisenberg, N., \& Thompson, M. (2010). Peer victimization and effortful control: Relations to school engagement and academic achievement. Merrill-Palmer Quarterly, 56(3), 361.

Jarratt, K. P., Riccio, C. A., \& Siekierski, B. M. (2005). Assessment of attention deficit hyperactivity disorder (ADHD) using the BASC and BRIEF. Applied Neuropsychology, 12(2), 83-93.

Jensen, S. A., \& Rosen, L. A. (2004). Emotional reactivity in children with attentiondeficit/hyperactivity disorder. Journal of Attention Disorders, 8(2), 53-61.

Jensen-Campbell, L. A., Knack, J. M., Waldrip, A., \& Ramirez, M. A. R. I. E. (2009). The importance of personality and effortful control processes in victimization. In In M. J. Harris (Ed.), Bullying rejection \& peer victimization: A social cognitive neuroscience perspective (pp. 103-123). New York, NY: Springer.

Ji, L., Pan, B., Zhang, W., Zhang, L., Chen, L., \& Deater-Deckard, K. (2019). Bidirectional Associations between Peer Relations and Attention Problems from 9 to 16 Years. Journal of Abnormal Child Psychology, 47(3), 381-392.

Juvonen, J., \& Graham, S. (2001). Peer harassment in school: The plight of the vulnerable and victimized. New York, NY: Guilford Press.

Kaufman, J., Birmaher, B., Brent, D., Rao, U. M. A., Flynn, C., Moreci, P., Williamson, D., \& Ryan, N. (1997). Schedule for affective disorders and schizophrenia for school-age children-present and lifetime version (K-SADS-PL): initial reliability and validity data. Journal of the American Academy of Child \& Adolescent Psychiatry, 36(7), 980-988. 
Kaynak, Ö., Lepore, S. J., Kliewer, W., \& Jaggi, L. (2015). Peer victimization and subsequent disruptive behavior in school: The protective functions of anger regulation coping. Personality and Individual Differences, 73, 1-6.

King, S., Waschbusch, D. A., Pelham Jr, W. E., Frankland, B. W., Andrade, B. F., Jacques, S., \& Corkum, P. V. (2009). Social information processing in elementary-school aged children with ADHD: Medication effects and comparisons with typical children. Journal of Abnormal Child Psychology, 37(4), $579-589$.

Kliewer, W., Dibble, A. E., Goodman, K. L., \& Sullivan, T. N. (2012). Physiological correlates of peer victimization and aggression in African American urban adolescents. Development and Psychopathology, 24(02), 637-650.

Klomek, A. B., Marrocco, F., Kleinman, M., Schonfeld, I. S., \& Gould, M. S. (2008). Peer victimization, depression, and suicidiality in adolescents. Suicide and LifeThreatening Behavior, 38(2), 166-180.

Kochanska, G., Coy, K. C., \& Murray, K. T. (2001). The development of self-regulation in the first four years of life. Child Development, 72(4), 1091-1111.

Kochanska, G., Philibert, R. A., \& Barry, R. A. (2009). Interplay of genes and early mother-child relationship in the development of self-regulation from toddler to preschool age. Journal of Child Psychology and Psychiatry, 50(11), 1331-1338.

Kochenderfer, B. J., \& Ladd, G. W. (1996). Peer victimization: Cause or consequence of school maladjustment?. Child development, 67(4), 1305-1317. 
Kochenderfer, B. J., \& Ladd, G. W. (1997). Victimized children's responses to peers' aggression: Behaviors associated with reduced versus continued victimization. Development and Psychopathology, 9(01), 59-73.

Kochenderfer-Ladd, B. (2004). Peer victimization: The role of emotions in adaptive and maladaptive coping. Social Development, 13(3), 329-349.

Kochenderfer-Ladd, B., \& Ladd, G. W. (2001). Variations in peer victimization: Relations to children's maladjustment. In J. Juvonen \& S. Graham (Eds.), Peer harassment in school: The plight of the vulnerable and victimized (pp. 25-48). New York: Guilford Press.

Kochenderfer-Ladd, B., \& Skinner, K. (2002). Children's coping strategies: Moderators of the effects of peer victimization?. Developmental Psychology, 38(2), 267.

Kopp, C. B. (1989). Regulation of distress and negative emotions: A developmental view. Developmental Psychology, 25(3), 343.

Ladd, G. W., \& Kochenderfer-Ladd, B. (2002). Identifying victims of peer aggression from early to middle childhood: analysis of cross-informant data for concordance, estimation of relational adjustment, prevalence of victimization, and characteristics of identified victims. Psychological Assessment, 14(1), 74.

Laurent, J., Catanzaro, S. J., Joiner Jr, T. E., Rudolph, K. D., Potter, K. I., Lambert, S., Osborne, L., \& Gathright, T. (1999). A measure of positive and negative affect for children: scale development and preliminary validation. Psychological Assessment, 11(3), 326.

Leaberry, K. D., Rosen, P. J., Fogleman, N. D., Walerius, D. M., \& Slaughter, K. E. (2018). Physiological Emotion Regulation in Children with ADHD with and 
without Comorbid Internalizing Disorders: a Preliminary Study. Journal of Psychopathology and Behavioral Assessment, 40, 452-464.

Lewis, M. D., Lamm, C., Segalowitz, S. J., Stieben, J., \& Zelazo, P. D. (2006). Neurophysiological correlates of emotion regulation in children and adolescents. Journal of Cognitive Neuroscience, 18(3), 430-443.

Linder, N., Kroyzer, N., Maeir, A., Wertman-Elad, R., \& Pollak, Y. (2010). Do ADHD and executive dysfunctions, measured by the Hebrew version of Behavioral Rating Inventory of Executive Functions (BRIEF), completely overlap?. Child Neuropsychology, 16(5), 494-502.

Loe, I. M., \& Feldman, H. M. (2007). Academic and educational outcomes of children with ADHD. Journal of Pediatric Psychology, 32(6), 643-654.

Loeber, R., Green, S. M., Lahey, B. B., \& Stouthamer-Loeber, M. (1991). Differences and similarities between children, mothers, and teachers as informants on disruptive child behavior. Journal of Abnormal Child Psychology, 19(1), 75-95.

MacDermott, S. T., Gullone, E., Allen, J. S., King, N. J., \& Tonge, B. (2010). The emotion regulation index for children and adolescents (ERICA): a psychometric investigation. Journal of Psychopathology and Behavioral Assessment, 32(3), 301-314.

Mahady Wilton, M. M., Craig, W. M., \& Pepler, D. J. (2000). Emotional regulation and display in classroom victims of bullying: Characteristic expressions of affect, coping styles and relevant contextual factors. Social Development, 9(2), 226-245.

Marquaridt, D. W. (1970). Generalized inverses, ridge regression, biased linear estimation, and nonlinear estimation. Technometrics, 12(3), 591-612. 
Martel, M. M. (2009). Research Review: A new perspective on attentiondeficit/hyperactivity disorder: emotion dysregulation and trait models. Journal of Child Psychology and Psychiatry, 50(9), 1042-1051.

Martel, M. M., Roberts, B., \& Gremillion, M. L. (2013). Emerging control and disruptive behavior disorders during early childhood. Developmental neuropsychology, $38(3), 153-166$.

Maszk, P., Eisenberg, N., \& Guthrie, I. K. (1999). Relations of children's social status to their emotionality and regulation: A short-term longitudinal study. Merrill-Palmer Quarterly 45, 468-492.

McCandless, S., \& O'Laughlin, L. (2007). The clinical utility of the Behavior Rating Inventory of Executive Function (BRIEF) in the diagnosis of ADHD. Journal of Attention Disorders, 10(4), 381-389.

McDowell, D. J., O'Neil, R., \& Parke, R. D. (2000). Display rule application in a disappointing situation and children's emotional reactivity: Relations with social competence. Merrill-Palmer Quarterly, 46, 306-324.

McLaughlin, K. A., Hatzenbuehler, M. L., \& Hilt, L. M. (2009). Emotion dysregulation as a mechanism linking peer victimization to internalizing symptoms in adolescents. Journal of Consulting and Clinical Psychology, 77(5), 894.

McRae, K., Gross, J. J., Weber, J., Robertson, E. R., Sokol-Hessner, P., Ray, R. D., Gabrielli, J. D. E., \& Ochsner, K. N. (2012). The development of emotion regulation: an fMRI study of cognitive reappraisal in children, adolescents and young adults. Social Cognitive and Affective Neuroscience, 7(1), 11-22. 
McQuade, J. D., Tomb, M., Hoza, B., Waschbusch, D. A., Hurt, E. A., \& Vaughn, A. J. (2011). Cognitive deficits and positively biased self-perceptions in children with ADHD. Journal of Abnormal Child Psychology, 39(2), 307-319.

Melnick, S. M., \& Hinshaw, S. P. (2000). Emotion regulation and parenting in AD/HD and comparison boys: Linkages with social behaviors and peer preference. Journal of Abnormal Child Psychology, 28(1), 73-86.

Meyers, L. S., Gamst, G., \& Guarino, A. J. (2006). Applied multivariate research: Design and interpretation. Thousand Oaks, CA: Sage.

Milich, R., \& Dodge, K. A. (1984). Social information processing in child psychiatric populations. Journal of Abnormal Child Psychology, 12(3), 471-489.

Mitchell, T. B., Cooley, J. L., Evans, S. C., \& Fite, P. J. (2016). The Moderating Effect of Physical Activity on the Association Between ADHD Symptoms and Peer Victimization in Middle Childhood. Child Psychiatry \& Human Development, 47(6), 871-882.

Mitsis, E. M., McKay, K. E., Schulz, K. P., Newcorn, J. H., \& Halperin, J. M. (2000). Parent-teacher concordance for DSM-IV attention-deficit/hyperactivity disorder in a clinic-referred sample. Journal of the American Academy of Child \& Adolescent Psychiatry, 39(3), 308-313.

Miyake, A., Friedman, N. P., Emerson, M. J., Witzki, A. H., Howerter, A., \& Wager, T. D. (2000). The unity and diversity of executive functions and their contributions to complex "frontal lobe" tasks: A latent variable analysis. Cognitive Psychology, 41(1), 49-100. 
Molina, P., Sala, M. N., Zappulla, C., Bonfigliuoli, C., Cavioni, V., Zanetti, M. A., Baiocco, R., Laghi, F., Pallini, S., De Stasio, S., \& Raccanello, D. (2014). The Emotion Regulation Checklist-Italian translation. Validation of parent and teacher versions. European Journal of Developmental Psychology, 11(5), 624634.

Morelen, D., Southam-Gerow, M., \& Zeman, J. (2016). Child emotion regulation and peer victimization: The moderating role of child sex. Journal of Child and Family Studies, 25(6), 1941-1953.

Morrow, M. T., Hubbard, J. A., Rubin, R. M., \& McAuliffe, M. D. (2008). The relation between childhood aggression and depressive symptoms: The unique and joint mediating roles of peer rejection and peer victimization. Merrill-Palmer Quarterly, 54, 316-340.

MTA Cooperative Group. (2004). National Institute of Mental Health Multimodal Treatment Study of ADHD follow-up: 24-month outcomes of treatment strategies for attention-deficit/hyperactivity disorder. Pediatrics, 113(4), 754-761.

Musser, E. D., Backs, R. W., Schmitt, C. F., Ablow, J. C., Measelle, J. R., \& Nigg, J. T. (2011). Emotion regulation via the autonomic nervous system in children with attention-deficit/hyperactivity disorder (ADHD). Journal of Abnormal Child Psychology, 39(6), 841-852.

Musser, E. D., Galloway-Long, H. S., Frick, P. J., \& Nigg, J. T. (2013). Emotion regulation and heterogeneity in attention-deficit/hyperactivity disorder. Journal of the American Academy of Child \& Adolescent Psychiatry, 52(2), 163-171. 
Nakamoto, J., \& Schwartz, D. (2010). Is peer victimization associated with academic achievement? A meta-analytic review. Social Development, 19(2), 221-242.

Nansel, T. R., Overpeck, M., Pilla, R. S., Ruan, W. J., Simons-Morton, B., \& Scheidt, P. (2001). Bullying behaviors among US youth: Prevalence and association with psychosocial adjustment. JAMA, 285(16), 2094-2100.

Nigg, J. T., \& Casey, B. J. (2005). An integrative theory of attention-deficit/hyperactivity disorder based on the cognitive and affective neurosciences. Development and Psychopathology, 17(03), 785-806.

Ochsner, K. N., \& Gross, J. J. (2007). The neural architecture of emotion regulation. In J. J. Gross (Ed.), Handbook of emotion regulation, (pp. 87-109). New York, NY: Guilford Press.

Olweus, D. (1978). Aggression in the schools: Bullies and whipping boys. New York, NY: Wiley.

Olweus, D. (1994). Bullying at school: basic facts and effects of a school based intervention program. Journal of Child Psychology and Psychiatry, 35(7), 11711190.

Olweus, D. (1999). Norway. In P. K. Smith, Y. Morita, J. Junger-Tas, D. Olweus, R. Catalano, \& P. Slee (Eds.), The nature of school bullying: A cross-national perspective (pp. 28-48). London: Routledge.

Olweus, D., \& Solberg, C. (1998). Bullying among children and young people. Information and guidance for parents. [translation to English: Caroline Bond] Oslo: Pedagogisk forum. 
Ostrov, J. M., Woods, K. E., Jansen, E. A., Casas, J. F., \& Crick, N. R. (2004). An observational study of delivered and received aggression, gender, and socialpsychological adjustment in preschool: “This White Crayon Doesn't Work...”. Early Childhood Research Quarterly, 19(2), 355-371.

Owens, E. B., Zalecki, C., Gillette, P., \& Hinshaw, S. P. (2017). Girls with childhood ADHD as adults: Cross-domain outcomes by diagnostic persistence. Journal of Consulting and Clinical Psychology, 85(7), 723.

Pearce, M. J., Boergers, J., \& Prinstein, M. J. (2002). Adolescent obesity, overt and relational peer victimization, and romantic relationships. Obesity, 10(5), 386-393.

Pelham Jr, W. E., \& Fabiano, G. A. (2008). Evidence-based psychosocial treatments for attention-deficit/hyperactivity disorder. Journal of Clinical Child \& Adolescent Psychology, 37(1), 184-214.

Pellegrini, A. D. (1998). Bullies and victims in school: A review and call for research. Journal of Applied Developmental Psychology, 19(2), 165-176.

Pellegrini, A. D. (2001). Sampling instances of victimization in middle school. In J. Juvonen \& S. Graham (Eds.), Peer harassment in school: The plight of the vulnerable and victimized (pp. 125-144). New York, NY: Guilford Press.

Pellegrini, A. U., \& Bartini, M. (2000). An empirical comparison of methods of sampling aggression and victimization in school settings. Journal of Educational Psychology, 92(2), 360.

Pellegrini, A. D., \& Long, J. D. (2002). A longitudinal study of bullying, dominance, and victimization during the transition from primary school through secondary school. British Journal of Developmental Psychology, 20(2), 259-280. 
Perry, D. G., Hodges, E. V., \& Egan, S. K. (2001). Determinants of chronic victimization by peers: A review and new model of family influence. In J. Juvonen \& S. Graham (Eds.), Peer harassment in school: The plight of the vulnerable and victimized (pp. 73-104). New York, NY, US: The Guilford Press.

Perry, D. G., Kusel, S. J., \& Perry, L. C. (1988). Victims of peer aggression. Developmental Psychology, 24(6), 807.

Perry, D. C., Williard, J. C., \& Perry, L. C. (1990). Peers' perceptions of the consequences that victimized children provide aggressors. Child Development, 61(5), 1310-1325.

Phillips, B. M., Lonigan, C. J., Driscoll, K., \& Hooe, E. S. (2002). Positive and negative affectivity in children: A multitrait-multimethod investigation. Journal of Clinical Child and Adolescent Psychology, 31(4), 465-479.

Plessen, K. J., Bansal, R., Zhu, H., Whiteman, R., Amat, J., Quackenbush, G. A., Martin, L., Durkin, K., Blair, C., Royal, J., \& Hugdahl, K. (2006). Hippocampus and amygdala morphology in attention-deficit/hyperactivity disorder. Archives of General Psychiatry, 63(7), 795-807.

Polanczyk, G., de Lima, M. S., Horta, B. L., Biederman, J., \& Rohde, L. A. (2007). The worldwide prevalence of ADHD: a systematic review and metaregression analysis. American Journal of Psychiatry, 164(6), 942-948.

Porges, S. W. (1992). Vagal tone: a physiologic marker of stress vulnerability. Pediatrics, 90(3), 498-504.

Porges, S. W. (1995). Orienting in a defensive world: Mammalian modifications of our evolutionary heritage. A polyvagal theory. Psychophysiology, 32(4), 301-318. 
Porges, S. W. (2001). The polyvagal theory: phylogenetic substrates of a social nervous system. International Journal of Psychophysiology, 42(2), 123-146.

Porges, S. W. (2011). The Polyvagal Theory: Neurophysiological Foundations of Emotions, Attachment, Communication, and Self-regulation. New York, NY: Norton.

Porges, S. W., Doussard-Roosevelt, J. A., \& Maiti, A. K. (1994). Vagal tone and the physiological regulation of emotion. Monographs of the Society for Research in Child Development, 59(2-3), 167-186.

Power, T. J., Doherty, B. J., Panichelli-Mindel, S. M., Karustis, J. L., Eiraldi, R. B., Anastopoulos, A. D., \& DuPaul, G. J. (1998). The predictive validity of parent and teacher reports of ADHD symptoms. Journal of Psychopathology and Behavioral Assessment, 20(1), 57-81.

Putallaz, M., Grimes, C. L., Foster, K. J., Kupersmidt, J. B., Coie, J. D., \& Dearing, K. (2007). Overt and relational aggression and victimization: Multiple perspectives within the school setting. Journal of school psychology, 45(5), 523-547.

Redmond, S. M. (2011). Peer victimization among students with specific language impairment, attention-deficit/hyperactivity disorder, and typical development. Language, Speech, and Hearing Services in Schools, 42(4), 520-535.

Reijntjes, A., Kamphuis, J. H., Prinzie, P., Boelen, P. A., Van der Schoot, M., \& Telch, M. J. (2011). Prospective linkages between peer victimization and externalizing problems in children: A meta-analysis. Aggressive Behavior, 37(3), 215-222. 
Reijntjes, A., Kamphuis, J. H., Prinzie, P., \& Telch, M. J. (2010). Peer victimization and internalizing problems in children: A meta-analysis of longitudinal studies. Child Abuse \& Neglect, 34(4), 244-252.

Rhee, S. H., Waldman, I. D., Hay, D. A., \& Levy, F. (1999). Sex differences in genetic and environmental influences on DSM-III-R attention-deficit/hyperactivity disorder. Journal of Abnormal Psychology, 108(1), 24.

Roberts, W., Peters, J. R., Adams, Z. W., Lynam, D. R., \& Milich, R. (2014). Identifying the facets of impulsivity that explain the relation between ADHD symptoms and substance use in a nonclinical sample. Addictive Behaviors, 39(8), 1272-1277.

Röll, J., Koglin, U., \& Petermann, F. (2012). Emotion regulation and childhood aggression: Longitudinal associations. Child Psychiatry \& Human Development, 43(6), 909-923.

Rose, C. A., Monda-Amaya, L. E., \& Espelage, D. L. (2011). Bullying perpetration and victimization in special education: A review of the literature. Remedial and Special Education, 32(2), 114-130.

Rose-Krasnor, L. (1997). The nature of social competence: A theoretical review. Social Development, 6(1), 111-135.

Rosen, P. J., \& Epstein, J. N. (2010). A pilot study of ecological momentary assessment of emotion dysregulation in children. Journal of ADHD and Related Disorders, $1(4), 39-52$.

Rosen, P. J., Epstein, J. N., \& Van Orden, G. (2013). I know it when I quantify it: ecological momentary assessment and recurrence quantification analysis of 
emotion dysregulation in children with ADHD. ADHD Attention Deficit and Hyperactivity Disorders, 5(3), 283-294.

Rosen, P. J., \& Factor, P. I. (2015). Emotional impulsivity and emotional and behavioral difficulties among children with ADHD: An ecological momentary assessment study. Journal of Attention Disorders, 19(9), 779-793.

Rosen, P. J., Leaberry, K. D., Slaughter, K., Fogleman, N. D., Walerius, D. M., Loren, R. E., \& Epstein, J. N. (2018). Managing frustration for children (MFC) group intervention for ADHD: an open trial of a novel group intervention for deficient emotion regulation. Cognitive and Behavioral Practice.

Rosen, P. J., Milich, R., \& Harris, M. J. (2007). Victims of their own cognitions: Implicit social cognitions, emotional distress, and peer victimization. Journal of Applied Developmental Psychology, 28(3), 211-226.

Rosen, P. J., Milich, R., \& Harris, M. J. (2009). Why's everybody always picking on me? Social cognition, emotion regulation, and chronic peer victimization in children. In M. J. Harris (Ed.), Bullying rejection \& peer victimization: A social cognitive neuroscience perspective (pp. 79-100). Springer New York, NY.

Rosen, P. J., Milich, R., \& Harris, M. J. (2012). Dysregulated negative emotional reactivity as a predictor of chronic peer victimization in childhood. Aggressive Behavior, 38(5), 414-427.

Rosen, P. J., Walerius, D. M., Fogleman, N. D., \& Factor, P. I. (2015). The association of emotional lability and emotional and behavioral difficulties among children with and without ADHD. ADHD Attention Deficit and Hyperactivity Disorders, 7(4), 281-294. 
Rothbart, M. K., Ziaie, H., \& O'boyle, C. G. (1992). Self-regulation and emotion in infancy. New Directions for Child and Adolescent Development, 1992(55), 7-23.

Ruggieri, S., Bendixen, M., Gabriel, U., \& Alsaker, F. (2013). Do victimization experiences accentuate reactions to ostracism? An experiment using Cyberball. International Journal of Developmental Science, 7(1), 25-32.

Saarento, S., Kärnä, A., Hodges, E. V., \& Salmivalli, C. (2013). Student-, classroom-, and school-level risk factors for victimization. Journal of School Psychology, $51(3), 421-434$.

Salmon, G., \& West, A. (2000). Physical and mental health issues related to bullying in schools. Current Opinion in Psychiatry, 13(4), 375-380.

Salmivalli, C., \& Isaacs, J. (2005). Prospective relations among victimization, rejection, friendlessness, and children's self-and peer-perceptions. Child Development, 76(6), 1161-1171.

Saudino, K. J. (2005). Rater bias. In B. Everitt \& D. Howell (Eds.), Encyclopedia of statistics in behavioral science (pp. 1716-1717) Chichester, England: Wiley.

Schmidt, M. E., \& Bagwell, C. L. (2007). The protective role of friendships in overtly and relationally victimized boys and girls. Merrill-Palmer Quarterly, 53(3), 439460.

Scholte, R. H., Engels, R. C., Overbeek, G., De Kemp, R. A., \& Haselager, G. J. (2007). Stability in bullying and victimization and its association with social adjustment in childhood and adolescence. Journal of Abnormal Child Psychology, 35(2), 217-228. 
Schwartz, D., Gorman, A. H., Nakamoto, J., \& Toblin, R. L. (2005). Victimization in the Peer Group and Children's Academic Functioning. Journal of Educational Psychology, 97(3), 425.

Schwartz, D., McFadyen-Ketchum, S., Dodge, K. A., Pettit, G. S., \& Bates, J. E. (1999). Early behavior problems as a predictor of later peer group victimization: Moderators and mediators in the pathways of social risk. Journal of Abnormal Child Psychology, 27(3), 191-201.

Schwartz, D., \& Proctor, L. J. (2000). Community violence exposure and children's social adjustment in the school peer group: the mediating roles of emotion regulation and social cognition. Journal of Consulting and Clinical Psychology, 68(4), 670.

Schwartz, D., Proctor, L. J., \& Chien, D. H. (2001). The aggressive victim of bullying: Emotional and behavioral dysregulation as a pathway to victimization by peers. In J. Juvonen \& S. Graham (Eds.), Peer harassment in school: The plight of the vulnerable and victimized (pp. 147-174). New York: Guilford Press.

Sciberras, E., Ohan, J., \& Anderson, V. (2012). Bullying and peer victimisation in adolescent girls with attention-deficit/hyperactivity disorder. Child Psychiatry \& Human Development, 43(2), 254-270.

Scime, M., \& Norvilitis, J. M. (2006). Task performance and response to frustration in children with attention deficit hyperactivity disorder. Psychology in the Schools, 43(3), 377-386.

Seals, D., \& Young, J. (2003). Bullying and victimization: Prevalence and relationship to gender, grade level, ethnicity, self-esteem, and depression. Adolescence, 38(152), 735. 
Semrud-Clikeman, M., Walkowiak, J., Wilkinson, A., \& Butcher, B. (2010). Executive functioning in children with Asperger syndrome, ADHD-combined type, ADHDpredominately inattentive type, and controls. Journal of autism and developmental disorders, 40(8), 1017-1027.

Sentenac, M., Arnaud, C., Gavin, A., Molcho, M., Gabhainn, S. N., \& Godeau, E. (2011). Peer victimization among school-aged children with chronic conditions. Epidemiologic Reviews, 34(1), 120-128.

Seymour, K. E., Chronis-Tuscano, A., Halldorsdottir, T., Stupica, B., Owens, K., \& Sacks, T. (2012). Emotion regulation mediates the relationship between ADHD and depressive symptoms in youth. Journal of Abnormal Child Psychology, 40(4), 595-606.

Shaffer, D., Fisher, P., Lucas, C. P., Dulcan, M. K., \& Schwab-Stone, M. E. (2000). NIMH Diagnostic Interview Schedule for Children Version IV (NIMH DISC-IV): description, differences from previous versions, and reliability of some common diagnoses. Journal of the American Academy of Child \& Adolescent Psychiatry, 39(1), 28-38.

Shaw, P., Eckstrand, K., Sharp, W., Blumenthal, J., Lerch, J. P., Greenstein, D. E. E. A., Clasen, L., Evans, A., Giedd, J.. \& Rapoport, J. L. (2007). Attentiondeficit/hyperactivity disorder is characterized by a delay in cortical maturation. Proceedings of the National Academy of Sciences, 104(49), 19649-19654.

Shaw, P., Malek, M., Watson, B., Sharp, W., Evans, A., \& Greenstein, D. (2012). Development of cortical surface area and gyrification in attentiondeficit/hyperactivity disorder. Biological Psychiatry, 72(3), 191-197. 
Shaw, P., Stringaris, A., Nigg, J., \& Leibenluft, E. (2014). Emotion dysregulation in attention deficit hyperactivity disorder. American Journal of Psychiatry, 171(3), 276-293.

Shea, B., \& Wiener, J. (2003). Social exile: the cycle of peer victimization for boys with ADHD. Canadian Journal of School Psychology, 18(1-2), 55-90.

Shields, A. M., \& Cicchetti, D. (1995, March). The development of an emotion regulation assessment battery: Reliability and validity among at-risk grade-school children. Poster session presented at the biennial meeting of the Society for Research in Child Development. Indianapolis, IN.

Shields, A., \& Cicchetti, D. (1997). Emotion regulation among school-age children: The development and validation of a new criterion Q-sort scale. Developmental Psychology, 33(6), 906.

Shields, A., \& Cicchetti, D. (2001). Parental maltreatment and emotion dysregulation as risk factors for bullying and victimization in middle childhood. Journal of Clinical Child Psychology, 30(3), 349-363.

Sibley, M. H., Campez, M., \& Raiker, J. S. (2019). Reexamining ADHD-related selfreporting problems using polynomial regression. Assessment, 26(2), 305-314.

Siegel, R. S., La Greca, A. M., \& Harrison, H. M. (2009). Peer victimization and social anxiety in adolescents: Prospective and reciprocal relationships. Journal of Youth and Adolescence, 38(8), 1096-1109.

Sjöwall, D., Backman, A., \& Thorell, L. B. (2015). Neuropsychological heterogeneity in preschool ADHD: investigating the interplay between cognitive, affective and 
motivation-based forms of regulation. Journal of abnormal child psychology, 43(4), 669-680.

Sjöwall, D., Roth, L., Lindqvist, S., \& Thorell, L. B. (2013). Multiple deficits in ADHD: executive dysfunction, delay aversion, reaction time variability, and emotional deficits. Journal of Child Psychology and Psychiatry, 54(6), 619-627.

Smith, P. K., Shu, S., \& Madsen, K. (2001). Characteristics of victims of school bullying. In J. Juvonen \& S. Graham (Eds.), Peer harassment in school: The plight of the vulnerable and victimized (pp. 147-174). New York: Guilford Press.

Sobanski, E., Banaschewski, T., Asherson, P., Buitelaar, J., Chen, W., Franke, B., Holtmann, M., Krumm, B., Sergeant, J., Sonuga-Burke, E., Stringaris, A., Taylor, E., Anney, R., Ebstein, R.P., Gill, M., Miranda, A., Mulas, M., Oades, R.D., Roeyers, H., Rotherberger, A., Steinhausen, H., \& Faraone, S.V. (2010). Emotional lability in children and adolescents with attention deficit/hyperactivity disorder (ADHD): clinical correlates and familial prevalence. Journal of Child Psychology and Psychiatry, 51(8), 915-923.

Southam-Gerow, M. A., \& Kendall, P. C. (2002). Emotion regulation and understanding: Implications for child psychopathology and therapy. Clinical Psychology Review, 22(2), 189-222.

Spencer, T. J., Faraone, S. V., Surman, C. B., Petty, C., Clarke, A., Batchelder, H., Wozniak, J., \& Biederman, J. (2011). Toward defining deficient emotional selfregulation in children with attention-deficit/hyperactivity disorder using the Child Behavior Checklist: a controlled study. Postgraduate Medicine, 123(5), 50-59. 
Spriggs, A. L., Iannotti, R. J., Nansel, T. R., \& Haynie, D. L. (2007). Adolescent bullying involvement and perceived family, peer and school relations: Commonalities and differences across race/ethnicity. Journal of Adolescent Health, 41(3), 283-293.

Stadler, C., Feifel, J., Rohrmann, S., Vermeiren, R., \& Poustka, F. (2010). Peervictimization and mental health problems in adolescents: are parental and school support protective?. Child Psychiatry \& Human Development, 41(4), 371-386.

Stegge, H., \& Terwogt, M. M. (2007). Awareness and regulation of emotion in typical and atypical development. In J. J. Gross (Ed.), Handbook of emotion regulation, (pp. 269-286). New York, NY: Guilford Press.

Steinberg, E. A., \& Drabick, D. A. (2015). A developmental psychopathology perspective on ADHD and comorbid conditions: the role of emotion regulation. Child Psychiatry \& Human Development, 46(6), 951-966.

Storch, E. A., \& Ledley, D. R. (2005). Peer victimization and psychosocial adjustment in children: Current knowledge and future directions. Clinical Pediatrics, 44(1), 2938.

Strine, T. W., Lesesne, C. A., Okoro, C. A., McGuire, L. C., Chapman, D. P., Balluz, L. S., \& Mokdad, A. H. (2006). Emotional and behavioral difficulties and impairments in everyday functioning among children with a history of attentiondeficit/hyperactivity disorder. Preventing Chronic Disease, 3(2), A52.

Stringaris, A., \& Goodman, R. (2009). Mood lability and psychopathology in youth. Psychological Medicine, 39(08), 1237-1245.

Sullivan, E. L., Holton, K. F., Nousen, E. K., Barling, A. N., Sullivan, C. A., Propper, C. B., \& Nigg, J. T. (2015). Early identification of ADHD risk via infant 
temperament and emotion regulation: a pilot study. Journal of Child Psychology and Psychiatry, 56(9), 949-957.

Swanson, J. M., McBurnett, K., Christian, D. L., \& Wigal, T. (1995). Stimulant medications and the treatment of children with ADHD. In T. H. Ollendick \& R. J. Prinz (Eds.), Advances in Clinical Child Psychology (pp. 265-322). New York, NY: Plenum Press.

Tapper, K., \& Boulton, M. J. (2004). Sex differences in levels of physical, verbal, and indirect aggression amongst primary school children and their associations with beliefs about aggression. Aggressive behavior, 30(2), 123-145.

Taylor, L. A., Saylor, C., Twyman, K., \& Macias, M. (2010). Adding insult to injury: Bullying experiences of youth with attention deficit hyperactivity disorder. Children's Health Care, 39(1), 59-72.

Terranova, A. M. (2009). Factors that influence children's responses to peer victimization. Child \& Youth Care Forum, 38, 253-271.

Thomas, R., Sanders, S., Doust, J., Beller, E., \& Glasziou, P. (2015). Prevalence of attention-deficit/hyperactivity disorder: a systematic review and meta-analysis. Pediatrics, 135(4), e994-e1001.

Thompson, R. A., \& Goodman, M. (2010). Development of emotion regulation: More than meets the eye. In A. M. Kring \& D. M. Sloan (Eds.), Emotion regulation and psychopathology: A transdiagnostic approach to etiology and treatment (pp. 3858). New York, NY: Guildford Press. 
Thompson, R. A., \& Meyer, S. (2007). Socialization of emotion regulation in the family. In J. J. Gross (Ed.), Handbook of emotion regulation, (pp. 249-268). New York, NY: Guilford Press.

Toblin, R. L., Schwartz, D., Gorman, A. H., \& Abou-ezzeddine, T. (2005). Socialcognitive and behavioral attributes of aggressive victims of bullying. Journal of Applied Developmental Psychology, 26(3), 329-346.

Troop-Gordon, W. (2017). Peer victimization in adolescence: The nature, progression, and consequences of being bullied within a developmental context. Journal of Adolescence, 55, 116-128.

Troop-Gordon, W., \& Ladd, G. W. (2005). Trajectories of peer victimization and perceptions of the self and schoolmates: Precursors to internalizing and externalizing problems. Child Development, 76(5), 1072-1091.

Ttofi, M. M., \& Farrington, D. P. (2011). Effectiveness of school-based programs to reduce bullying: A systematic and meta-analytic review. Journal of Experimental Criminology, 7(1), 27-56.

Turner, H. A., Finkelhor, D., Hamby, S. L., Shattuck, A., \& Ormrod, R. K. (2011). Specifying type and location of peer victimization in a national sample of children and youth. Journal of Youth and Adolescence, 40(8), 1052-1067.

Unnever, J. D., \& Cornell, D. G. (2003). Bullying, self-control, and ADHD. Journal of Interpersonal Violence, 18(2), 129-147.

Van Geel, M., Vedder, P., \& Tanilon, J. (2014). Relationship between peer victimization, cyberbullying, and suicide in children and adolescents: a meta-analysis. JAMA Pediatrics, 168(5), 435-442. 
VanVoorhis, C. W., \& Morgan, B. L. (2007). Understanding power and rules of thumb for determining sample sizes. Tutorials in Quantitative Methods for Psychology, $3(2), 43-50$.

Walcott, C. M., \& Landau, S. (2004). The relation between disinhibition and emotion regulation in boys with attention deficit hyperactivity disorder. Journal of Clinical Child and Adolescent Psychology, 33(4), 772-782.

Wåhlstedt, C., Thorell, L. B., \& Bohlin, G. (2008). ADHD symptoms and executive function impairment: Early predictors of later behavioral problems.

Developmental neuropsychology, 33(2), 160-178.

Walerius, D. M., Reyes, R. A., Rosen, P. J., \& Factor, P. I. (2018). Functional impairment variability in children with ADHD due to emotional impulsivity. Journal of Attention Disorders, 22(8), 724-737.

Watson, D., Clark, L. A., \& Tellegen, A. (1988). Development and validation of brief measures of positive and negative affect: the PANAS scales. Journal of Personality and Social Psychology, 54(6), 1063.

Waxmonsky, J. G., Wymbs, F. A., Pariseau, M. E., Belin, P. J., Waschbusch, D. A., Babocsai, L., Fabiano, G.A., Akinnusi, O.O., Haak, J.L., \& Pelham, W. E. (2013). A novel group therapy for children with ADHD and severe mood dysregulation. Journal of Attention Disorders, 17(6), 527-541.

Wechsler, D. (2011). WASI-II: Wechsler abbreviated scale of intelligence. San Antonio, TX: Psychological Corporation. 
Wehmeier, P. M., Schacht, A., \& Barkley, R. A. (2010). Social and emotional impairment in children and adolescents with ADHD and the impact on quality of life. Journal of Adolescent Health, 46(3), 209-217.

Weissman, M. M., Orvaschel, H., \& Padian, N. (1980). Children's Symptom and Social Functioning Self-Report Scales Comparison of Mothers' and Children's Reports. The Journal of Nervous and Mental Disease, 168(12), 736-740.

Wheeler, J., \& Carlson, C. L. (1994). The social functioning of children with ADD with hyperactivity and ADD without hyperactivity: A comparison of their peer relations and social deficits. Journal of Emotional and Behavioral Disorders, 2(1), 2-12.

Wheeler Maedgen, J., \& Carlson, C. L. (2000). Social functioning and emotional regulation in the attention deficit hyperactivity disorder subtypes. Journal of Clinical Child Psychology, 29(1), 30-42.

Wiener, J., \& Mak, M. (2009). Peer victimization in children with AttentionDeficit/Hyperactivity Disorder. Psychology in the Schools, 46(2), 116-131.

Williams, K. S., Yeager, D. S., Cheung, C. K., \& Choi, W. (2012). Cyberball (version 4.0) [Computer software]. Available from https://cyberball.wikispaces.com.

Wolraich, M. L., Bard, D. E., Neas, B., Doffing, M., \& Beck, L. (2013). The psychometric properties of the Vanderbilt attention-deficit hyperactivity disorder diagnostic teacher rating scale in a community population. Journal of Developmental \& Behavioral Pediatrics, 34(2), 83-93. 
Wolraich, M. L., Feurer, I. D., Hannah, J. N., Baumgaertel, A., \& Pinnock, T. Y. (1998). Obtaining systematic teacher reports of disruptive behavior disorders utilizing DSM-IV. Journal of Abnormal Child Psychology, 26(2), 141-152.

Wolraich, M. L., Lambert, W., Doffing, M. A., Bickman, L., Simmons, T., \& Worley, K. (2003). Psychometric properties of the Vanderbilt ADHD diagnostic parent rating scale in a referred population. Journal of Pediatric Psychology, 28(8), 559-568.

Wolraich, M. L., Lambert, E. W., Bickman, L., Simmons, T., Doffing, M. A., \& Worley, K. A. (2004). Assessing the impact of parent and teacher agreement on diagnosing attention-deficit hyperactivity disorder. Journal of Developmental \& Behavioral Pediatrics, 25(1), 41-47.

Yeager, D. S., Fong, C. J., Lee, H. Y., \& Espelage, D. L. (2015). Declines in efficacy of anti-bullying programs among older adolescents: Theory and a three-level metaanalysis. Journal of Applied Developmental Psychology, 37, 36-51.

Yeager, D. S., Trzesniewski, K. H., \& Dweck, C. S. (2013). An implicit theories of personality intervention reduces adolescent aggression in response to victimization and exclusion. Child Development, 84(3), 970-988.

Yu, C. H. (1977). Exploratory data analysis. Methods, 2, 131-160.

Zadro, L., Hawes, D. J., Iannuzzelli, R. E., Godwin, A., MacNevin, G., Griffiths, B., \& Gonsalkorale, K. (2013). Ostracism and children: A guide to effectively using the cyberball paradigm with a child sample. International Journal of Developmental Science, 7(1), 7-11.

Zadro, L., Williams, K. D., \& Richardson, R. (2004). How low can you go? Ostracism by a computer is sufficient to lower self-reported levels of belonging, control, self- 
esteem, and meaningful existence. Journal of Experimental Social Psychology, $40(4), 560-567$.

Zelazo, P. D., \& Carlson, S. M. (2012). Hot and cool executive function in childhood and adolescence: Development and plasticity. Child Development Perspectives, 6(4), 354-360.

Zelazo, P. D., \& Cunningham, W. A. (2007). Executive Function: Mechanisms Underlying Emotion Regulation. In J. J. Gross (Ed.), Handbook of Emotion Regulation (pp. 135-158). New York, NY: Guilford Press.

Zelazo, P. D., \& Müller, U. (2002). Executive function in typical and atypical development. In U. Goswami (Ed.), Handbook of Childhood Cognitive Development, (pp. 445-469). Oxford, England: Blackwell Publishers.

Zeman, J., Cassano, M., Perry-Parrish, C., \& Stegall, S. (2006). Emotion regulation in children and adolescents. Journal of Developmental \& Behavioral Pediatrics, 27(2), 155-168.

Zeman, J. L., Cassano, M., Suveg, C., \& Shipman, K. (2010). Initial validation of the children's worry management scale. Journal of Child and Family Studies, 19(4), 381-392.

Zeman, J., Shipman, K., \& Penza-Clyve, S. (2001). Development and initial validation of the Children's Sadness Management Scale. Journal of Nonverbal Behavior, 25(3), 187-205.

Zeman, J., Shipman, K., \& Suveg, C. (2002). Anger and sadness regulation: Predictions to internalizing and externalizing symptoms in children. Journal of Clinical Child and Adolescent Psychology, 31(3), 393-398. 


\section{Appendix A.}

\section{Multisource Peer Victimization Inventory (Child)}

Please consider the description contained in each of the following item and rate the extent to which each of these descriptions applies to your experiences with other children in class.

\begin{tabular}{|c|c|c|c|}
\hline Items & NO? & or & \\
\hline (Training Items) ARE THERE TIMES WHEN YOU: & Never & Sometimes & A lot \\
\hline Have ice cream for dessert? & 1 & 2 & 3 \\
\hline Ride the bus to school? & 1 & 2 & 3 \\
\hline Eat breakfast at night-time? & 1 & 2 & 3 \\
\hline \multicolumn{4}{|l|}{$\begin{array}{l}\text { WHEN IN SCHOOL, DOES ANYONE IN YOUR } \\
\text { CLASS: }\end{array}$} \\
\hline 1. Pick on you at school? & 1 & 2 & 3 \\
\hline 2. Play games with you? & 1 & 2 & 3 \\
\hline 3. Tell you you're good at doing things? & 1 & 2 & 3 \\
\hline $\begin{array}{l}\text { 4. Make you feel better if you are having } \\
\text { a bad day? }\end{array}$ & 1 & 2 & 3 \\
\hline 5. Let you play with them? & 1 & 2 & 3 \\
\hline 6. Say mean things to you? & 1 & 2 & 3 \\
\hline $\begin{array}{l}\text { 7. Say bad things about you to other } \\
\text { kids? }\end{array}$ & 1 & 2 & 3 \\
\hline $\begin{array}{l}\text { 8. Share things like stickers, toys, and } \\
\text { games with you? }\end{array}$ & 1 & 2 & 3 \\
\hline 9. Hit or kick you? & 1 & 2 & 3 \\
\hline 10. Miss you if you weren't at school? & 1 & 2 & 3 \\
\hline 11. Cheer you up if you feel sad? & 1 & 2 & 3 \\
\hline $\begin{array}{l}\text { 12. Help you if kids are being mean to } \\
\text { you? }\end{array}$ & 1 & 2 & 3 \\
\hline
\end{tabular}

Note. Copyright 2001 by G. W. Ladd \& B. Kochenderfer-Ladd (peer victimization items $=1,6,7,9$; remaining items $=$ fillers $)$. 


\section{Multisource Peer Victimization Inventory (Parent)}

Please consider the description contained in each of the following item and rate the extent to which each of these descriptions applies to your child's experiences with other children in his or her class.

\begin{tabular}{|c|c|c|c|}
\hline My Child... & Seldom & Sometimes & Often \\
\hline 1. ... is picked on by other children. & 1 & 2 & 3 \\
\hline 2. ... plays games with other children. & 1 & 2 & 3 \\
\hline $\begin{array}{l}\text { 3. ... shares things like stickers, toys, and } \\
\text { games with other children. }\end{array}$ & 1 & 2 & 3 \\
\hline 4. ...is called names by peers. & 1 & 2 & 3 \\
\hline 5. ... acts kindly toward other peers. & 1 & 2 & 3 \\
\hline $\begin{array}{l}\text { 6. ... has peers who say negative things } \\
\text { about him or her to other children. }\end{array}$ & 1 & 2 & 3 \\
\hline 7. ... takes turns with play materials. & 1 & 2 & 3 \\
\hline $\begin{array}{l}\text { 8. ... says negative things about other } \\
\text { children. }\end{array}$ & 1 & 2 & 3 \\
\hline 9. ... is hit or kicked by other children & 1 & 2 & 3 \\
\hline 10. ... plays alone at school & 1 & 2 & 3 \\
\hline 11. ... is teased or made fun of by peers & 1 & 2 & 3 \\
\hline 12. ... likes to paint or draw & 1 & 2 & 3 \\
\hline 13. ... likes to read. & 1 & 2 & 3 \\
\hline
\end{tabular}

Note. Copyright 2001 by G. W. Ladd \& B. Kochenderfer-Ladd (peer victimization items $=1,4,6,9,11$; remaining items $=$ fillers $)$. 


\section{Appendix B.}

Table 1. Sample characteristics.

\begin{tabular}{lc}
\hline Variable & $M \pm S D$ \\
\hline Age & $12.22 \pm 1.71$ \\
Estimated IQ $^{1}$ & $102.49 \pm 14.19$ \\
Sex & $N(\%)$ \\
$\quad$ Male & $32(65.3 \%)$ \\
Female & $17(34.7 \%)$ \\
& \\
Race/Ethnicity & \\
White/Caucasian & $38(77.6 \%)$ \\
Black/African American & $6(12.3 \%)$ \\
Asian & $1(2.0 \%)$ \\
Hispanic/Latino & $1(2.0 \%)$ \\
Multiracial & $3(6.1 \%)$ \\
Income & \\
\$0 - \$75,000 & \\
Above \$75,000 & $21(42.8 \%)$ \\
ADHD Presentation & $28(57.2 \%)$ \\
ADHD-I & \\
ADHD-H/I & $24(49.0 \%)$ \\
ADHD-C & $1(2.0 \%)$ \\
ADHD medication & $24(49.0 \%)$ \\
\hline
\end{tabular}

Note.

$n=49$.

${ }^{1}$ Estimated intelligence quotient (IQ) determined using the Wechsler Abbreviated Scale of Intelligence - Second Edition (WASI-II). 
Table 2. Bivariate correlations for ADHD symptoms, child-report of emotion regulation, parent-report of emotion regulation, and child-report of peer victimization and parent-report of peer victimization.

\begin{tabular}{|c|c|c|c|c|c|}
\hline \multirow[b]{2}{*}{ Measure } & \multicolumn{5}{|c|}{ Correlation $(r)$} \\
\hline & 1 & 2 & 3 & 4 & 5 \\
\hline 1. ADHD symptoms (VAPRS) & -- & & & & \\
\hline 2. Child-report emotion regulation (ERICA) & .12 & -- & & & \\
\hline 3. Parent-report emotion regulation (ERC) & $.53^{* * *}$ & .25 & -- & & \\
\hline 4. Child-report peer victimization (MVPI-C) & $.36^{*}$ & $.32^{*}$ & $.38^{* *}$ & -- & \\
\hline 5. Parent-report peer victimization (MVPI-P) & $.38^{* *}$ & .22 & $.53^{* * *}$ & $.59^{* * *}$ & -- \\
\hline Mean & 1.79 & 2.47 & 2.06 & 1.58 & 1.52 \\
\hline Standard Deviation & .51 & .43 & .39 & .46 & .49 \\
\hline
\end{tabular}

Note.

$n=49,{ }^{*} p<.05 . * * p<.01 . * * * p<.001$. 
Table 3. Hierarchical linear regression: Relation of child-report of emotion regulation and parent-report of emotion regulation to the estimation of child-report of peer victimization.

\begin{tabular}{|c|c|c|c|c|c|c|c|}
\hline Step/variable & $\mathrm{R}^{2}$ & $\Delta \mathrm{R}^{2}$ & AIC & $\mathrm{B}$ & SE B & $t$ & $\beta$ \\
\hline Step 1 & .10 & .10 & -75.69 & & & & \\
\hline Race/ethnicity & & & & -.35 & .15 & $-2.24^{*}$ & -.32 \\
\hline ADHD medication & & & & -.05 & .13 & -.41 & -.06 \\
\hline Step 2 & .17 & .07 & -77.78 & & & & \\
\hline ADHD symptoms (VAPRS) & & & & .28 & .14 & $1.98^{*}$ & .31 \\
\hline Step 3 & .28 & .11 & -80.72 & & & & \\
\hline Child-report emotion regulation (ERICA) & & & & .29 & .15 & $2.01^{*}$ & .27 \\
\hline Parent-report emotion regulation (ERC) & & & & .20 & .19 & 1.09 & .17 \\
\hline Step 4 & .40 & .12 & -85.52 & & & & \\
\hline $\begin{array}{l}\text { Child-report emotion regulation x ADHD symptoms } \\
\text { (ERICA x VAPRS) }\end{array}$ & & & & .13 & .29 & .44 & .06 \\
\hline $\begin{array}{l}\text { Parent-report emotion regulation x ADHD symptoms } \\
\quad(\text { ERC x VAPRS })\end{array}$ & & & & .76 & .29 & $2.62^{*}$ & .37 \\
\hline
\end{tabular}

Note.

For race/ethnicity, 0 = non-White/Caucasian, $1=$ White/Caucasian. For ADHD medication, $0=$ not prescribed medication, $1=$ prescribed medication.

$n=49, * p<.05$. 
Table 4. Hierarchical linear regression: Relation of child-report of emotion regulation and parent-report of emotion regulation to the estimation of parent-report peer victimization.

\begin{tabular}{|c|c|c|c|c|c|c|c|}
\hline Step/variable & $\mathrm{R}^{2}$ & $\Delta \mathrm{R}^{2}$ & AIC & $\mathrm{B}$ & SE B & $t$ & $\beta$ \\
\hline Step 1 & .17 & .17 & -73.15 & & & & \\
\hline Race/ethnicity & & & & -.29 & .16 & -1.80 & -.24 \\
\hline ADHD medication & & & & .31 & .13 & $2.36^{*}$ & .32 \\
\hline Step 2 & .22 & .05 & -73.95 & & & & \\
\hline ADHD symptoms (VAPRS) & & & & .24 & .15 & 1.63 & .25 \\
\hline Step 3 & .39 & .17 & -82.28 & & & & \\
\hline Child-report emotion regulation (ERICA) & & & & .14 & .14 & .99 & .12 \\
\hline Parent-report emotion regulation (ERC) & & & & .56 & .18 & $3.05^{* *}$ & .44 \\
\hline Step 4 & .42 & .03 & -80.51 & & & & \\
\hline $\begin{array}{l}\text { Child-report emotion regulation x ADHD symptoms } \\
\text { (ERICA x VAPRS) }\end{array}$ & & & & -.09 & .30 & -.31 & -.04 \\
\hline $\begin{array}{l}\text { Parent-report emotion regulation x ADHD symptoms } \\
\quad(\text { ERC x VAPRS })\end{array}$ & & & & .42 & .30 & 1.38 & .19 \\
\hline
\end{tabular}

Note.

For race/ethnicity, $0=$ non-White/Caucasian, $1=$ White/Caucasian. For ADHD medication, $0=$ not prescribed medication, $1=$ prescribed medication.

$n=49, * p<.05 . * * p<.01$. 
Table 5. Bivariate correlations for child-report changes in positive affect and child-report changes in negative affect to a discrete peer stressor, and child-report of peer victimization and parent-report of peer victimization.

\begin{tabular}{|c|c|c|c|c|}
\hline \multirow[b]{2}{*}{ Measure } & \multicolumn{4}{|c|}{ Correlation $(r)$} \\
\hline & 1 & 2 & 3 & 4 \\
\hline 1. $\triangle$ Positive Affect (PANAS) & -- & & & \\
\hline 2. $\Delta$ Negative Affect (PANAS) & -.20 & -- & & \\
\hline 3. Child-report peer victimization (MVPI-C) & -.01 & .10 & -- & \\
\hline 4. Parent-report peer victimization (MVPI-C) & .04 & .21 & $.59^{* * *}$ & -- \\
\hline
\end{tabular}

Note.

$n=49, * * * p<.001$.

$\Delta$ Positive Affect $=$ Child-report changes in positive affect from Condition 1 (i.e., basal inclusion condition) to Condition 2 (i.e., exclusion condition) of Cyberball.

$\Delta$ Negative Affect $=$ Child-report changes in negative affect from Condition 1 (i.e., basal inclusion condition) to Condition 2 (i.e., exclusion condition) of Cyberball. 
Table 6. Bivariate correlations for child-report of anger regulation, parent-report of anger regulation, parent-report of sadness regulation, parent-report of worry regulation, and child-report of peer victimization and parent-report of peer victimization.

\begin{tabular}{|c|c|c|c|c|c|c|}
\hline \multirow[b]{2}{*}{ Measure } & \multicolumn{6}{|c|}{ Correlation $(r)$} \\
\hline & 1 & 2 & 3 & 4 & 5 & 6 \\
\hline 1. Child-report anger regulation (CEMS-C) & -- & & & & & \\
\hline 2. Parent-report anger regulation (CEMS-P) & $.54^{* * *}$ & -- & & & & \\
\hline 3. Parent-report sadness regulation (CEMS-P) & $.38^{* *}$ & $.48^{* * *}$ & -- & & & \\
\hline 4. Parent-report worry regulation (CEMS-P) & $.51^{* * *}$ & $.56^{* * *}$ & $.74^{* * *}$ & -- & & \\
\hline 5. Child-report peer victimization (MVPI-C) & $.32^{*}$ & .18 & $.31^{*}$ & .11 & -- & \\
\hline 6. Parent-report peer victimization (MVPI-P) & $.42^{* *}$ & .23 & $.35^{*}$ & .21 & $.59^{* * *}$ & -- \\
\hline Mean & 1.97 & 2.21 & 2.21 & 2.03 & 1.58 & 1.52 \\
\hline Standard Deviation & .39 & .49 & .37 & .40 & .46 & .49 \\
\hline
\end{tabular}

Note.

$n=49,{ }^{*} p<.05 .{ }^{* *} p<.01 . *^{* * *} p<.001$. 
Table 7. Hierarchical linear regression: Relation of child-report of anger regulation to the estimation of child-report of peer victimization.

\begin{tabular}{|c|c|c|c|c|c|c|c|}
\hline Step/variable & $\mathrm{R}^{2}$ & $\Delta \mathrm{R}^{2}$ & AIC & $\mathrm{B}$ & SE B & $t$ & $\beta$ \\
\hline Step 1 & .10 & .10 & -75.69 & & & & \\
\hline Race/ethnicity & & & & -.35 & .15 & $-2.24^{*}$ & -.32 \\
\hline ADHD medication & & & & -.05 & .13 & -.41 & -.06 \\
\hline Step 2 & .18 & .08 & -78.00 & & & & \\
\hline Child-report anger regulation (CEMS-C) & & & & .33 & .16 & $2.03^{*}$ & .28 \\
\hline
\end{tabular}

$\vec{\infty}$ Note.

For race/ethnicity, $0=$ non-White/Caucasian, $1=$ White/Caucasian. For ADHD medication, $0=$ not prescribed medication, $1=$ prescribed medication. $n=49, * p<.05$. 
Table 8. Hierarchical linear regression: Relation of child-report of anger regulation to the estimation of parent-report of peer victimization.

\begin{tabular}{|c|c|c|c|c|c|c|c|}
\hline Step/variable & $\mathrm{R}^{2}$ & $\Delta \mathrm{R}^{2}$ & AIC & $\mathrm{B}$ & SE B & $t$ & $\beta$ \\
\hline Step 1 & .17 & .17 & -73.15 & & & & \\
\hline Race/ethnicity & & & & -.29 & .16 & -1.80 & -.24 \\
\hline ADHD medication & & & & .31 & .13 & $2.36^{*}$ & .32 \\
\hline Step 2 & .33 & .16 & -81.74 & & & & \\
\hline Child-report anger regulation (CEMS-C) & & & & .51 & .16 & $3.30^{* *}$ & .41 \\
\hline
\end{tabular}

$\vec{E}$ Note.

For race/ethnicity, $0=$ non-White/Caucasian, $1=$ White/Caucasian. For ADHD medication, $0=$ not prescribed medication, $1=$ prescribed medication.

$n=49,{ }^{*} p<.05$. ${ }^{*} * p<.01$. 
Table 9. Hierarchical linear regression: Relation of parent-report of sadness regulation to the estimation of child-report of peer victimization.

\begin{tabular}{|c|c|c|c|c|c|c|c|}
\hline Step/variable & $\mathrm{R}^{2}$ & $\Delta \mathrm{R}^{2}$ & AIC & B & SE B & $t$ & $\beta$ \\
\hline Step 1 & .10 & .10 & -75.69 & & & & \\
\hline Race/ethnicity & & & & -.35 & .15 & $-2.24^{*}$ & -.32 \\
\hline ADHD medication & & & & -.05 & .13 & -.41 & -.06 \\
\hline Step 2 & .18 & .08 & -78.29 & & & & \\
\hline Parent-report sadness regulation (CEMS-P) & & & & .37 & .17 & $2.10^{*}$ & .29 \\
\hline
\end{tabular}

$\bar{\sigma} \quad$ Note.

For race/ethnicity, $0=$ non-White/Caucasian, $1=$ White/Caucasian. For ADHD medication, $0=$ not prescribed medication, $1=$ prescribed medication. $n=49, * p<.05$. 
Table 10. Hierarchical linear regression: Relation of parent-report of sadness regulation to the estimation of parent-report of peer victimization.

\begin{tabular}{|c|c|c|c|c|c|c|c|}
\hline Step/variable & $\mathrm{R}^{2}$ & $\Delta \mathrm{R}^{2}$ & AIC & B & SE B & $t$ & $\beta$ \\
\hline Step 1 & .17 & .17 & -73.15 & & & & \\
\hline Race/ethnicity & & & & -.29 & .16 & -1.80 & -.24 \\
\hline ADHD medication & & & & .31 & .13 & $2.36^{*}$ & .32 \\
\hline Step 2 & .24 & .07 & -75.70 & & & & \\
\hline Parent-report sadness regulation (CEMS-P) & & & & .37 & .18 & $2.09^{*}$ & .28 \\
\hline
\end{tabular}

$\bar{\hookrightarrow} \quad$ Note.

For race/ethnicity, $0=$ non-White/Caucasian, $1=$ White/Caucasian. For ADHD medication, $0=$ not prescribed medication, $1=$ prescribed medication. $n=49, * p<.05$. 


\section{Appendix C.}

Figure 1. Relation of parent-report of emotion regulation and child-report of peer victimization moderated by ADHD Symptoms.

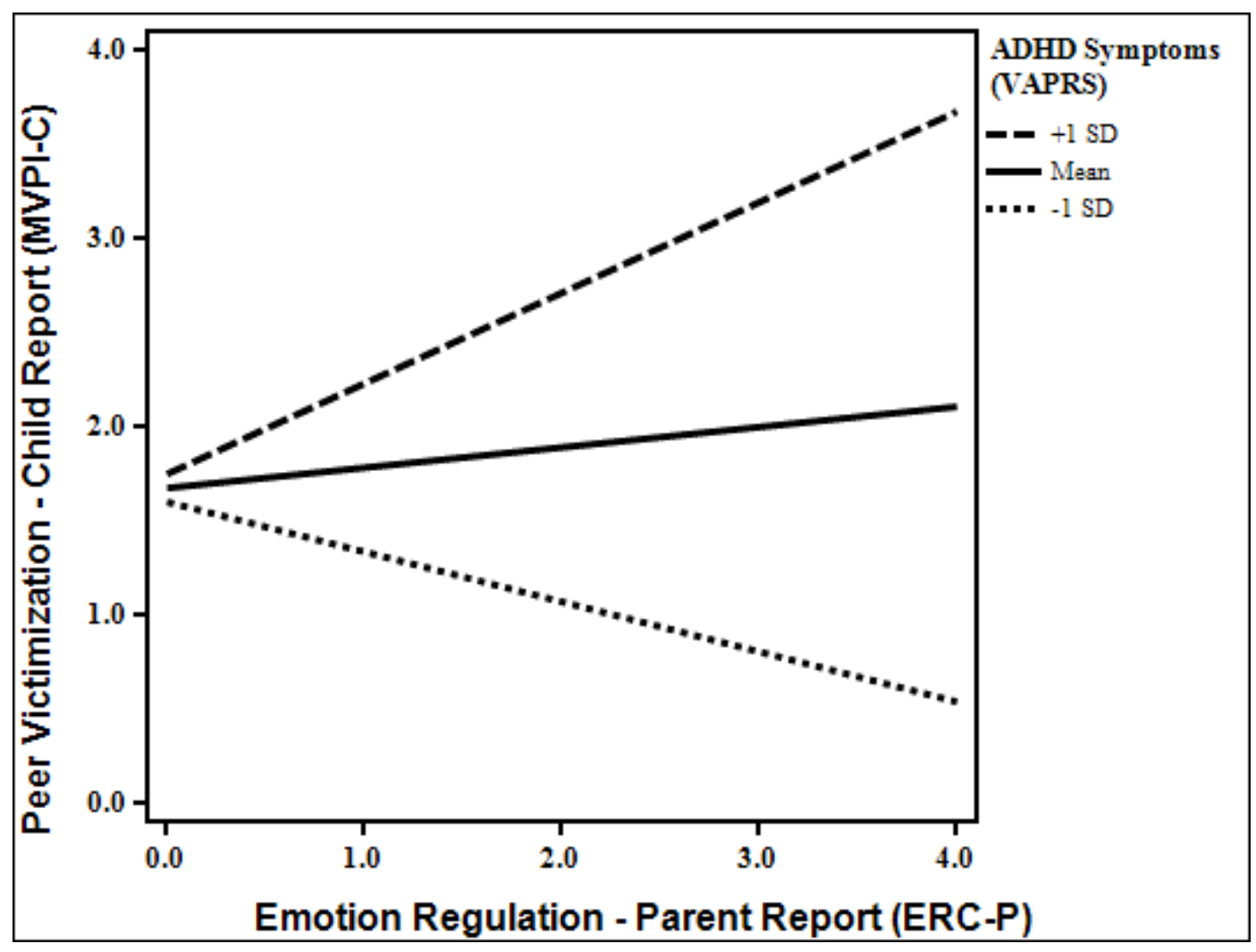




\section{Nicholas D. Fogleman, M.S.}

\author{
Cincinnati Children's Hospital Medical Center \\ Division of Behavioral Medicine \& Clinical Psychology \\ 3333 Burnet Avenue, MLC 3015 \\ Cincinnati, OH 45229-3026 \\ Phone: 513.803-0068 \\ Email: nicholas.fogleman@cchmc.org
}

\author{
University of Louisville \\ Department of Psychological \& Brain Sci. \\ Life Sciences Building, Room 317 \\ Louisville, KY 40292 \\ Phone: 402.305.3800 \\ Email: nicholas.fogleman@ louisville.edu
}

\section{EDUCATION AND TRAINING}

$\begin{array}{ll}2018-\text { Present } & \text { Cincinnati Children's Hospital Medical Center, Cincinnati, OH } \\ & \text { O'Grady Resident in Behavioral Medicine and Clinical Psychology } \\ & \text { Training Directors: Shanna M. Guilfoyle, Ph.D. \& Aaron J. Vaughn, Ph.D. } \\ & \text { Research Mentor: Stephen P. Becker, Ph.D. } \\ & \text { University of Louisville, Louisville, KY } \\ & \text { Doctoral Candidate, Clinical Psychology } \\ & \text { Dissertation title: Emotion regulation is associated with peer victimization } \\ & \text { among children with ADHD } \\ & \text { Chair: Paul J. Rosen, Ph.D. } \\ & \text { University of Louisville, Louisville, KY } \\ & \text { Master of Science, Clinical Psychology } \\ & \text { Advisor: Paul J. Rosen, Ph.D. } \\ & \text { National Institutes of Health, Bethesda, MD } \\ & \text { Technical Intramural Research Training Award } \\ & \text { Mentor: José A. Apud, M.D., Ph.D. } \\ & \text { Teach for America, Warrenton, NC } \\ & \text { Eastern North Carolina Corps Member } \\ 2012-2016 & \text { Loyola University Chicago, Chicago, IL } \\ \text { Bachelor of Science in Psychology with Honors, Minor in Biology } & \end{array}$

\section{AWARDS AND GRANTS}

American Professional Society of ADHD and Related Disorders Travel Award Graduate Student Council Research Grant, University of Louisville Graduate Network in Arts and Sciences Grant, University of Louisville Graduate Network in Arts and Sciences Grant, University of Louisville Operation Immersion Scholarship, Kentucky National Guard Graduate Student Council Travel Scholarship, University of Louisville 


$\begin{array}{ll}2015 & \text { Graduate Network in Arts and Sciences Grant, University of Louisville } \\ 2014 & \text { Graduate Student Council Travel Scholarship, University of Louisville } \\ 2014 & \text { Graduate Student Union Grant, University of Louisville } \\ 2008 & \text { Provost Fellowship, Loyola University Chicago } \\ 2007 & \text { Summer Undergraduate Research Fellowship, University of Nebraska Medical } \\ & \text { Center }\end{array}$

\section{ACADEMIC AND PROFESSIONAL HONORS}

2017

$2014-2016$

2009

2009

2008

2008

$2008-2009$

$2008-2009$

$2007-2009$

$2007-2009$

$2007-2009$
Preliminary Exam: Passed with Distinction, University of Louisville

University Fellowship, University of Louisville

Damen Award, Loyola University Chicago

Greek Member of the Year, Loyola University Chicago

Greek Scholar of the Year, Loyola University Chicago

Magis Award, Loyola University Chicago

National Residence Hall Honorary, Loyola University Chicago

Tri-Beta National Honor Society, Loyola University Chicago

Psi Chi National Honor Society, Loyola University Chicago

W. Emil Foreman Scholarship, Sigma Alpha Epsilon

Academic Scholarship, Loyola University Chicago

\section{EDITORIAL ACTIVITY}

\section{Ad Hoc Invited Journal Reviews}

2017

2017

2016
European Child \& Adolescent Psychiatry [1]

Congenital Heart Disease [1]

Journal of Clinical Child and Adolescent Psychology [1]

\section{PEER-REVIEWED PUBLICATIONS}

1. Leaberry, K.D., Rosen, P.J., Slaughter, K.E., Reese, J.S., Fogleman, N.D. (2019). Temperamental negative affect, emotion-specific regulation, and concurrent internalizing and externalizing pathology among children with ADHD. ADHD Attention Deficit and Hyperactivity Disorders. DOI:10.1007/s12402-019-00294-8

2. Knight, L. K., Stoica, T., Fogleman, N. D., Depue, B. E. (2019). Convergent neural correlates of empathy and anxiety during socioemotional processing. Frontiers in Human Neuroscience.

DOI.10.3389/fnhum.2019.00094

3. Faul, L., Fogleman, N.D., Mattingly, K., Depue, B.E. (2019). Inhibitory control mediates a negative relationship between body mass index and intelligence: A neurocognitive investigation. Cognitive, Affective, and Behavioral Neuroscience. DOI: 10.3758/s13415-019-00695-2.

4. Fogleman, N.D., Slaughter, K.E., Rosen, P.J., Leaberry, K.D., Walerius, D.M. (2018). Emotion regulation accounts for the relation between ADHD and peer victimization. Journal of Child and Family Studies. DOI: 10.1007/s10826-018-1297-8

5. Rosen, P.J., Leaberry, K.D., Slaughter, K.E., Fogleman, N.D., Walerius, D.M., Loren, R.E.A., Epstein, J.N. (2018). Managing Frustration for Children (MFC) group intervention for ADHD: An open trial of a novel group intervention for emotion regulation difficulties. Cognitive and Behavioral Practice. DOI: 10.1016/j.cbpra.2018.04.002 
6. Fogleman, N.D., Leaberry, K.D., Rosen, P.J., Walerius, D.M., Slaughter, K.E. (2018). How do children with and without ADHD talk about frustration?: Use of a novel emotion narrative recall task. Attention Deficit and Hyperactivity Disorders ADHD. DOI: 10.1007/s12402-018-0255-z

7. Holbein, C., Fogleman, N.D., Hommel, K., Apers, S., Moons, P., Luyckx, K., Kovacs, A., Morrison, S., Tomlin, M., Gosney, K., Sluman, M. A., Johansson, B., Enomoto, J., Wang, K., Subramanyan, R., Budts, W., Daniels, C., Soufi, A., Eriksen, K., Thomet, C., Callus, E., Fernandes, S.M., Caruana, M., Cook, S.C., White, K., Khairy, P., Kutty, S., Veldtman, G. (2017). A multinational observational investigation of illness perceptions and quality of life among patients with a Fontan circulation. Congenital Heart Disease. DOI: 10.1111/chd.12583

8. Leaberry, K.D., Rosen, P.J., Fogleman, N.D., Walerius, D.M., Slaughter, K.E. (2018) Physiological emotion regulation in children with ADHD with and without comorbid internalizing disorders: a preliminary study. Journal of Psychopathology and Behavioral Assessment. DOI: 10.1007/s10862018-9644-z

9. Fogleman, N.D., Leaberry, K.D., Rosen, P.J., Walerius, D.M., Slaughter, K.E. (2018) Relation between internalizing behaviors, externalizing behaviors, and peer victimization among children with and without ADHD. ADHD Attention Deficit and Hyperactivity Disorders. DOI: 10.1007/s12402018-0248-y

10. Gramszlo, C., Fogleman, N.D., Rosen, P. J., \& Woodruff-Borden, J. (2017). Intolerance of uncertainty in children with attention-deficit/hyperactivity disorder. ADHD Attention Deficit and Hyperactivity Disorders. DOI: 10.1007/s12402-017-0244-7

11. Fogleman, N.D., Apers, S., Moons, P., Morrison, S., Tomlin, M., Gosney, K., Sluman, M.A., Johansson, B., Enomoto, J., Wang, K., Subramanyan, R., Luyckx, K., Budts, W., Daniels, C., Kovacs, A., Soufi, A., Eriksen, K., Thomet, C., Callus, E., Fernandes, S.M., Caruana, M., Cook, S.C., White, K., Khairy, P., Kutty, S., Veldtman, G. (2017). Regional variation in quality of life in patients with a Fontan operation - A multinational perspective. American Heart Journal. DOI: 10.1016/j.ahj.2017.07.019

12. Fogleman, N.D., Naaz, F., Knight, L.K., Stoica, T., Patton, S.C., Olson-Madden, J.H., Barnhart, M.C., Hostetter, T.A., Forster, J., Brenner, L.A., Banich, M.T., Depue, B.E. (2017). Reduced Lateral Prefrontal Cortical Volume is associated with Performance on the Modified Iowa Gambling Task: A Surface Based Morphometric Analysis of Previously Deployed Veterans with Post-traumatic Stress Disorder (PTSD), Mild Traumatic Brain Injury (mTBI), or Co-occurring PTSD/mTBI. Psychiatry Research: Neuroimaging. DOI: 10.1016/j.pscychresns.2017.06.014

13. Leaberry, K.D., Rosen, P.J., Fogleman, N.D., Walerius, D.M., Slaughter, K.E. (2017). Comorbid Internalizing and Externalizing Disorders Predict Lability of Negative Emotions Among Children with ADHD. Journal of Attention Disorders. DOI: 10.1177/1087054717734647

14. Fogleman, N.D., Walerius, D.M., Rosen, P.J., Leaberry, K.D. (2016). Peer victimization linked to negative affect in children with and without ADHD. Journal of Applied Developmental Psychology. DOI: 10.1016/j.appdev.2016.05.003

15. Walerius, D.M., Fogleman, N.D., Rosen, P.J. (2016). The role of ADHD and negative emotional lability in predicting changes in parenting daily hassles. Journal of Child and Family Studies. DOI: $10.1007 / \mathrm{s} 10826-016-0381-1$

16. Rosen, P.J., Walerius, D.M., Fogleman, N.D., \& Factor, P.I. (2015). The association of emotional lability and emotional and behavioral difficulties among children with and without ADHD. ADHD Attention Deficit and Hyperactivity Disorders. DOI: 10.1007/s12402-015-0175-0 


\section{PEER-REVIEWED MANUSCRIPTS UNDER REVIEW}

1. Slaughter, K.E., Fogleman, N.D., Rosen, P.J., Leaberry, K.D. (under review). Reactive and proactive aggression in children with emotional lability and Attention-Deficit/Hyperactivity Disorder. Social Development.

2. Fogleman, N.D., McQuade, J.D., Mehari, K., Becker, S.P. (under review). In-person and cyber victimization among adolescents with ADHD: differential associations with anxiety, depression, and self-esteem?

\section{INVITED BOOK CHAPTERS AND NON-REFERRED PUBLICATIONS}

1. Becker, S.P., Fogleman, N.D. (in press). Psychiatric co-occurrence in adolescents with ADHD. To appear in S.P. Becker (Ed.), ADHD in adolescence: Development, assessment, and treatment. New York: Guilford Press.

2. Leaberry, K.D., Walerius, D.M., Rosen, P.J., Fogleman, N.D. (2017). Emotional Lability. In: ZeiglerHill V., Shackelford T. (Eds.), Encyclopedia of Personality and Individual Differences. Springer, Cham. DOI: 10.1007/978-3-319-28099-8_510-1

\section{CONFERENCE PRESENTATIONS}

1. Marsh, N. P., Fogleman, N. D., Langberg, J. M., \& Becker, S. P. (November, 2019). Too connected to being connected? Social media emotional investment moderates the association between cybervictimization and internalizing symptoms in adolescents with and without ADHD. Association for Behavioral and Cognitive Therapies, Atlanta, Georgia.

2. Fogleman, N. D., McQuade, J. D., Mehari, K. R., Becker, S. P. (March, 2019). In-person and cyber victimization among adolescents with ADHD: differential associations with anxiety, depression, and self-esteem? Society for Research in Child Development, Baltimore, Maryland.

3. Leaberry, K.D., Slaughter, K.E., Fogleman, N.D., Rosen, P.J. (November, 2018). Temperamental negative affect, anger dysregulation, and externalizing problems in children with ADHD. Association for Behavioral and Cognitive Therapies, Washington D.C.

4. Daugherty, M., Slaughter, K.E., Fogleman, N.D., Rosen, P.J., Leaberry, K.D. (April, 2018). Social Impairment and anger regulation among children with ADHD. Midwestern Psychological Association, Chicago, IL.

5. Knight, L., Stoica, T., Naaz, F., Fogleman, N.D., Depue, B.E. (March, 2018). Common Neural Correlates of Empathy and Worry when Processing Fearful Humans Faces. Cognitive Neuroscience Society, Boston, MA.

6. Fogleman, N.D., Leaberry, K.D., Slaughter, K.E., Walerius, D.M., Rosen, P.J. (March, 2018). Emotion regulation accounts for the relation between attention-deficit/hyperactivity disorder and peer victimization. University of Louisville Graduate Student Regional Research Conference, Louisville, KY.

7. Fogleman, N.D., Slaughter, K.E., Leaberry, K.D., Walerius, D.M., Rosen, P.J. (November, 2017). Relation between emotion recognition and peer victimization among children with ADHD. Association for Behavioral and Cognitive Therapies, San Diego, California. 
8. Fogleman, N.D., Leaberry, K.D., Slaughter, K.E., Walerius, D.M., Rosen, P.J. (November, 2017) Emotion dysregulation linked to peer victimization among children with ADHD. Association for Behavioral and Cognitive Therapies, San Diego, California.

9. Fogleman, N.D., Gramszlo, C., Rosen, P.J., Woodruff-Borden, J. (November, 2017). Relation between intolerance of uncertainty and emotion regulation in children with ADHD. Association for Behavioral and Cognitive Therapies, San Diego, California.

10. Gramszlo, C., Fogleman, N.D., Rosen, P.J., Woodruff-Borden, J. (November, 2017). Intolerance of Uncertainty in Children with Anxiety Disorders and Attention-Deficit/Hyperactivity Disorder. Association for Behavioral and Cognitive Therapies, San Diego, California.

11. Leaberry, K.D., Fogleman, N.D., Slaughter, K.E., Walerius, D.M., Rosen, P.J. (November, 2017). Comorbidity predicts anger dysregulation among children with ADHD. Association for Behavioral and Cognitive Therapies, San Diego, California.

12. Slaughter, K.E., Fogleman, N.D., Leaberry, K.D., Walerius, D.M., Rosen, P.J. (November, 2017). Reactive and proactive aggression in children with emotional lability and ADHD. Association for Behavioral and Cognitive Therapies, San Diego, California.

13. Rosen, P.J., Leaberry, K.D., Walerius, D.M., Fogleman, N.D., Slaughter, K.E. (April, 2017). Physiological emotion dysregulation among children with ADHD is predicted by comorbid internalizing disorders. Society for Research in Child Development, Austin, Texas.

14. Leaberry, K.D., Fogleman, N.D., Walerius, D.M., Slaughter, K.E., Rosen, P.J. (April, 2017). Comorbid internalizing and externalizing disorders predict negative emotional lability in children with ADHD. Society for Research in Child Development, Austin, Texas.

15. Slaughter, K.E., Leaberry, K.D., Fogleman, N.D., Walerius, D.M., Rosen, P.J. (April, 2017). Parentchild agreement on children's emotion management style. Society for Research in Child Development, Austin, Texas.

16. Fogleman, N.D., Walerius, D.M., Leaberry, K.D., Rosen, P.J. (November, 2016). Negative affect predicts aggression in children with and without ADHD. Association for Behavioral and Cognitive Therapies, New York, New York.

17. Fogleman, N.D., Purcell, L.A., Leaberry, K.D., Walerius, D.M., Rosen, P.J. (November, 2016). The influence of internalizing and externalizing behaviors on peer difficulties in children with and without ADHD. Association for Behavioral and Cognitive Therapies, New York, New York.

18. Walerius, D.M., Fogleman, N.D., Leaberry, K.D., Rosen, P.J. (November, 2016). The Role of ADHD and Emotional Lability in Predicting Changes in Parenting Stress at Six Month Follow-Up. Association for Behavioral and Cognitive Therapies, New York, New York.

19. Walerius, D.M., Leaberry, K.D., Fogleman, N.D., Rosen, P.J. (November, 2016). Functional Impairment and Dimensions of Parenting Stress among Children with and without ADHD. Association for Behavioral and Cognitive Therapies, New York, New York.

20. Leaberry, K.D., Walerius, D.M., Fogleman, N.D., Rosen, P.J. (November, 2016). Comorbid Internalizing Disorders in Children with ADHD Predict Variability in Negative Affect. Association for Behavioral and Cognitive Therapies, New York, New York.

21. Fogleman, N.D., Walerius, D.M., Leaberry, K.D., Rosen, P.J. (May, 2016). Internalizing behaviors predict peer-victimization in children with and without Attention-Deficit/Hyperactivity Disorder. Midwestern Psychological Association, Chicago, IL. 
22. Walerius, D.M., Fogleman, N.D., Leaberry, K.D., Rosen, P.J. (May, 2016). The role of ADHD and negative emotional lability in predicting changes in parenting daily hassles. Midwestern Psychological Association, Chicago, IL.

23. Purcell, L.A., Fogleman, N.D., Walerius, D.M., Leaberry, K.D., Rosen, P.J. (April, 2016). Internalizing and externalizing behaviors are linked to parenting stress in children with and without Attention-Deficit/Hyperactivity Disorder. Kentucky Psychological Association, Georgetown, KY. * Indicates shared contribution and authorship.

24. Koehl, S.M., Fogleman, N.D., Leaberry, K.D., Walerius, D.M., Rosen, P.J. (April, 2016). Parentperceived emotion recognition deficits in children with comorbid ADHD/ODD. Kentucky Psychological Association, Georgetown, KY. * Indicates shared contribution and authorship.

25. Fogleman, N.D., Walerius, D.M., Factor, P.I., Rosen, P.J. (November, 2015). Negative affect is linked to peer victimization in children with and without ADHD. Association for Behavioral and Cognitive Therapies, Chicago, IL.

26. Purcell, L.A., Fogleman, N.D., Rosen, P.J. (November, 2015). Internalizing and externalizing behaviors are linked to peer difficulties in children with Attention-Deficit/Hyperactivity Disorder. Association for Behavioral and Cognitive Therapies, ADHD SIG Poster Exposition, Chicago, IL.

27. Leaberry, K.D., Fogleman, N.D., Walerius, D.M., Rosen, P.J. (November, 2015). Differences in levels of frustration following a narrative task are related to ADHD. Association for Behavioral and Cognitive Therapies, ADHD SIG Poster Exposition, Chicago, IL.

28. Fogleman, N.D., Patton, S.C., Stoica, T., Knight, L.K. Naaz, F., Depue, B.E. (October, 2015). Surface-based morphometry in lateral prefrontal cortex and lateral inferior parietal cortex is associated with impulse inhibition and attention in combat deployed veterans with mild traumatic brain injury. Research!Louisville, Louisville, KY.

29. Knight, L.K., Stoica, T., Fogleman, N.D., Patton, S.C., Naaz, F., Depue, B.E. (October, 2015). Compromised frontoparietal network in post-traumatic stress disorder veterans relates to poorer performance during risky decision-making. Research!Louisville, Louisville, KY.

30. Fogleman, N.D., Stoica, T., Knight, L.K., Patton, S.C., Naaz, F., Depue, B.E. (October, 2015). Surface-based morphometry in lateral prefrontal cortex is associated with reward processing and impulse inhibition in combat deployed veterans with post-traumatic stress disorder. Society for Neuroscience Annual Meeting, Chicago, IL.

31. Fogleman, N.D., Naaz, F., Depue, B.E. (April, 2015). Decreased volume of bilateral prefrontal cortex predicts increased risky decision making in post-traumatic stress disorder combat veterans. $25^{\text {th }}$ Annual Louisville Neuroscience Day, Louisville, KY.

32. Fogleman, N.D., Factor, P.I., Walerius, D.M., Rosen, P.J. (November, 2014). Negative affect is linked to peer victimization in children with ADHD. Association for Behavioral and Cognitive Therapies ADHD SIG Poster Exposition, Philadelphia, PA.

33. Fogleman, N.D., Sternberg, L., Callicott, J.H., Das, S., Rasetti, R., Kolachana, B., Berman, K.F., Weinberger, D.R., Mattay, V.S., Apud, J.A. (November, 2014). Tolcapone modulates neural circuits underlying emotion processing in patients with schizophrenia and healthy volunteers. Society for Neuroscience Annual Meeting, Washington D.C.

34. Pratt, D.N., Fogleman, N.D., Berman, K.F., Dickinson, D.D., Apud, J.A. (September, 2014). Interactive effects of tolcapone and COMT on anxiety in healthy volunteers. National Institutes of Health Research Festival, Bethesda, MD. 
35. Fogleman, N.D., Li, C.J., Rasetti, R., Kolachana, B., Chen, Q., Berman, K.F., Weinberger, D.R., Mattay, V.S., Apud, J.A. (November, 2013). Interactive effects of tolcapone and COMT val158met polymorphism on neural circuits underlying emotion processing. Society for Neuroscience Annual Meeting, San Diego, CA.

36. Sharma, R., Fogleman, N.D., Apud, J.A. (July, 2013). Interactive effects of tolcapone and COMT val108/158met polymorphism on mood and anxiety. National Institutes of Health Summer Poster Day, Bethesda, MD.

37. Li, C.J., Rasetti, R. Chen, Q., Fogleman, N.D., Berman, K.F., Apud, J.A., Weinberger, D.R., Mattay, V.S. (June, 2013). Tolcapone modulates functional connectivity of prefrontal and cingulate cortices during response inhibition in patients with schizophrenia. Organization for Human Brain Mapping Annual Meeting. Seattle, WA.

38. Fogleman, N.D., Li, C.J., Rasetti, R., Kolachana, B., Chen, Q., Berman, K.F., Weinberger, D.R., Mattay, V.S., Apud, J.A. (May, 2013). Interactive effects of tolcapone and COMT val158met polymorphism on neural circuits underlying emotion processing. National Institutes of Health Research Festival, Bethesda, MD.

39. Fogleman, N.D., Li, C.J., Rasetti, R., Kolachana, B., Chen, Q., Berman, K.F., Weinberger, D.R., Mattay, V.S., Apud, J.A. (April, 2013). Modulatory effects of tolcapone on neural circuits underlying emotion processing in healthy volunteers. National Institutes of Health Postbac Poster Day, Bethesda, MD.

40. Apud, J.A., Rasetti, R., Li, C.J., Hochheiser, J., Chen, Q., Cheng, X., Fogleman, N.D., Callicott, J.H., Berman, K.F., Weinberger, D.R. (December, 2012). Modafinil modulates activation and functional coupling of the prefrontal cortex during working memory in patients with schizophrenia. American College of Neuropsychopharmacology Annual Meeting. Hollywood, FL.

41. Fogleman, N.D., Burrow, A.L. (May, 2009). A Longitudinal study on the varying effects of parental divorce on child development and factors which contribute to protect children from negative outcomes. Loyola University Chicago Research Symposium, Chicago, IL; Loyola University Chicago Honor's Psychology Symposium, Chicago, IL.

42. Fogleman, N.D., Rennard, S. (August, 2007). Determination of chronic obstructive pulmonary disease (COPD) and smoking status using the electronic nose. University of Nebraska Medical Center Summer Poster Session, Omaha, NE.

\title{
RESEARCH EXPERIENCE
}

\author{
2018 - Present Cincinnati Children's Hospital Medical Center, Cincinnati, OH \\ Cincinnati Children's Center for ADHD \\ PI: Stephen P. Becker, Ph.D. \\ Clinical Psychology Resident \\ - Administer and score Children's Interview for Psychiatric Syndromes (ChIPS) \\ across a number of NIH- and IES-funded studies (ages 7-15); complete diagnostic \\ evaluations \\ - Independent research project examining the relation between social and emotional \\ functioning among adolescents with ADHD \\ 2014 - Present $\quad$ University of Louisville Research on Attention-Deficit/Hyperactivity Disorder \\ (ADHD) and Emotion Regulation (RACER) Lab, Louisville, KY \\ PI: Paul J. Rosen, Ph.D. \\ Graduate Student Research Assistant \\ - Coordinate research protocols investigating emotion regulation and social
}


$2014-2018$

$2016-2017$

$2012-2014$

$2008-2009$ functioning among children with and without ADHD; collect participant data using questionnaires, Ecological Momentary Assessment (EMA), and electrocardiography (ECG)

- Administer and score Diagnostic Interview Schedule for Children (DISC), Wechsler Abbreviated Scale of Intelligence (WASI), Wide Range Achievement Test (WRAT) and Wechsler Intelligence Scale for Children (WISC)

- Write diagnostic evaluations for children based on data obtained from structured interviews, questionnaires and assessments; provide feedback to parents

- Designed IRB-approved research protocols investigating emotion recognition, emotion regulation and peer victimization among children with ADHD

University of Louisville NeuroImaging Laboratory of Cognitive, Affective and Motoric Processes (NILCAMP), Louisville, KY

PI: Brendan Depue, Ph.D.

Graduate Student Research Assistant

- Investigated neural mechanisms underlying cognitive and emotional processing in typical and clinical populations using structural and functional magnetic resonance imaging (MRI) techniques

- Participated in weekly journal club discussing neuroanatomical structures and neural mechanisms involved in a variety of cognitive and emotional processes

\section{Cincinnati Children's Hospital Medical Center, Cincinnati, OH Behavioral Medicine and Clinical Psychology PI: Gruschen R. Veldtman, FRCP, MBChB Graduate Student Research Assistant}

- Analyzed data from the Assessment of Patterns of Patient-Reported Outcomes in Adults with Congenital Heart disease - International Study (APPROACH-IS)

- Collaborated with researchers across 15 countries to investigate how patients with a Fontan circulation differ relative to patients with simple congenital heart defects

- Investigated regional variation in quality of life outcomes in a large multinational sample of patients with a Fontan circulation, and investigated the relation between illness perceptions and quality of life outcomes among patients with a Fontan circulation and patients with atrial and ventricular septal defects

\section{National Institutes of Health (NIH), National Institute of Mental Health (NIMH)} and Clinical Brain Disorders Branch (CBDB), Bethesda, MD

PI: José A. Apud, M.D., Ph.D.

Technical Intramural Research Training Award (IRTA)

- Coordinated Tolcapone (ClinicalTrials.gov Identifier: NCT00044083) and Modafinil (ClinicalTrials.gov Identifier: NCT00057707) protocols (doubleblinded, placebo-controlled counter-balanced trails) investigating interactive effects of medications and catechol-O-methyltransferase (COMT) Val108/158Met polymorphism on cognitive functioning in patients with schizophrenia

- $\quad$ Recruited healthy volunteers; developed weekly schedules and meeting agendas for colleagues; led weekly journal club at department meetings

- $\quad$ Processed and stored genetic samples for drug metabolic analysis; input data and maintained research databases; presented findings at department meetings

- Examined interactive effects of Tolcapone and COMT Val108/158Met polymorphism on neural circuits underlying emotion processing

Loyola University Chicago Provost Fellowship, Chicago, IL PI: Anthony Burrow, Ph.D.

Research Fellow, Psychology Honors Research Thesis 
- Applied for and received grant (i.e. Provost Fellowship) from Loyola University Chicago to purchase longitudinal data from The National Longitudinal Study of Adolescent to Adult Health (Add Health)

- Designed IRB-approved research protocol, completed written thesis and presented at multiple Loyola University Chicago symposia

- Explored effects of parental divorce on child development and factors that contribute to protecting children from experiencing negative outcomes

$2007-2008 \quad$ University of Nebraska Medical Center (UNMC), Omaha, NE PI: Stephen Rennard, M.D.

Intern, Summer Undergraduate Research Fellow; Pulmonary Department

- Conducted a summer clinical research project on identifying the scent of Chronic Obstructive Pulmonary Disease (COPD)

- Recruited more than 50 study volunteers from UNMC smoking kiosks, collected subject samples, calibrated Cyranose Electronic Nose and analyzed chemical compounds present in exhaled breath

- Computed statistical algorithms to quantify scent, interpreted data and presented findings at UNMC Summer Undergraduate Research Symposium

\section{RESEARCH SKILLS}

Data Collection: Diagnostic Interview; Cognitive Assessment; Ecological Momentary Assessment; Electrocardiogram; Magnetic Resonance Imaging; Questionnaire

Data Analysis: $\quad$ AMOS; Free Surfer; FMRIB Software Library (familiar); PROCESS; SPSS; Statistica

\section{CLINICAL EXPERIENCE}

2018 - Present $\quad$ Cincinnati Children's Hospital Medical Center, Cincinnati, OH

Behavioral Medicine and Clinical Psychology: Center for ADHD

Supervisors: Richard E. A. Loren, Ph.D. \& Aaron Vaughn, Ph.D.

Clinical Psychology Resident

- Conduct diagnostic interviews, prepare integrative reports including history of academic, behavioral, emotional and social functioning for children suspected of having $\mathrm{ADHD}$, and provide clinical recommendations

- Administer individual treatment for children/adolescents with ADHD and cooccurring internalizing and externalizing disorders

- Co-lead a behavioral parent training group for caregivers of children with ADHD; will co-lead a managing frustration group for children with ADHD in the Spring of 2019

2018 - Present $\quad$ Cincinnati Children's Hospital Medical Center, Cincinnati, OH Behavioral Medicine and Clinical Psychology: Neurology Clinic Supervisor: Shanna Guilfoyle, Ph.D.

Clinical Psychology Resident

- Conduct brief psychological assessments and provide individualized interventions to address psychosocial concerns for children, adolescents and young adults diagnosed with epilepsy

- Provide services in the context of a multidisciplinary team of pediatric nurse practitioners, neurologists and registered nurses

2018 - Present Cincinnati Children's Hospital Medical Center, Cincinnati, OH Behavioral Medicine and Clinical Psychology: Mayerson Center Supervisors: Erica Pearl Messer, Psy.D. \& Heather Bensman, Psy.D. 
Clinical Psychology Resident

- Administer Parent-Child Interaction Therapy (PCIT) to youth with disruptive behavior disorders who have experienced trauma and/or neglect

- Co-lead and observe trauma-focused cognitive-behavioral therapy sessions for children and adolescents

$2017-2018$

$2015-2018$

2015 - Present

$2016-2017$
Noble H. Kelley Psychological Services Center, Louisville, KY Anxiety Research and Treatment Team Supervisor: Janet Woodruff-Borden, Ph.D. Graduate Student Therapist

- Administered individual treatment to children and adults with mood and anxiety disorders

- Participated in weekly team and individual supervision, peer consultation, individual supervision of peers, case conceptualizations, audio/digital recording review and live observations, chart reviews, clinical report writing and administrative duties

- Treatment modalities: Cognitive-Behavioral

Noble H. Kelley Psychological Services Center, Louisville, KY Diagnostic Interviewing and Assessment Supervisor: Bernadette Walter, Ph.D. Graduate Student Therapist

- Conducted intellectual and advanced placement assessments for children and semi-structured interviewing of parents/legal guardians

- Prepared integrative reports including history, symptoms, assessment results and interpretation, diagnosis and clinical recommendations; conducted feedback sessions

Noble H. Kelly Psychological Services Center, Louisville, KY

Diagnostic Interviewing and Assessment Supervisor: David Winsch, Ph.D.

Graduate Student Therapist

- Administered semi-structured interviewing for diagnostic and intake assessments of adults

- Conducted psychological and neuropsychological assessment batteries and scoring for diagnostic and assessment purposes

- Prepared integrative client reports including history, key symptoms, assessment results and interpretation, diagnosis and clinical recommendations; conducted feedback sessions

Noble H. Kelley Psychological Services Center, Louisville, KY Integrative Intervention Supervisor: Richard Lewine, Ph.D.

Graduate Student Therapist

- Administered individual treatment for adults using a broad range of evidencebased and evidence-supported strategies to address cognitive, emotional, and interpersonal difficulties encountered in a variety of life settings

- Collaborated with clinical team to assess weekly client treatment progress and identify effective therapeutic techniques; reviewed current literature on mood disorders

- Received individual and group supervision from a licensed psychologist to learn effective adult therapeutic techniques

- Treatment modalities: Cognitive-Behavioral, Mindfulness, and Narrative 
- Administered assessments to evaluate cognitive and socioemotional functioning in children with congenital heart disease (CHD)

- Completed diagnostic evaluation reports based on information obtained through parent and child intake interviews, clinical measures, and cognitive assessments; provided feedback to parents and children; received individual supervision

- Participated in multidisciplinary team planning and interviewing families of CHD patients through the Neurodevelopmental Education Clinic

- Conducted diagnostic evaluations and administered assessments to evaluate cognitive and socioemotional functioning in children with medical and psychiatric disorders

- Completed diagnostic evaluation reports integrating information obtained from interviews, clinical measures and cognitive assessments; provided evaluation feedback to children and their families

- Received individual supervision from a licensed psychologist and developed effective assessment techniques

\section{Noble H. Kelley Psychological Services Center, Louisville, KY Children with ADHD and Related Disorders (CARDS) Supervisor: Paul J. Rosen, Ph.D. Graduate Student Therapist}

- Administered individual treatment for children with ADHD and co-occurring internalizing and externalizing disorders; conducted diagnostic evaluations for ADHD and co-occurring disorders

- Lead Managing Frustration for Children group treatment designed to teach children between the ages of 8 and 12 effective methods for alleviating feelings of frustration

- Collaborated with clinical team to assess weekly client treatment progress and identified productive therapeutic techniques; reviewed current literature on ADHD and co-occurring internalizing and externalizing disorders

- Received individual and group supervision from a licensed psychologist to learn effective child and parent therapeutic and assessment techniques

- Treatment modalities: Cognitive-Behavioral, Behavior Management, Managing Frustration Group for Children, Parent Skills Training Group, Organizational Skills Training for Children Schizophrenia Research Program, Bethesda, MD Supervisor: José A. Apud, M.D., Ph.D. Technical Intramural Research Training Award

- Collaborated with research team and assessed weekly patient interviews using integrative multidisciplinary approach to collectively address mood, behavior, medications, research and upcoming treatment

- Assisted with weekly men's therapy group designed to encourage patients to discuss current concerns and symptoms

- Administered and scored weekly Structured Clinical Interview for DSM-IV Axis I Disorders (SCID) assessments to patients with schizophrenia, affected siblings 
and healthy volunteers under the supervision of trained clinical psychologists

- Completed orientation to NIMH Schizophrenia Ward; received training on how to work with patients diagnosed with schizophrenia; specific training for identifying positive, negative and cognitive symptoms

\section{CERTIFICATIONS AND TRAININGS}

2018

2018

2018

2018

2017

2017

2017

2016

2016

2016

2015

2015

2015
Parent Child Interaction Therapy, PCIT International

Mindful Awareness Practices for ADHD in Adulthood, Duke ADHD Program

Treating Eating Disorders in the Real World, Louisville Center for Eating Disorders Enhancing Substance Use Disorder Treatment Responsiveness for LGBT Clients, UCLA Brain Injury Awareness, Brain Injury Alliance of Kentucky

Supporting Survivors of Sexual Trauma, The Center for Women and Families

Mental Health Communities for Early Intervention, Emory University

Intimate Partner Violence, The Center for Women and Families

Introduction to Dialectical Behavior Therapy, Xavier University

Suicide Prevention, University of Louisville

Operation Immersion, Kentucky National Guard

Safe Zone Ally Training, University of Louisville

Microaggressions, racial stress and trauma, University of Louisville

\section{TEACHING EXPERIENCE}

2016 - $2018 \quad$ University of Louisville, Louisville, KY

Graduate Teaching Assistant

- Abnormal Psychology, Lead Instructor: Alison McLeish, Ph.D.

- Child Development, Lead Instructor: Nicholaus Noles, Ph.D.

- Child Psychopathology, Lead Instructor: Paul Rosen, Ph.D.

- Cognitive Processes, Lead Instructor: John Pani, Ph.D.

- Life Span Developmental Psychology, Lead Instructor: Lora Haynes, Ph.D.

$2009-2012 \quad$ Teach for America

Warren County Middle School, Warrenton, NC

6th Grade Science Teacher; 6th Grade Department Chair

- Developed rigorous curriculum based on North Carolina Standard Course of Study to increase student literacy levels and comprehension of scientific material for approximately 100 students per year

- Elected $6^{\text {th }}$ Grade Department Chair by colleagues; duties included organizing individual student behavior plans, scheduling weekly grade level meetings, creating staff assignments and collaborating with team members to efficiently meet administrators' requests

2009-2012 Warren County Middle School Athletics, Warrenton, NC Head Soccer Coach; Open Gym Coordinator

- Coached co-ed middle school soccer team of 20 students, designed basic and intermediate drills, created positive and welcoming team environment

- Spearheaded weekly open gym incentive program for high school students who attended all courses and completed daily course assignments.

2009 - $2011 \quad$ Warren County Middle School End-of-Grade (EOG) Academy, Warrenton, NC Remediation Math Teacher

- $\quad$ Tutored 30 sixth grade students for EOG Mathematics exam; tutoring sessions targeted students at-risk for failing grade level exams

- Provided one-on-one mentoring to increase student mastery of math concepts and 
raised overall student pass rate above $80 \%$ goal

2009 - $2010 \quad$ Warren County Middle School Young Scholars Program, Warrenton, NC

Science Instructor; Physical Education Instructor

- Developed and implemented after-school curriculum to supplement learning for 25 academically underperforming students

- Trained colleagues on how to connect aspects of physical education to science curriculum to make learning more engaging and relevant for adolescent children

$2009 \quad$ Teach for America

Carver Military Academy, Chicago, IL.

Biology Teacher

- Designed and implemented rigorous summer-school curriculum for high school students who failed to complete grade level requirements during the school year

- Developed engaging teaching techniques used to reach students with different and unique learning styles

\section{PROFESSIONAL SERVICE}

2017

2017

2017

2016

2010

2009

2009
Student Representative, University of Louisville Dept. of Psychological \& Brain Sciences Loyola University Chicago Alumni Board Member, Teach For America Center for Experiential Learning Alumni Reflection, Loyola University Chicago Student Liaison, University of Louisville Dept. of Psychological \& Brain Sciences Grade Department Chair, Warren County Middle School President, Loyola University Chicago Psi Chi National Honor Society Vice-President, Loyola University Chicago Psychology Club

\section{PROFESSIONAL AFFILIATIONS}

\section{Association for Behavioral and Cognitive Therapies (ABCT)}

- Student Member

- ADHD Special Interest Group Student Member

- Oppression and Resilience: Minority Mental Health Special Interest Group Student Member

\section{Association for Psychological Science}

- Student Member

Midwestern Psychological Association (MPA)

- Student Member

\section{Society for Neuroscience ( $\mathrm{SfN}$ )}

- Student Member 